\title{
ROBOTIC STEERING OF \\ FLEXIBLE ENDOSCOPES
}

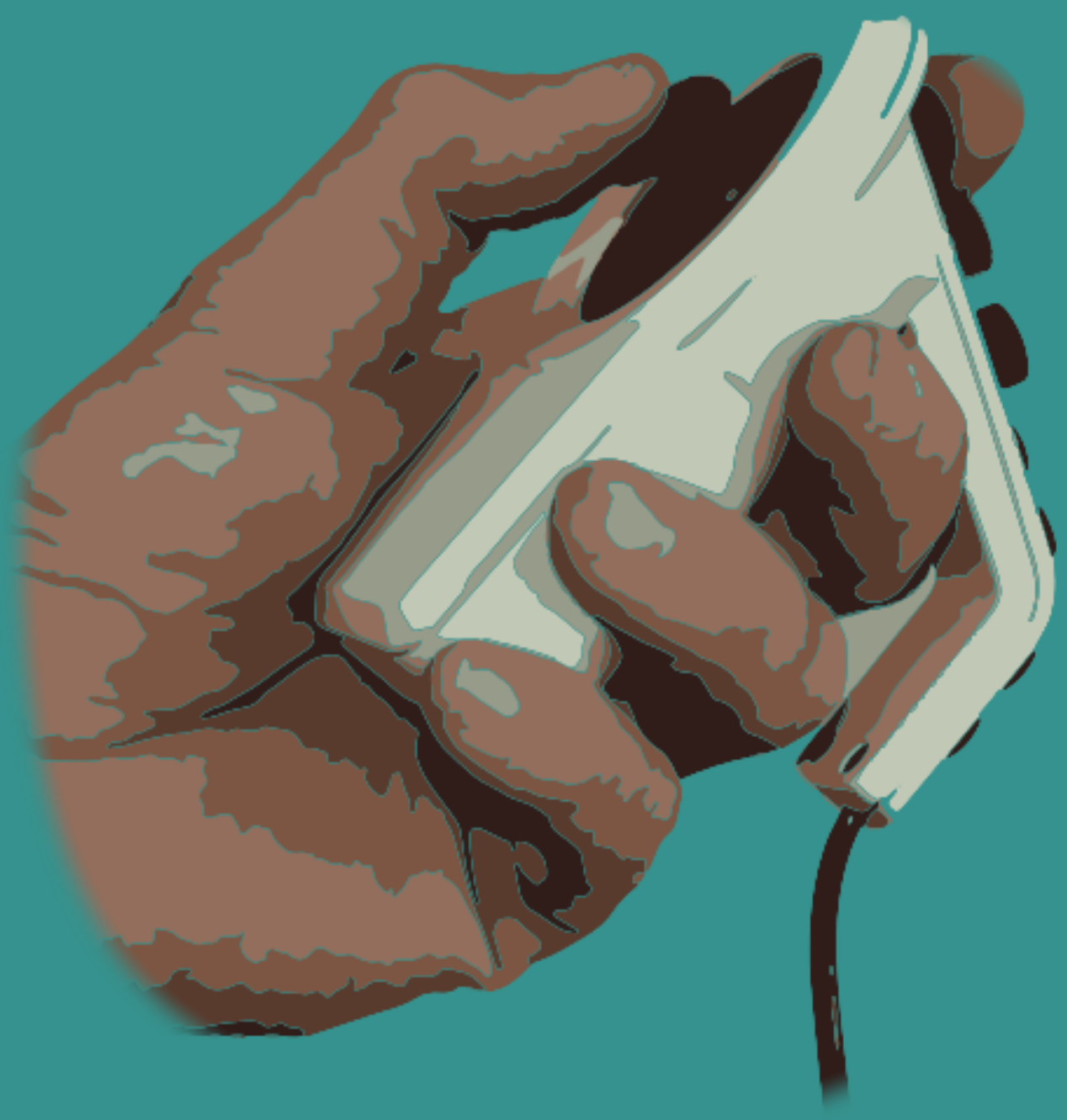

Esther Rozeboom 


\title{
Robotic steering of flexible endoscopes
}

\author{
E. D. Rozeboom
}


This research has been conducted within the TeleFLEX project at the Department of Robotics and Mechatronics from the University of Twente in collaboration with DEMCON Advanced Mechatronics in Enschede, the Meander Medical Center in Amersfoort and the Academic Medical Center in Amsterdam.

Cover photo by Dr. ir. J.G. Ruiter

The printing of this thesis was financially supported by:

DEMCON Advanced Mechatronics

Olympus Nederland B.V.

Printed by Ipskamp Drukkers, Enschede

ISBN 978-90-365-4129-9

DOI 10.3990/1.9789036541299

CO2016 Esther Rozeboom, Haaksbergen, The Netherlands 


\section{ROBOTIC STEERING OF FLEXIBLE ENDOSCOPES}

\section{PROEFSCHRIFT}

ter verkrijging van

de graad van doctor aan de Universiteit Twente, op gezag van de rector magnificus, prof. dr. H. Brinksma, volgens besluit van het College voor Promoties op vrijdag 28 oktober 2016 om 14.45 uur

$$
\text { door }
$$

Esther Dorothea Rozeboom

geboren op 9 oktober 1986

te Groningen 
Dit proefschrift is goedgekeurd door:

Prof. dr. I.A.M.J. Broeders (promotor)

Prof. dr. P. Fockens (promotor) 
Graduation committee:

Chairman: Prof. dr. P.M.G. Apers

Promotor: Prof. dr. I.A.M.J. Broeders, MD

Promotor: Prof. dr. P. Fockens, MD

Members: Prof. dr. ir. F. van Houten

Prof. dr. ir. S. Stramigioli

Prof. dr. B.L.A.M. Weusten, MD

Prof. dr. R. van Hillegersberg, MD

Referees: Dr. M.P. Schwarts, MD

Dr. ir. J.G. Ruiter
University of Twente

University of Twente

University of Amsterdam

University of Twente

University of Twente

University of Amsterdam

University of Utrecht

Meander medical center

DEMCON 



\section{Summary}

Flexible endoscopes were originally designed for non-invasive inspection of body cavities and hollow organs. Today, they are also used for complex minimal invasive interventions. Control of the endoscope is difficult and complexity rises with interventional procedures. Endoscopists suffer from long learning curves, ergonomic complaints and multi-person control is needed to steer endoscope and instrument(s).

Robotics have the potential to overcome these problems. The combined forces of a technical university, mechatronic company and physicians from multiple hospitals led to the design of an add-on robotic platform. The platform aims to improve usability of conventional flexible endoscopes for complex interventions. These interventions require accurate and precise tip steering.

This thesis describes the design and clinical evaluation of the platform's tip steering module. An optimal user interface and control algorithm was sought to improve usability of the endoscope in clinical practise.

First, critical user aspects of conventional gastro- and colonoscopes were identified and copied to the robotic platform. The control module includes a remote interface that was evaluated by novices in a simulated colonoscopy environment. This study indicated that robotic steering, using a position-controlled touchpad or a ratecontrolled joystick increases efficiency and satisfaction. However, breaking the mechanical linkage between operator and endoscope tip led to a lack of force feedback on tip bending.

The first results did not show a clear preference between two regular user interfaces and their control algorithms. A position-controlled touchpad has benefits for precise targeting (instrument placement), whereas a rate-controlled joystick is better suited for quick tip steering (lumen navigation). Endoscopy requires both quick and precise tip motions. The second study describes the design of a non-linear rate 
control algorithm. This study showed that between regular intuitive interfaces, the joystick with non-linear rate control showed highest efficiency and users' preference.

A single-handed controller was introduced to further reduce the experienced workload of flexible endoscopy. The controller was compared to a bimanual interface and conventional control in a simulated colonoscopy procedure. Both the single-handed and a bimanual controller reduced the workload of colonoscopy without reducing efficiency or effectiveness. Despite the single-handed approach, novices appeared to steer the endoscope tip and shaft consecutively, not simultaneously. Making bimanual control the logical route to pursue.

The first three studies indicated that the platform changed the current routine of handling an endoscope. A fourth study was designed to determine if expert endoscopists and endoscopists in training were able to perform the complex manoeuvres required in colonoscopy. Experts and $\mathrm{PhD}$ students without previous hands-on experience trained on a computer simulator to perform colonoscope intubation. Experts needed a relatively short training period to achieve their personal level of expertise in colonoscopy using the add-on platform. The students were as effective and as efficient in endoscope manipulation when comparing the add-on platform with conventional endoscope control.

These results showed non-inferiority of the platform in simulated diagnostic procedures. To determine the clinical safety and efficiency of endoscope navigation, two expert endoscopists performed colonoscope introduction in adult patients scheduled for routine diagnostic colonoscopy. Upon cecum intubation, the add-on was detached and the procedure continued using conventional control. This patient study showed that the add-on platform allows a safe and feasible introduction of an endoscope through the bowel.

Alternative tip steering options were investigated to further improve endoscope tip control. One option was the use of semi-automated image-based endoscope tip control. An assisting automated lumen centralization algorithm was implemented into the control software of the add-on platform. Both experts and novices were as efficient in simulated colonoscopy with the assistive algorithm, compared to conventional endoscope control. The relatively extensive use of the algorithm during the withdrawal phase of the procedure suggests a potentially interesting added value in this phase. 
The robotic platform proposed in this thesis is based on pairing with conventional endoscopes. Consequently, performance results of the add-on platform also depend on the tip bending response of the used endoscopes. The tip bending response of clinically used endoscopes was evaluated by rotating the navigation wheel of gastroand colonoscopes while recording the tip bending. The findings suggest that the vast majority of endoscopes are not optimally tuned to reach maximal bending angles and adequate tip response.

This research shows that an add-on platform for conventional flexible endoscope tip control is a safe and feasible method to guide the endoscope towards intervention sites throughout the bowel. Innovations that close the control loop and hysteresis control methods are expected to further improve precise and efficient endoscope tip steering. 



\section{Samenvatting}

Flexibele endoscopen zijn ontworpen om via natuurlijke lichaamsopeningen in de mens te kijken. Tegenwoordig worden ze ook ingezet bij het uitvoeren van minimaal invasieve chirurgische interventies. Het besturen van de endoscoop is echter moeilijk en de moeilijkheidsgraad stijgt met het uitvoeren van deze complexe interventies. Endoscopisten hebben te maken met lange leercurves, ergonomie klachten en de moeilijkheid om met meerdere personen één endoscoop met instrumenten aan te sturen.

De inzet van robotica kan oplossingen bieden. De Universiteit Twente heeft samen met mechatronica bedrijf DEMCON en artsen van verschillende medische centra een robotisch platform ontworpen dat aan een conventionele endoscoop gekoppeld kan worden. Deze zogenaamde add-on heeft als doel de bruikbaarheid van conventionele flexibele endoscopen te vergroten. Het platform richt zich specifiek op het uitvoeren van de complexe interventies. Bij deze interventies worden hoge eisen gesteld aan precieze en accurate endoscoop tip besturing.

Deze dissertatie beschrijft het ontwerp en de klinische evaluatie van de tip besturingsmodule van het robotische platform. De optimale combinatie van gebruikers interface en besturingsalgoritme is gezocht waarmee de bruikbaarheid van endoscopen verhoogt kan worden in de klinische praktijk.

Allereerst zijn de kritische gebruikers- en omgevingsaspecten van conventionele gastroscopieën (maag) en colonoscopieën (darm) in kaart gebracht en meegenomen in het ontwerp van het platform. Het platform bevat twee afstandsbedieningen; een touchpad met positiebesturing en een joystick met snelheidsbesturing. Het gebruik van deze besturingen is geëvalueerd door onervaren gebruikers tijdens een gesimuleerde colonoscopie procedure. Dit onderzoek liet zien dat robotische besturing de efficiëntie en tevredenheid van de gebruiker verhoogt. Het platform verbreekt 
echter de directe verbinding tussen bestuurder en de endoscoop tip, waardoor kracht terugkoppeling niet meer mogelijk is.

De eerste studie liet geen voorkeur zien tussen de gebruikte joystick of touchpad. Een positie-gestuurde touchpad heeft doorgaans de voorkeur bij precieze besturing zoals instrument positionering. De joystick met snelheidsbesturing heeft voordelen bij snellere tip verplaatsing, zoals bij navigatie door de darm of maag. Tijdens endoscopieën zijn zowel precisie als snelheid van belang. Het tweede onderzoek beschrijft het ontwerp en de evaluatie van een snelheidsbesturingsalgoritme bestaande uit twee componenten voor snelle en precieze besturing. In een vergelijking met de vorige interfaces levert de joystick met deze niet-lineaire besturing de hoogste efficëntie en heeft deze combinatie de voorkeur van gebruikers.

Voor verdere verlaging van de ervaren werkdruk is een interface ontwikkeld waarmee in één hand zowel de endoscoop schacht als de tip bestuurd kunnen worden. Het gebruik van deze interface is vergeleken met de hiervoor gebruikte tweehandige en conventionele endoscoop besturing in een gesimuleerde endoscopie procedure. Zowel de één als tweehandige besturing verlaagden de ervaren werkdruk zonder vermindering van efficiëntie of effectiviteit van de procedure. De éénhandige interface biedt de mogelijkheid om tegelijk de endoscoop tip en schacht te besturen. Desondanks stuurden de testpersonen schacht en tip vaak achtereenvolgens aan, waardoor een tweehandige besturing de meest logische interface lijkt.

Tijdens de eerst drie studies bleek dat het robotische platform niet alleen de tip-besturing, maar ook de huidige routine tijdens een endoscopie veranderd. De vierde studie moest aantonen of getrainde endoscopisten en endoscopisten in opleiding de benodigde endoscoop manipulaties konden uitvoeren die nodig zijn tijdens een colonoscopie. $\mathrm{PhD}$ studenten zonder ervaring en experts in endoscopie bestuurden de endoscoop met en zonder het add-on platform in een simulatie omgeving. De experts bereikten hun conventionele niveau van colonoscoop besturing ook met de robotische besturing, na een korte leercurve. De studenten waren met robotische besturing even effectief en even efficiënt als met conventionele besturing.

Bovenstaande resultaten laten zien dat het platform niet onder doet voor de efficiëntie en effectiviteit van conventionele besturing in gesimuleerde diagnostische procedures. De veiligheid en haalbaarheid van robotische besturing is hierna geëvalueerd in een patiënten studie. Twee experts in endoscopie bestuurden een 
colonoscoop middels het add-on platform tijdens het opvoeren van de scoop in de darm. Na succesvolle intubatie van de endoscoop werd het platform afgekoppeld en de procedure vervolgt met conventionele besturing. Dit onderzoek is uitgevoerd bij volwassen patiënten die een diagnostische coloscopie moesten ondergaan. De studie laat zien dat de endoscoop op een veilige manier door de dikke darm gevoerd kan worden middels het add-on platform. Het platform kan de endoscoop tip dus op een veilige manier naar een plaats sturen waar een interventie moet plaatsvinden.

Naast besturing met joystick en touchpad is ook onderzoek gedaan naar semiautomatische besturing van de tip op basis van endoscopie beelden. Een algoritme is ontwikkeld dat de arts ondersteund door automatisch het lumen (centrum van de darm) in het midden van het beeld te houden. Dit algoritme is in de besturingssoftware van het platform geïntegreerd en geëvalueerd door onervaren en ervaren gebruikers. Beide gebruikersgroepen waren even snel in het opvoeren van de endoscoop met de automatische als met de conventionele besturing. Het algoritme heeft mogelijk een toegevoegde waarde op de terugweg van de colonoscopie, aangezien het relatief veel tijdens deze fase is aangezet.

Het robotische platform dat in deze dissertatie beschreven is maakt een koppeling met conventionele endoscopen. Als gevolg hiervan hangt de besturing van de tip ook af van de endoscoop zelf. De endoscoop tip buigt door het draaien aan twee wielen. Deze tip-buiging reactie is onderzocht bij endoscopen die in de kliniek gebruikt worden. De buiging van de tip is op camera vastgelegd terwijl er aan de wielen gedraaid werd. Uit dit onderzoek volgde dat de tip van endoscopen die in de kliniek gebruikt worden niet optimaal reageert wanneer aan de wielen wordt gedraaid. De tip buigt vaak niet ver genoeg en reageert niet snel genoeg. De efficiëntie en precisie van tip besturing met het platform kan verbeteren door de tip reactie terug te koppelen in de besturingssoftware zodat hiervoor gecompenseerd kan worden. 



\section{Contents}

Summary iii

Samenvatting vii

List of publications $\quad$ xiii

List of Figures $\quad$ xv

List of Tables $\quad$ xvii

1 Introduction 1

1.1 Flexible endoscopy . . . . . . . . . . . . . . . . 2

1.2 Robotic solutions . . . . . . . . . . . . . . . . . 5

1.3 Robotic add-on platform $\ldots \ldots \ldots \ldots \ldots$

1.4 Thesis objective . . . . . . . . . . . . . . . . 7

1.5 Thesis outline . . . . . . . . . . . . . . . 8

2 Design and evaluation of an add-on robotic system for a flexible endoscope

2.1 Introduction . . . . . . . . . . . . . . . . . . . . . 11

2.2 Current user interface $\ldots \ldots \ldots \ldots$

2.3 Design directions . . . . . . . . . . . . . . . . . 13

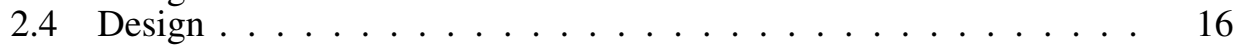

2.5 Evaluation . . . . . . . . . . . . . . . . . . 21

2.6 Results . . . . . . . . . . . . . . . . . . . . . . . . 23

2.7 Discussion . . . . . . . . . . . . . . . . . . . . 25

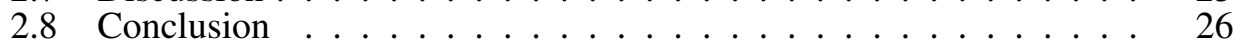

3 Robotic steering increases efficiency in endoscope tip control 27

3.1 Introduction . . . . . . . . . . . . . . . . . . . . . . . 29

3.2 Materials and Methods . . . . . . . . . . . . . . . . 30

3.3 Results . . . . . . . . . . . . . . . . . . . . . . . 34

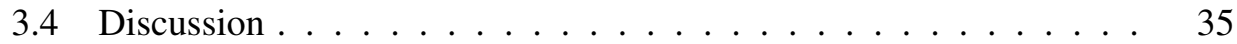


4 Single-handed controller reduces the workload of flexible endoscopy 39

4.1 Introduction . . . . . . . . . . . . . . . . . . . . . . . 41

4.2 Materials and Methods . . . . . . . . . . . . . . . . . . . . 42

4.3 Results . . . . . . . . . . . . . . . . . . . . . 46

4.4 Discussion . . . . . . . . . . . . . . . . . . . . . . . . . . . . . 48

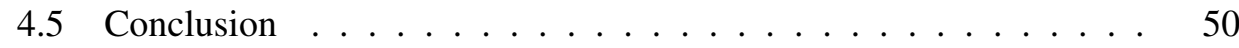

5 Feasibility of joystick guided colonoscopy 51

5.1 Introduction . . . . . . . . . . . . . . . . . . 53

5.2 Methods . . . . . . . . . . . . . . . . . . . . 53

5.3 Results . . . . . . . . . . . . . . . . . . 56

5.4 Discussion . . . . . . . . . . . . . . . . . . . 57

5.5 Conclusion . . . . . . . . . . . . . . . . . . . 59

5.6 Acknowledgements . . . . . . . . . . . . . . . . . . 59

6 Preliminary safety and efficacy in humans $\quad 61$

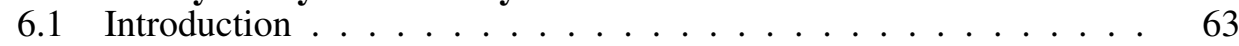

6.2 Methods . . . . . . . . . . . . . . . . . 63

6.3 Results . . . . . . . . . . . . . . . . . . . 66

6.4 Discussion . . . . . . . . . . . . . . . . . . . . . 67

6.5 Conclusion ..................... 68

7 Feasibility of automated lumen centralization for colonoscopy 69

7.1 Introduction . . . . . . . . . . . . . . . . 71

7.2 Methods and materials . . . . . . . . . . . . . . . . 72

7.3 Methods . . . . . . . . . . . . . . . . . . . 75

7.4 Results . . . . . . . . . . . . . . . . . . . . . . . . 77

7.5 Discussion . . . . . . . . . . . . . . . . . . 79

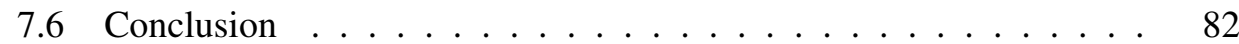

8 Evaluation of tip bending response in clinically used endoscopes 83

8.1 Introduction . . . . . . . . . . . . . . . 85

8.2 Materials and Methods . . . . . . . . . . . . . . . . . 86

8.3 Results . . . . . . . . . . . . . . . . . . . . . 92

8.4 Discussion . . . . . . . . . . . . . . . . . . . . . 93

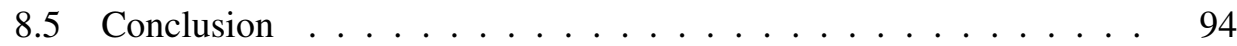

8.6 Acknowledgements . . . . . . . . . . . . . . . . 94

9 Conclusion \& Discussion 97

9.1 Reduce tip steering difficulty . . . . . . . . . . . . . . . . . 98

9.2 Single-person instrument control . . . . . . . . . . . . . . . . . . . . 99

9.3 Challenges of conventional endoscopes . . . . . . . . . . 100

9.4 Alternative endoscope designs . . . . . . . . . . . . . . . 101

9.5 Route for the future . . . . . . . . . . . . . . . . . . . 101

$\begin{array}{ll}\text { Bibliography } & 103\end{array}$

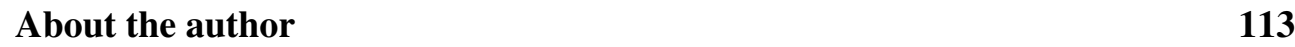

$\begin{array}{ll}\text { Dankwoord } & 115\end{array}$ 


\section{List of publications}

1. J.G. Ruiter, E.D. Rozeboom, M.C. Van der Voort, G.M. Bonnema and I.A.M.J. Broeders. Design and Evaluation of Robotic Steering of a Flexible Endoscope. IEEE International Conference on Biomedical Robotics and Biomechatronics, 2012; 761-767

2. E.D. Rozeboom, J.G. Ruiter, M. Franken and I.A.M.J. Broeders. Intuitive user interfaces increase efficiency in endoscope tip control. Surgical Endoscopy, 2014; 9: 2600-2605

3. E.D. Rozeboom, J.G. Ruiter, M. Franken, M.P. Schwartz, S. Stramigioli and I.A.M.J. Broeders. Single-handed controller reduces the workload of flexible endoscopy, Journal of Robotic Surgery, 2014; 8: 319-324

4. E.D. Rozeboom, I.A.M.J. Broeders, and P. Fockens. Feasibility of joystick guided colonoscopy; assessing the learning curves of experts and novices. Journal of Robotic Surgery, 2015; 9: 173-178

5. E.D. Rozeboom, B.A. Bastiaansen, E.S. De Vries, E. Dekker, P. Fockens, and I.A.M.J Broeders. Robotic flexible colonoscopy; preliminary safety and efficiency in humans, Gastrointestinal Endoscopy, 2016; 6: 1267-1271

6. H.J.M. Pullens, N. Van der Stap, E.D. Rozeboom, M.P. Schwartz, F. Van der Heijden, M.G.H. Van Oijen, P.D. Siersema and I.A.M.J. Broeders. Colonoscopy with robotic steering and automated lumen centralization: a feasibility study in a colon model, Endoscopy, 2015; 48: 286-290

7. N. Van der Stap, E.D. Rozeboom, H.J.M. Pullens, F. Van der Heijden and I.A.M.J. Broeders. Feasibility of Automated Target Centralization in Colonoscopy, Int. J. Comp. Ass. Radiology and Surgery, 2016; 11: 457-165

8. E.D. Rozeboom, R. Reilink, M.P. Schwartz, P. Fockens and I.A.M.J. Broeders. Evaluation of tip bending response in clinically used endoscopes, Endoscopy International Open, 2016; 4: 466-471 



\section{List of Figures}

1.1 Conventional colonoscopy procedure . . . . . . . . . . 2

1.2 Endoscopic intervention procedures: EMR, ESD, POEM . . . . . . 3

1.3 Conventional endoscope control . . . . . . . . . . . . 4

1.4 Alternative mechanical platforms for endoscopic interventions . . . 5

1.5 Motorized endoscopes for endoscopic interventions . . . . . . . 6

1.6 Three modules of the robotic add-on platform . . . . . . . . 7

2.1 Conventional control section . . . . . . . . . . . . . . . 12

2.2 Stationary vs mobile add-on control setup . . . . . . . . . . . . . . . . . . . . . .

2.3 Add-on system design . . . . . . . . . . . . . . . . . . . . 17

2.4 Add-on mobile drive unit . . . . . . . . . . . . . . . . . . 18

2.5 Add-on coupling mechanism . . . . . . . . . . . . . . . 19

2.6 Joystick and touchpad remote controllers . . . . . . . . . . . . . 20

2.7 Add-on system on conventional endoscopy cart . . . . . . . . 20

2.8 Feedback circle of add-on control input . . . . . . . . . . . . . 21

2.9 Design study setup . . . . . . . . . . . . . . . . . . 22

2.10 Conventional, touchpad and joystick cecum intubation times . . . 24

3.1 Non-linear rate control . . . . . . . . . . . . . . . 30

3.2 Tip steering study setup . . . . . . . . . . . . . . . 31

3.3 Tip steering simulation model and tasks $\ldots \ldots \ldots \ldots \ldots$

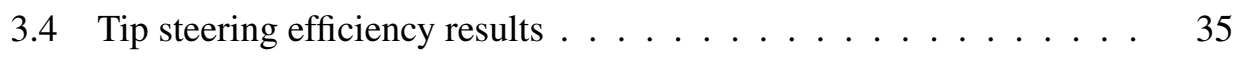

3.5 Tip steering motor input $\ldots \ldots \ldots \ldots \ldots$

4.1 Single-handed controller $\ldots \ldots \ldots \ldots$. . . . . . . . 43 
4.2 Single-handed control test configurations . . . . . . . . . . . . . . . . . . 43

4.3 Single-handed control study setup . . . . . . . . . . . . . . 45

4.4 Single-handed control workload scores . . . . . . . . . . . . 48

5.1 Connecting add-on platform $\ldots \ldots \ldots \ldots \ldots \ldots$

5.2 Colonoscopy feasibility study setup $\ldots \ldots \ldots \ldots \ldots 5$

5.3 Colonoscopy learning curves $\ldots \ldots \ldots \ldots \ldots$

6.1 Patient pilot study setup . . . . . . . . . . . . . . . . . . 64

6.2 Disconnection method for add-on platform . . . . . . . . . 65

7.1 Automatic lumen centralisation control algorithm . . . . . . . 73

7.2 ALC study setup . . . . . . . . . . . . . . . . . . 74

7.3 ALC user feedback . . . . . . . . . . . . . . . . . . 74

7.4 ALC joystick configuration . . . . . . . . . . . . . . . . . . . . . . . . . . 74

7.5 ALC control loop . . . . . . . . . . . . . . . . . 74

7.6 ALC study colon configurations . . . . . . . . . . . 76

7.7 ALC vs. observer found target locations . . . . . . . . . . . 81

8.1 Endoscope cable pulling system _. . . . . . . . . . . . 85

8.2 Setup for measuring cable tension $\ldots \ldots \ldots \ldots$

8.3 Hysteresis curve with explanation $\ldots \ldots \ldots$. . . . . . . . 89

8.4 Hysteresis parameters . . . . . . . . . . . . . . . . . 90

8.5 Hysteresis setup validation $\ldots \ldots \ldots \ldots \ldots$. . . . . . . . 91

9.1 User interfaces for single-person endoscope and instrument control . 100 


\section{List of Tables}

2.1 Add-on platform design specifications _ . . . . . . . . . . . 17

2.2 Results of endoscopy performance with conventional vs. add-on plat-

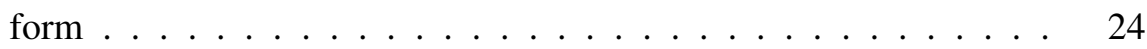

2.3 Preference rates between conventional, joystick and touchpad . . . 25

3.1 Results of intuitive user interfaces evaluation $\ldots \ldots \ldots \ldots$

4.1 Results of single-handed control study . . . . . . . . . . . . . 47

5.1 Results feasibility study . . . . . . . . . . . . . . . . . 57

6.1 Results pilot study and patient data . . . . . . . . . . . . 66

7.1 Colon segments with different in intubation times between ALC and

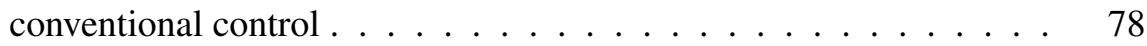

8.1 Scopes included for cable tension analysis . . . . . . . . . . . . 87

8.2 Cable tension setup validation $\ldots \ldots \ldots \ldots$. . . . . . . 91

8.3 Results of maximal tip bending angles . . . . . . . . . . . 92

8.4 Results of cable slackness . . . . . . . . . . . . . . . . . . 95 



\section{Chapter 1}

\section{Introduction}




\subsection{FLEXIBLE ENDOSCOPY}

Flexible video-endoscopes are long bendable tubes with a camera mounted on the steerable tip. The gastro- and colonoscope are particularly used for visualisation of the interior surface of the gastrointestinal tract. Upon detection of (suspicious) anomalies or lesions, the endoscope allows introduction of small instruments for interventions, such as polyp removal. The minimal invasive character of this equipment together with early detection of local lesions led to the use of this instrument for more complex interventional procedures. However, control of the endoscope is difficult. Endoscopists suffer from long learning curves, ergonomic complaints and multi-person control is needed to steer endoscope and instrument(s).

Robotics have the potential to overcome these problems. A robotic add-on platform was designed to improve usability of the conventional endoscope for complex intervention procedures. These procedures depend on efficient, accurate and precise endoscope tip positioning. This thesis describes the design and clinical evaluation of the tip steering module of the add-on platform. Before introducing the robotic control, this chapter describes the conventional flexible endoscope followed by its challenges and the potential of robotic solutions.

\subsection{Flexible endoscopy}

The gastroscope and colonoscope are flexible video-endoscopes that visualise the interior surface of the upper and lower gastrointestinal tract (Figure 1.1). The flexible shaft allows introduction of a high quality camera through the tortuous and mobile tracts of oesophagus, stomach and colon without damaging these structures.

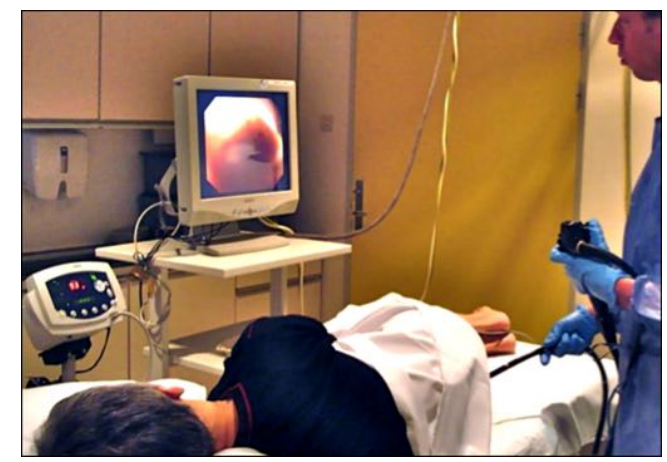

Figure 1.1: Colonoscopy procedure: The physician uses a flexible endoscope to inspect the large intestine of a patient. Reprint from [1] @212 IEEE 
Additional to excellent visualisation qualities, conventional endoscopes also provide access for small flexible instruments to reach intervention sites in the tracts. Upon detection, the endoscopist can determine to remove (parts of) a suspected lesion without the need for a second interventional procedure. In the last decades, image quality and contrast enhancement methods have improved, which led to early detection of small, local, lesions [2,3] At the same time, flexible surgical instruments were miniturised and commercialised. The minimal invasive character of the endoscope together with these optical and mechanical advances contributed to the endoscope's evolution from a pure diagnostic to an interventional platform. Experts in endoscopy now use flexible endoscopes to remove lesions inside the bowel but also accros bowel walls in procedures like Endoscopic Mucosal Resection (EMR), Endoscopic Submucosal Dissection (ESD), Peroral Endoscopic Myotomy (POEM) and Natural Orifice Transluminal Endoscopic Surgery (NOTES) (Figure 1.2) [4-6].
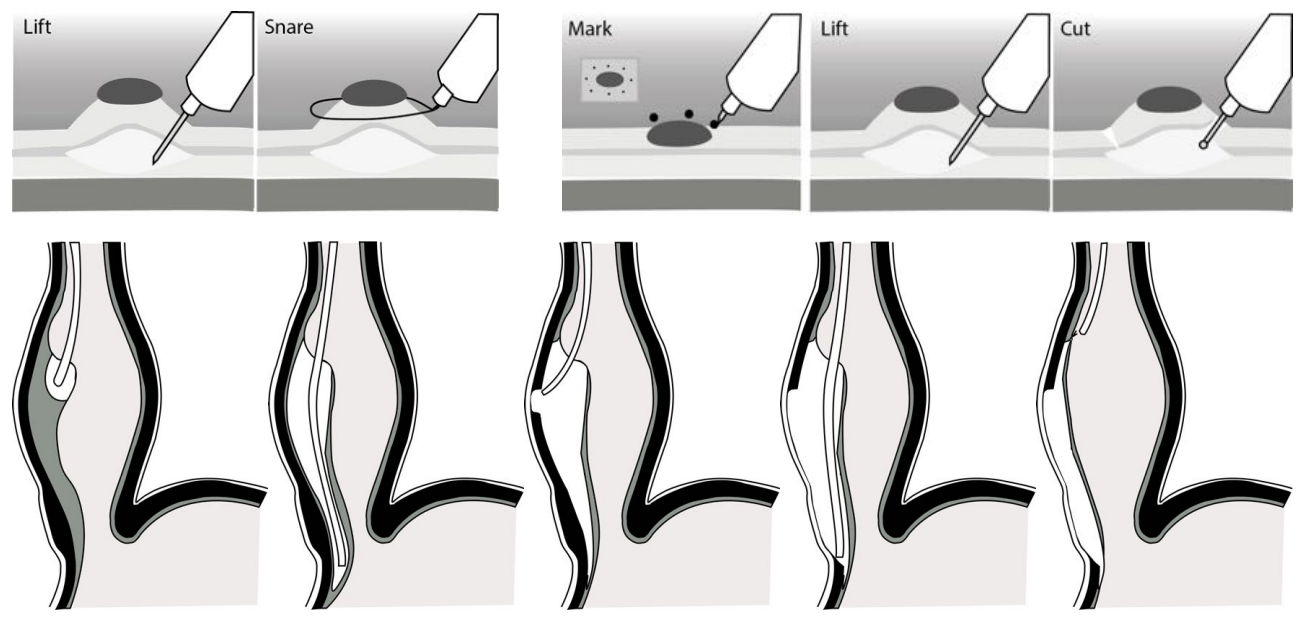

Figure 1.2: Upper left: Endoscopic Mucosal Resection, the (suspected) lesion is lifted and snared. Upper right: Endoscopic Submucosal Dissection, the (suspected) lesion is lifted and removed en-bloc. Bottom: PerOral Endoscopic Mucosectomy, the endoscope is introduced via the submucosal space to the musculature of the oesophagus and Upper Esophageal Sphincter. Circular muscles are cut to treat achalasia.

\subsubsection{Steering a flexible endoscope}

Control of the endoscope has not changed, despite the transition from relatively simple diagnostic into more complex interventional procedures. The endoscopist introduces the endoscope while inspecting the interior image on the endoscopic screen, 
(Figure 1.1). The endoscopic tip is steered by combining right-handed shaft manipulation (insertion, withdrawal and rotation) with left-handed wheel rotation to bend the tip in up/down and left/right facing positions. The left hand also operates valves for suction and air/water inflation [7], Figure 1.3. Together this is called single-person endoscope control.

Alternatively, endoscopists suffering from small hands, musceloskeletal complaints or who have not learned the single-handed approach use both hands for the control section, while an assistant manipulates the shaft according to spoken instructions [8]. This bimanual control is undesirable. Introducing the flexible endoscope into the tortuous and elastic colon is a delicate task that requires interpretation of force feedback to support steering. Inefficient steering may lead to time loss and excessive stretching of the intestinal wall, leading to increased patient discomfort $[9,10]$.

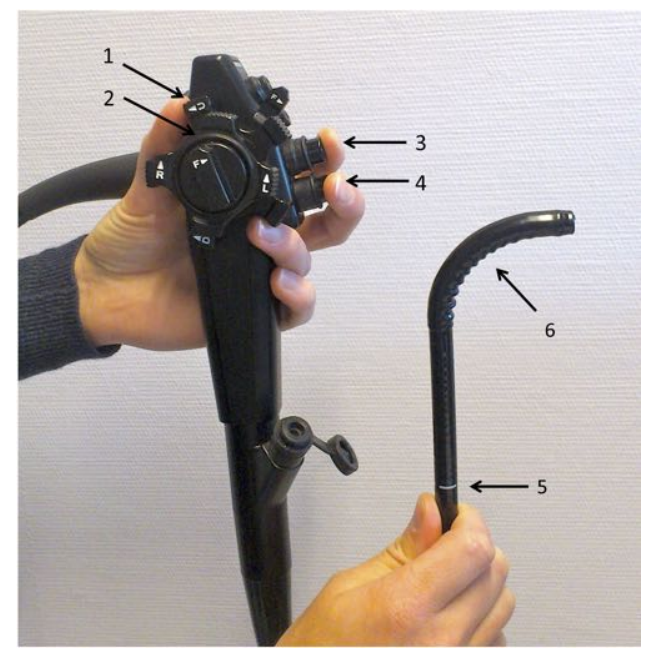

Figure 1.3: Conventional single-person endoscope control. The endoscopist holds the control body in his left hand, controlling the up/down (1), left/right (2) angulation wheels, suction (3) and air/water inflation valves (4). The right hand controls the endoscope shaft (5) with the distal bendable tip (6). Reprint from [11]

\subsubsection{Current challenges}

Current mechanical control of endoscopes is not perfect. It takes on average 275 procedures to learn the motor skills to adequately perform colonoscopy [12, 13]. Difficulties are in the manipulation of the control section, the combination of left and right-handed tasks that are out-phase and in different directions and the overall manipulation inside a non-static environment. Secondly, the non-ergonomic design of the endoscope causes musculoskeletal complaints and injuries, affecting up to $89 \%$ of endoscopists [14]. 
This mental and physical load of endoscopists will grow in the coming years. Population based screening programs for colorectal cancer increase the demand for colonoscopy, which is currently a vital part of the screening procedure [15-17].

\subsection{Robotic solutions}

Robotics or semi-automative mechanical platforms have the potential to reduce the experienced workload and allow easier and ergonomic single-person control of endoscope and instruments. The introduction of computer intelligence and motorized control allows a combination of different degrees of freedom in one intuitive and ergonomic hand-held control interface [18]. Several motorized mechanical platforms have already proven to reduce the mental and physical workload of bimanual manipulation tasks in laparoscopic and endoscopic procedures [1, 19, 20]. Examples are the da Vinci® platform for laparoscopic surgery (Intuitive Surgical, CA, USA), the MASTER system designed for NOTES procedures [21, 22], and the STRAS flexible robotic system designed for the ANUBIS NOTEScope ${ }^{\circledR}$ Karl Storz, Tuttlingen, Germany [23], Figure 1.4. The da Vinci system is the only platform currently on the market, albeit reserved for rigid laparoscopic instrumentation. Both MASTER and STRAS platforms performed their first in vivo clinical trials [24, 25]. However both platforms are not ready for routine sterile procedures and comprehensive clinical data is not published yet.
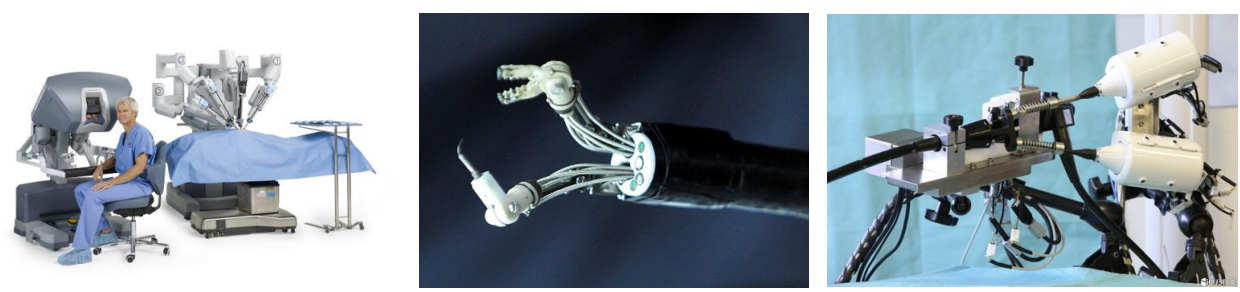

Figure 1.4: Left: da Vinci platform for laparoscopic surgey (C2016 Intuitive Surgical, Inc.. Center: Master And Slave Transluminal Endoscopic Robot, designed for NOTES procedures (Reprinted from [24], (C)2016 with permission from Elsevier). Right: STRAS, platform for endo- and transluminal surgery using the ANUBIS NOTEScope (®Karl Storz, Tuttlingen, Germany) @2016 iCUBE UMR7357. 
Alternatively to platforms using conventional equipment, endoscopes have also been motorized to reduce the effort of endoscope steering [26-29]. Examples are the Invendoscope (Invendo Medical, Weinheim, Germany), Aro-O-Scope (GI View Ltd., Ramat Gan, Israel) and Endotics System (Endotics, Peccioli, Italy), Figure 1.5. These redesigned endoscopes require a substantial investment in purchase of materials and training. None of these experimental designs are currently ready to be tested as cost effective, safe and user-friendly in clinical procedures [30-32].

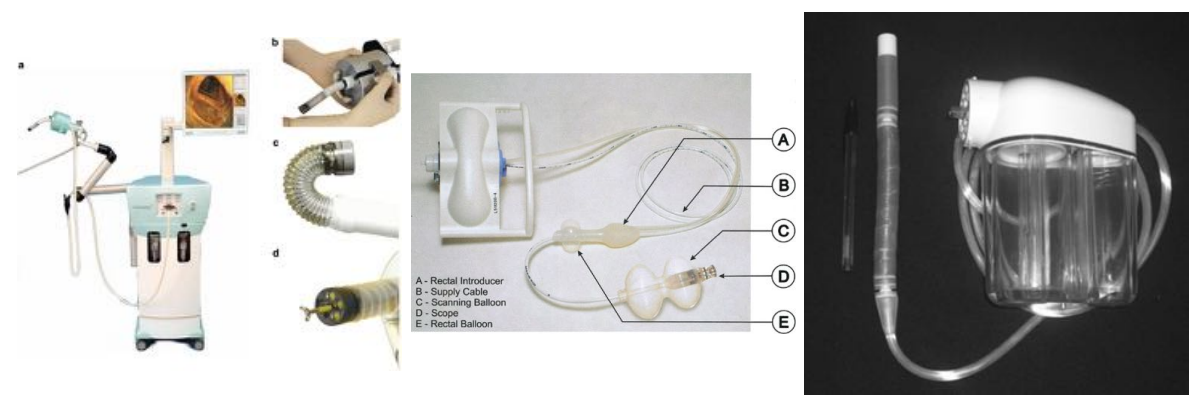

Figure 1.5: Left: Invendoscope, propelled by inverted sleeve mechanism. Reprint from [33] Center: Aer-O-Scope, a self-propelling, self-navigating disposable colonoscope for diagnostic colonoscopy. Reprint from [29] Right: Endotics, self-propelling endoscope without instrument channel. Reprint from [28]

\subsection{Robotic add-on platform}

The University of Twente (Enschede, NL), together with mechtronic company DEMCON Advanced Mechatronics (Enschede, NL) developed an add-on platform that allows single-person control of a conventional flexible endoscope and multiple instruments [34]. The platform consists of three modules to control endoscopic tip steering, shaft manipulation and instrument actuation, Figure 1.6. User-centered design considerations and preliminary experiments were previously introduced in the dissertation of Dr. J.G. Ruiter (2013) [30]. The use of haptic and image guidance was described in the dissertation of Dr. R. Reilink (2012) [35]. Extension of the platform using image guided navigation options was described in the dissertation of Dr. N. Van der Stap (2016) [36]. 

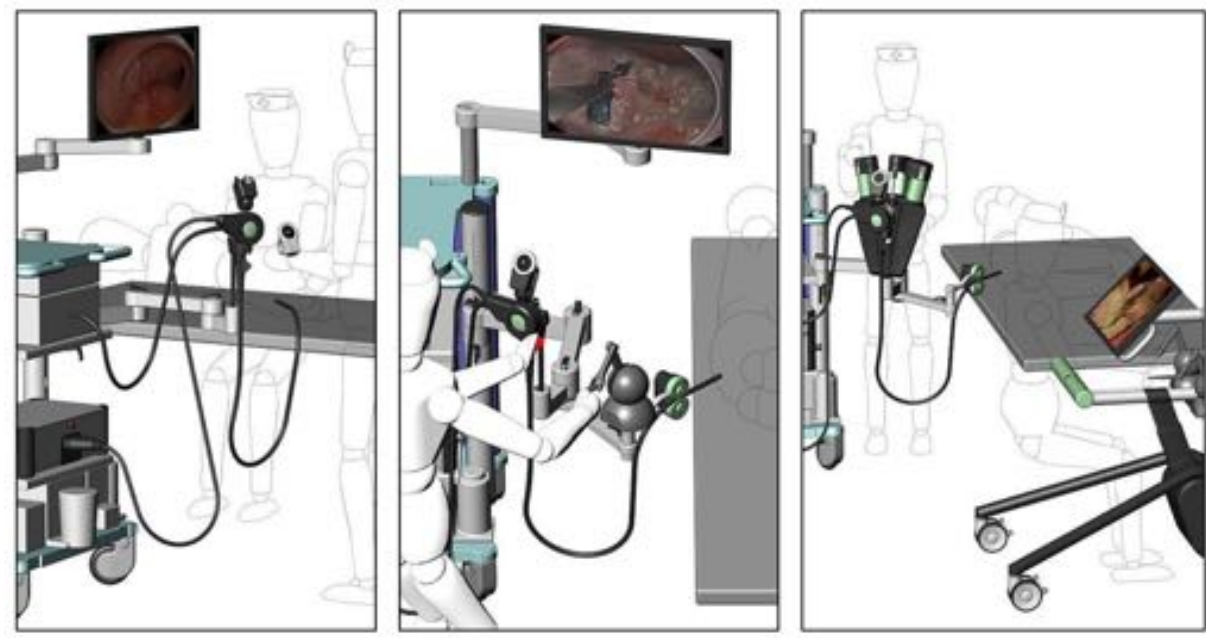

Figure 1.6: The add-on platform consists of three modules. Tip steering (Left), shaft manipulation (Center) and instrument control (Right).

\subsection{Thesis objective}

A robotic add-on platform was designed for complex intra- and transluminal interventions. Fundamental in these procedures is safe, efficient, accurate and precise tip actuation. The objective of this thesis is to determine the optimal user interface and control algorithm that improves endoscope tip steering in clinical practice. It is expected that the right user interface and algorithm will make tip steering easier, which in turn improves clinical performance.

To evaluate the clinical potential of such a user interface or control algorithm, this research is performed in close collaboration with end-users from medical hospitals. Endoscopic experts, trainees, nurses and technicians from ${ }^{1}$ the Academic Medical Center (Amsterdam, NL), Meander Medical Center (Amersfoort, NL), Medisch Spectrum Twente (Enschede, NL), University Medical Center Utrecht (Utrecht, NL) and Zorg Groep Twente (Hengelo, NL) participated by providing information on current practice, reflecting on design and taking part in performance studies.

\footnotetext{
${ }^{1}$ In alphabetic order
} 


\subsection{Thesis outline}

The first challenge in improved endoscope tip steering was to design an add-on control module that allows the benefits of robotic control and fits the current clinical workflow. Chapter two describes the design and a preliminary evaluation of the proposed tip steering module. Regular control algorithms proved user-dependent and showed limited improvements in endoscope tip steering efficiency. This led to the design of a novel control algorithm that satisfies the needs of tip control in clinical practice. An evaluation of the algorithms efficiency in endoscope tip positioning is described in Chapter three. To further reduce the experienced workload, an alternative design for single-handed control of the endoscope was designed and evaluated in Chapter four. Consequently, the feasibility of robotic endoscope manipulation using a combination of optimal control algorithm and user interface was evaluated in a simulation setup by novices and experts in Chapter five. The results of the first colonoscopy study in patients are reported in Chapter six.

Although the chosen interface and algorithm proved adequate in endoscope tip steering, a semi-automative image-guided control algorithm was expected to further improve endoscope tip control. Chapter seven introduces the image-guided steering algorithm and its evaluation.

Throughout the studies, differences in endoscope tip bending response of used endoscopes influenced the tip positioning performance. Chapter eight describes the current status of tip response in clinically used endoscopes to learn to deal with these differences in robotic control. 


\section{Chapter 2}

\section{Design and evaluation of an add-on robotic system for a flexible endoscope}

Published as:

JG Ruiter, ED Rozeboom, MC Van der Voort, GM Bonnema and IAMJ Broeders Design and Evaluation of Robotic Steering of a Flexible Endoscope IEEE Int. Conf. Biomedical Robotics and Biomechatronics, 2012; 761-767 (O2012, IEEE 


\section{Abstract}

\section{Background}

In current flexible endoscopy the physician faces problems in manipulating the endoscope. A lot of experience is required to master the procedure. This chapter describes the design of an add-on robotic module that improves the user interface of traditional endoscopes and allows a single physician to operate it easily.

\section{Methods}

We identified critical user aspects of traditional endoscopes that need to be copied in a robotic setup. In our design the physician uses a remote control that is connected to a light drive system. It allows manipulation of the robotic endoscope in space. 24 novices performed colonoscopy on a mechanical simulation model with simulated polyps to determine the usability of our system.

\section{Results}

All participants performed complete cecum intubation without causing a perforation. Thy were significantly faster using the mobile touchpad and stationary joystick compared to the conventional method, with $\mathrm{p}=0.001$ and 0.002 respectively. The polyp detection rate was not significantly different between control methods. The workload scores of mobile and stationary joystick as well as stationary touchpad were significantly better compared to the conventional method, with $\mathrm{p}=0.05,0.025$ and 0.025 respectively. Participants preferred the joystick control (mobile and stationary) over the touchpad and conventional methods in 15 of 24 cases.

\section{Conclusions}

Results indicate that robotic steering, using a position-controlled touchpad or a ratecontrolled joystick increases efficiency and satisfaction. 


\subsection{Introduction}

At present there are no flexible endoscopes available that can be controlled in an intuitive and user-friendly way by one person. A long term solution is to redesign the control section. However, despite the limited usability, current flexible endoscopes are widely used systems with qualities like cleanability, manoeuvrability, and good image quality [37]. We propose an add-on robotic module positioned on a traditional endoscope. The physician uses a remote control to actuate the bendable tip. Key factor is that tip steering and tip actuation are mechanically decoupled and computer intelligence is integrated. Robotic steering has the potential to improve usability, preserve current endoscope qualities, and prevent high costs related to replacement of endoscopic equipment. Acceptance is expected to be high since our robotic setup fits to the current workflow and infrastructure.

Allemann et al. [38] have developed a system with a game joystick to control a motorized traditional endoscope. In their evaluation both novices and experienced physicians required significantly more time to complete a given task when using a joystick compared to conventional controls. They concluded that possibly the limited maneuverability of the endoscope positioned in the setup is responsible for the disappointing results. Zhang et al. [39] performed a comparable experiment with a joystick controller and a motorized endoscope with a fixed position in the setup. They concluded that the time required to finish the process relies on the degree of familiarity with the robot system. After 3-5 test runs an expert in flexible endoscopy performs equal in both techniques. Nevertheless, the lack of proprioceptive feedback in robot supported manipulation was indicated to decrease the effectiveness of the system. Reilink et al. [40] conducted an experiment with a six degrees of freedom haptic controller, coupled to a stationary motorized traditional endoscope. Experts appeared faster when using the conventional steering method compared to motorized steering methods. Students who had done flexible endoscopy training showed no significant differences. In all above work endoscope handling opportunities were inferior to the current manual steering design.

We propose a hybrid setup in which mobile as well as stationary use of the robotic endoscope is possible. The control section of the robotic endoscope can be manipulated freely to resolve for instance shaft looping inside the lumen. Our robotic endoscope is based on the clinical workflow and integrates medical and technical state of 
the art. This chapter discusses the design and evaluation of such an add-on control method robotic flexible endoscope.

\subsection{Current user interface shortcomings}

This section discusses the current problems related to physician-instrument interaction. The left hand steers the distal tip by turning two navigation wheels on the control section, Figure 2.1. The control of the tip orientation is not very intuitive because the navigation wheels are arranged in the same plane while the bendable portion will bend in two perpendicular directions. Single-handed operation of the wheels is difficult due to size, position and force requirements, especially with small hands. In a survey of U.S. gastroenterology fellows, $41 \%$ of the respondents considered their hands too small for a standard endoscope's control section [41]. Some endoscopists release the grip of the right hand on the shaft and use it to turn the smaller outer wheel. The shaft position is maintained by trapping it between the physician's thigh and the examination table [7]. Other physicians use torque steering as an alternative technique. They turn the large navigation wheel, while the small wheel is locked in neutral position, and additionally torque the shaft of the endoscope [42].

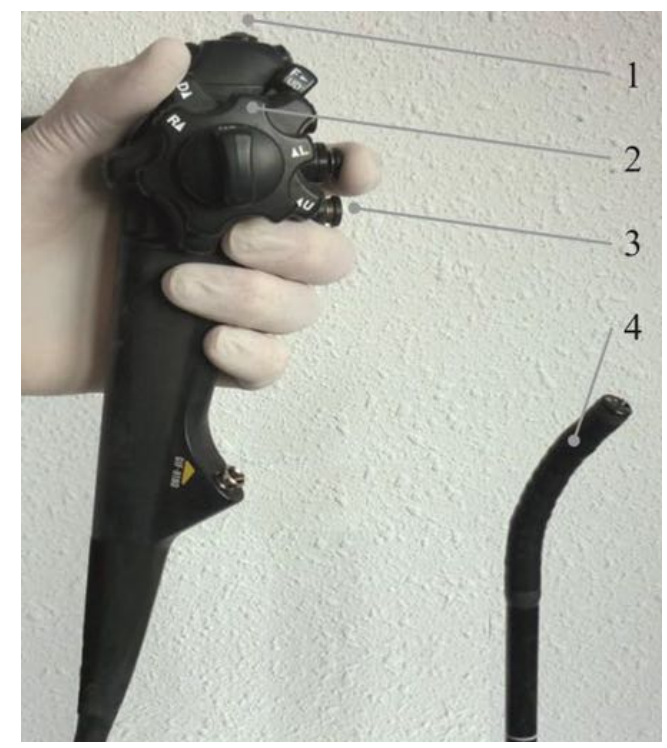

Figure 2.1: Control section endoscope: (1) Programmable switches, (2) Navigation wheels, (3) Valves for insufflation, rinsing, and suction, (4) Steerable tip with camera. 
The control section also contains manual operated valves to insufflate air or $\mathrm{CO} 2$ into the lumen, to rinse the camera lens, to suck fluids and gas out of the lumen, and some programmable switches for functions like taking a picture or switching to narrow band imaging. This complicates single-handed operation even further [7]. As a consequence, manipulation of flexible endoscopes is associated with awkward body rotations, bending of the knees, and a variety of arm movements. These movements are in the clinic sometimes referred to as the endoscopy dance and are especially performed during difficult parts of the procedure. The prevalence of musculoskeletal complaints has been shown to be higher for endoscopists than for other medical specialties [43]. Steering the navigation wheels and operating the control buttons of the control section require repetitive, extreme and prolonged wrist and finger flexion or extension. Manipulation of the shaft of a flexible endoscope is associated with awkward wrist, shoulder, and neck postures. In a questionnaire under colonoscopists concerning work related injuries, 226 out of the 608 respondents reported physical complaints obtained by performing colonoscopy. Most injuries were related to torquing the shaft and turning the dials [8].

It can thus be concluded that current endoscope handling is not ergonomic and user friendly. Physicians have learned to overcome the drawbacks, but at the expense of personal well-being.

\subsection{Design directions for robotic steering}

In this section the opportunities for robotics for intuitive and user-friendly singleperson endoscope handling are discussed. Many alternative endoscopes have been developed to improve colonoscopy physically and technically for the operator and make it more comfortable for patients. However, none of them is commercial available. Gaglia et al. [44] highlight technical innovations of new endoscopic devices. All described systems are designed to be less skill dependent compared to the user interface of conventional endoscopes, but all of them are also based on a new design of the endoscope. As stated in the introduction, we believe that acceptance is higher if conventional endoscopes can be used. The human-machine interface of the robotic endoscope should allow the physician to operate cooperatively with the robot. Thus, ergonomics and integration into the clinical workflow are essential elements of a successful design [45]. In the clinic the robotic module and the flexible endoscope are 
connected during preparation. The mechanical interfaces between the clean endoscope, the drive unit, and the user interface are critical. Even in case of non-sterile endoluminal interventions the patient should be protected against cross contamination. After the procedure, the assistant dismantles the robotic system for cleaning or replacement of disposable parts. The endoscope will be cleaned or disinfected according to the current clinical workflow. Direct manipulation of the endoscope handle may be required to pass difficult parts of the lumen.

We propose a hybrid setup that is configurable during the procedure. In one configuration the endoscope including the add-on robotic module is positioned in a docking station and the physician holds the remote control in one hand and the shaft in the other hand. In the other configuration the physician carries the robotic endoscope with the remote control that is directly coupled to the control section of the endoscope, as shown in Figure 2.2. The former is easy to carry while the latter allows for extra maneuverability of the endoscope. Possibly this is beneficial during insertion of the endoscope. If necessary during a procedure the setup can also be changed to conventional steering by taking the endoscope in a few seconds out of the robot.

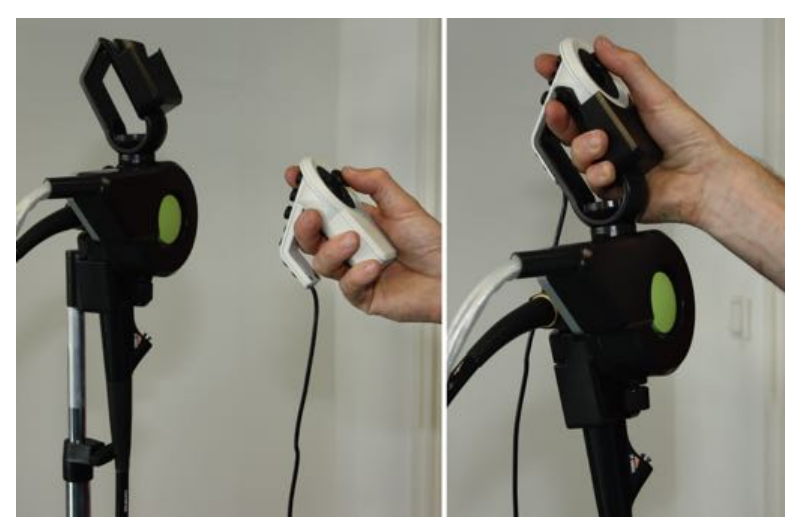

Figure 2.2: Stationary (left) versus mobile use of the robotic endoscope.

The remote control should be intuitive and suitable for single-handed use. It ought to reduce musculoskeletal complaints of the operator and has to be operated close to the patient. All input controls of the control section of the current endoscope should be included in the remote control. During intubation the physician should be able to actuate insufflation, suction or rinsing while steering the tip. In current 
practice the flow is controlled by repeatedly actuation of the buttons (digital input). In the robotic setup flow could be controlled proportional (analog input). In particular precise (limited) insufflation contributes to successful intubation [46] and minimal patient discomfort [47]. The remote control can be operated while wearing disposable gloves and should allow for left as well as right handed use. The delicate task of shaft manipulation, that requires precise interpretation of force feedback information, can always be done with the dominant hand. This optimizes the setup for the about $10 \%$ left handed physicians [48].

Different kind of input controllers that are used for computer applications (e.g. mouse, joystick, haptic controller) are used for clinical systems as well. New innovations are related to speech, gaze, and gesture control. The clinical application of these innovative techniques is limited, mainly because of safety issues, like limited accuracy and robustness. The input controller that steers the tip is a critical component with regard to usability and intuitive use. It should be able to manipulate the tip from $-180^{\circ}$ to $+180^{\circ}$ in left-right, up-down and combined (diagonal) directions. The controller should allow for fast large movements, precise small movements and stabilization of the bendable tip in a preferred position. For instance during inspection of the lumen, the tip should follow a smooth circular path. Thereby providing images of the entire mucosal surface within reasonable time and allowing for precise camera positioning to inspect suspicious areas.

In current practice the physician relates the forces required to turn the navigation wheels of a traditional endoscope to the shape of the tip and shaft inside the body. The navigation wheels transmit actuation forces to the tip by means of flexible Bowden cables. The force increases by friction in accordance with the degree of flexion of the endoscope. This helps the physician to estimate the flexion of the tip, interaction forces of the tip with tissue, and shaft loops that need to be straightened [49]. Force information from the navigation wheels need to be fed back to the physician in the robotic setup. Ideally this would be haptic feedback to achieve a sense of transparency but a haptic controller with at least 2 degrees of freedom that can be integrated with a small remote control is not available. Vision could provide an appropriate sensory substitute in the robotic setup. Indication bars reflecting force information are shown on the monitor. We have to verify in our setup if vision can adequately replace haptic information. 
The setup limits the number of controllers suitable to steer the tip. A thumb joystick as seen in gamepad controllers or a touchpad like in laptops are the most likely options. Position and rate control are the two common transfer functions. In position control the input device indicates the desired position of the end effector, whereas in rate control the input device indicates the desired end effector velocity. There is no upfront evidence in literature to choose between these alternatives [50]. In our setup a thumb joystick combines best with rate control. It allows the physician to use the full bending range of the tip of the endoscope. Additionally, rate control can freeze the tip in a preferred position when releasing the joystick. The joystick, with spring loaded return-to-center functionality, returns to its initial position and sets the speed to zero. A touchpad can be best combined with incremental position control. Like in mouse navigation, clutching allows the physician to use the full manipulation range. Lifting the finger fixates the tip of the endoscope into position. In our experiment we try to determine the best control option.

Above considerations are implemented in our design of a robotic endoscope, as described in the next section.

\subsection{Design}

The add-on robotic module can be integrated in a conventional flexible endoscopy cart, Figure 2.3. The configuration is designed to obtain a light robotic endoscope that can be manipulated freely by the operator. For that reason all heavy components, like motors, are placed in a stationary positioned motor unit that is connected through a flexible transmission to a compact and light mobile drive unit. If the two motors for navigation wheel actuation would be positioned in the mobile drive unit it would add about $0.7 \mathrm{~kg}$ to the weight. The motor unit is placed on the endoscopy cart and the generic mobile drive unit connects with a dedicated interface to the navigation wheels of each individual type of endoscope. On top of the interface unit the holder of the remote control is positioned. Table 2.1 contains an overview of some general specifications of the designed mobile drive unit.

\subsubsection{Drive system}

Antagonistic cable pairs between the stationary motor unit and the mobile drive unit actuate the navigation wheels of the endoscope, Figure 2.4. The cables are preten- 


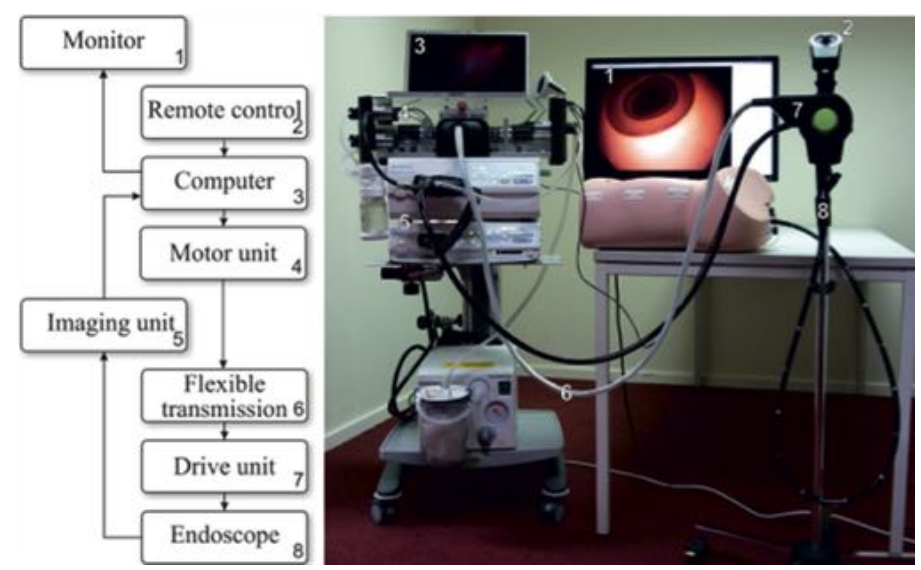

Figure 2.3: System design of the add-on robotic control module.

Table 2.1: Specifications of the designed mobile drive unit.

\begin{tabular}{rr}
\hline Maximum torque on wheels & $1.5 \mathrm{Nm}$ \\
\hline Range of motion & $360^{\circ}$ (omnidirectional) \\
\hline Maximum angular velocity & $2 \pi \mathrm{rad} / \mathrm{s}$ \\
\hline Weight mobile drive unit & $0.92 \mathrm{~kg}$ \\
\hline
\end{tabular}

sioned to prevent backlash and delay in control. The outer sheath of the Bowden cables at the load side are supported by load cells to measure the applied force to the navigation wheels. The drive system is self-locking so the position of the tip of the endoscope (camera position) is maintained when the controller of the remote control is not actuated. Two optical encoders are added to the load side to be able to improve control. In the current setup these are not in use.

Two DC servo motors were selected for actuation. The motors, motor controllers and power supply are all integrated in the motor unit box. The main program is computed on an external computer.

\subsubsection{Coupling mechanism}

The drive system cannot be sterilized. A sterile interface couples the drive unit to the clean endoscope to prevent cross contamination. If preferred the drive unit is sealed in a bag as shown in Figure 2.5. The interface is first connected to the endoscope. It is 


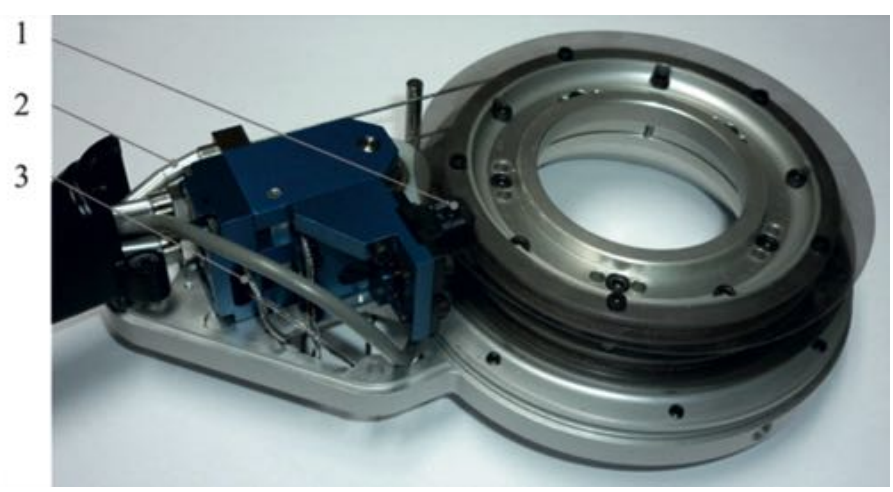

Figure 2.4: Mobile drive unit: (1) Optical disc encoders, (2) Bowden cables, (3) Force sensors.

locked by an endoscope specific plug that bridges the valves of insufflation, rinsing, and suction on the endoscope so these can be controlled with the remote control. This assembly is subsequently connected with the mobile drive unit by threaded knobs. Torque between drive unit and interface is transferred with a pin hole connection. A configurable holder for the remote control is integrated with the interface. The physician is able to position it to personal preferences to comfortably hold and carry the robotic endoscope. If preferred the robotic endoscope is positioned in a docking station on a pole cart and the remote control can be detached from the holder. The docking station allows axial rotation of the shaft of the endoscope that is induced by the physician during the procedure. 


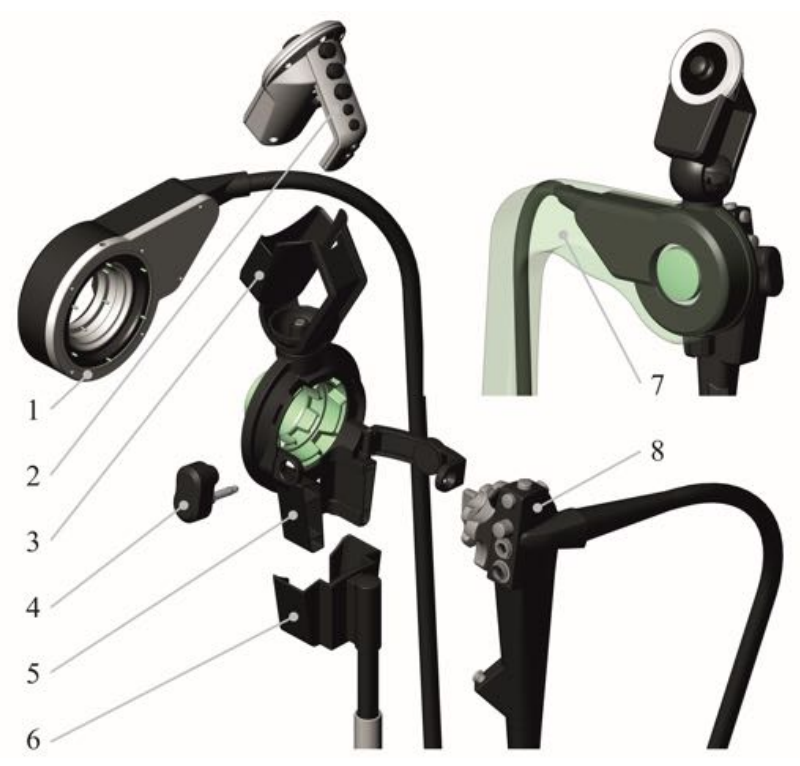

Figure 2.5: Exploded view of the coupling mechanism, with (1) Drive unit, (2) Remote control, (3) Holder remote control, (4) Plug,

(5) Sterile interface,

(6) Docking station,

(7) Sterile bag,

\subsubsection{Remote control}

The remote control allows single-handed control of all available functionality of a traditional endoscope, as shown in Figure 2.6. A thumb joystick as well as a touchpad can be integrated as input controller to steer the tip. Push buttons are arranged to operate all valves and switches of the control section of the current endoscope. Buttons for proportional insufflation, rinsing, and suction are pressure sensitive by means of an underlying force sensing resistor. Flow is controlled with solenoid pinch valves that are positioned in the motor unit, Figures 2.7 . A hold-to-run safety switch needs to be pressed during operation of the robotic endoscope to prevent unintended actuation of input controls.

\subsubsection{Feedback information}

The operator is provided with several sources of visual feedback to support control of the robotic endoscope. These are integrated in a single monitor. The endoscopic images that visualize patient tissue are most important and take up most surface of the monitor. The endoscope and its imaging unit determine the characteristics of these images. Often these are provided in high definition. One fourth of the monitor is reserved for additional feedback provided by the robotic system. The flexion of the 

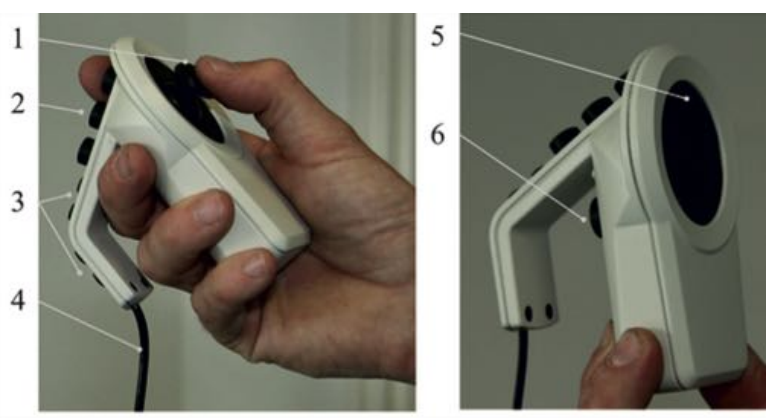

Figure 2.6: Joystick and touchpad remote controllers: (1) Thumb joystick, (2) Buttons for insufflation, rinsing, and suction, (3) Programmable switches, (4) USB cable to computer, (5) Touchpad, (6) Holdto-run safety switch.

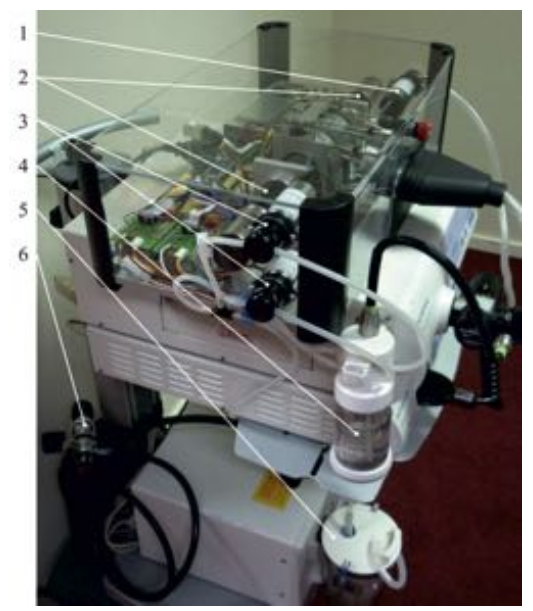

Figure 2.7: Endoscopy cart: (1) Solenoid valve suction, (2) Motors Bowden cables, (3) Solenoid valves insufflation and rinsing, (4) Water container, (5) Pump unit, (6) Air/CO2 gas cylinder.

endoscope tip is shown in a bending diagram. The diagram shows a bar in a white circle that extends from the center into the direction that the tip is moving, Figure 2.8. The direction and length of the bar are an indication for tip direction and flexion respectively. Additional bar indicators provide information about the torque required to turn the navigation wheels. This relates to the shape of the shaft and interaction of the endoscope tip with tissue. Flow information of insufflation, rinsing, and suction is also fed back by bar indicators. 

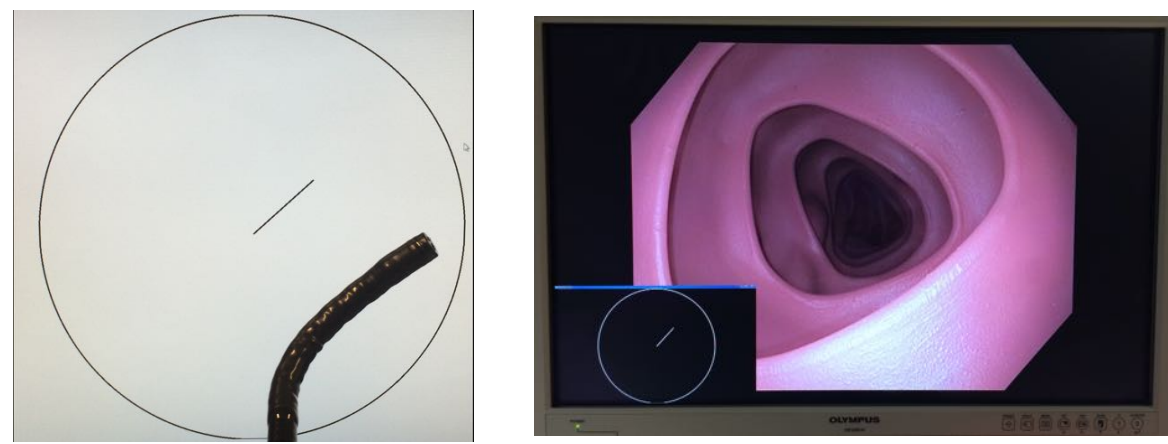

Figure 2.8: Left: Feedback circle depicting the input of the remote controller to endoscopic tip bending. The length and angle of the line indicate the amount and direction of tip bending, with the circle outlining the maximal bending angle. Right: Feedback circle as presented to the physician.

\subsection{Evaluation}

\subsubsection{Experimental setup}

This section describes the experiments conducted to determine the optimal settings of our robotic endoscope and to assess its intuitiveness and user-friendliness. We compared conventional steering of the tip to robotic steering to obtain knowledge about the best input controller and the required maneuverability of the endoscope. The tested setups were:

1. Conventional steering with navigation wheels. We use this method as a reference for the robotic setups.

2. Joystick steering with stationary endoscope. The endoscope including the drive unit is positioned in a docking station and the endoscopist only holds the remote control, as shown in 2.6.

3. Touchpad steering with stationary endoscope.

4. Joystick steering with mobile endoscope. The endoscopist carries the endoscope with the remote control that is directly coupled to the control section of the endoscope, as shown in 2.6 and 2.9.

5. Touchpad steering with mobile endoscope.

A standard flexible colonoscope (Exeria II CF-H180AL, Olympus, Tokyo, Japan) and imaging unit (Exeria II CLV 180, Olympus, Tokyo, Japan) were used for all experimental conditions. 24 novices, without experience in handling an endoscope 


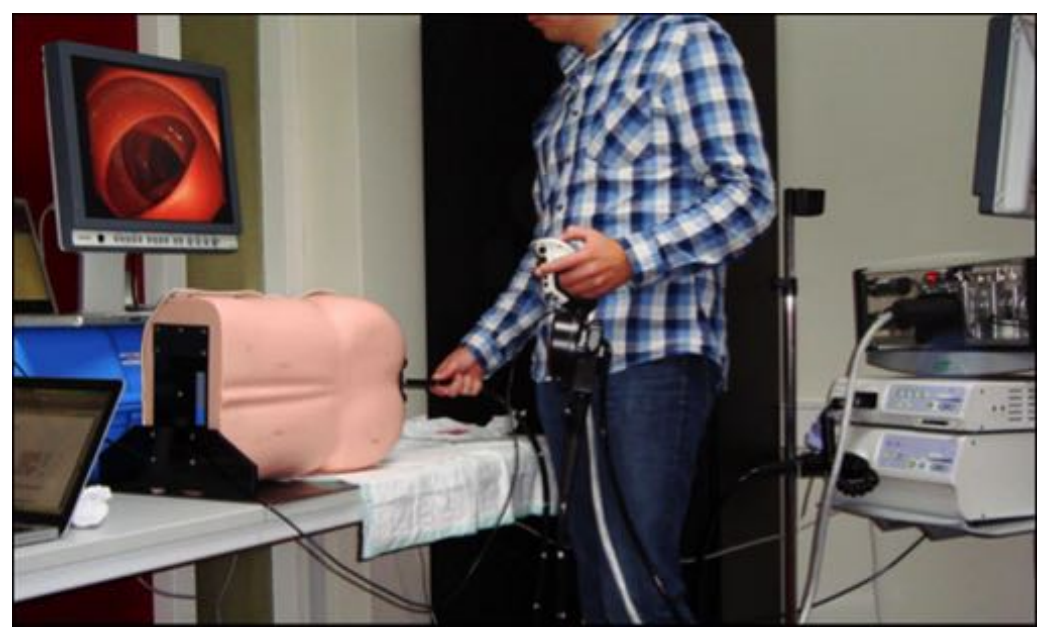

Figure 2.9: Experimental setup

and without medical background, were asked to perform 2 colonoscopy tasks on an anatomical model (M40, Kyoto Kagaku, Kyoto, Japan). The absence of experience enabled testing of intuitiveness.

First, participants had to introduce the endoscope to the cecum. Second, the endoscope had to be withdrawn while inspecting the mucosal surfaces for lesions, represented by 7 prepositioned red blocks sized $2 \times 2 \times 1 \mathrm{~mm}$. It was too time consuming to test all setups on all individual participants. For that reason the population of 24 participants (aged 21-50 years, 7 women and 17 men) was divided over 2 groups. One group tested setup 1, 2 and 5. The other group tested setup 1, 3 and 4 . This way all participants experienced both input controllers and both settings of endoscope handling. Each of the six possible orders of the three conditions was performed equally often to correct for learning effects and fatigue. For each setup 5 minutes of practice time was available and the opportunity to ask for advice on usage.

An easy bowel configuration was chosen in which all participants could complete the task. Our focus was to test the steering usability of the endoscope. Future experiments by experienced physicians will be more challenging to test also the (clinical) usability of features like insufflation, suction and force feedback information that are typically required in difficult procedures. These functionalities were not available in this novices experiment. 


\subsubsection{Evaluation parameters}

Usability is defined by the International Standardisation Organisation (ISO) as: 'the extent to which a product can be used by specific users to achieve goals with effectiveness, efficiency, and satisfaction in a specified context of use' [51]. The three factors are widely accepted to concern distinct measures and were evaluated in the experiment [52]. In our experiment the following dependent variables were measured:

- Full intubation into the cecum (effectiveness)

- Detection rate of lesions (effectiveness)

- Intubation time (efficiency)

- Subjective workload analysis measuring mental and physical demand, performance, effor and frustration. Based on assigning scores to a modified NASA Task Load Index, [53] (efficiency)

- Rank interfaces according to preference (satisfaction)

- Questionnaire by interview (satisfaction)

\subsubsection{Statistical analysis}

Statistical models in PASW Statistics v.18 were used to analyze the experimental data. Within group differences were assessed using Friedmans ANOVA with Wilcoxons signed rank test as a post hoc test.[54] Differences between groups 1 and 2 were determined using the independent T-tests for a normal distribution, non-normal distribuations were analyzed using the Mann-Whitney test. In every analysis, a statistical significant difference was defined with $p<0.05$. This represents a chance of $5 \%$ that the test reveals a difference, when there is none.

\subsection{Results}

All participants performed complete cecum intubation without causing a perforation. There was no significant difference in the intubation time, detection rate and workload scoring between group 1 and 2 when using conventional control, Table 2.2 and Figure 2.10.

Group 2 was significantly faster using the mobile touchpad and stationary joystick compared to the conventional method, with $\mathrm{p}=0.001$ and 0.002 respectively. 
Table 2.2: Quantative results experiment.

\begin{tabular}{lccccc}
\hline Setup & $\begin{array}{c}\text { Conventional } \\
(\mathrm{n}=24)\end{array}$ & $\begin{array}{c}\text { Joystick - stationary } \\
\text { scope }(\mathrm{n}=12)\end{array}$ & $\begin{array}{c}\text { Touchpad - stationary } \\
\text { scope }(\mathrm{n}=12)\end{array}$ & $\begin{array}{c}\text { Joystick - mobile } \\
\text { scope }(\mathrm{n}=12)\end{array}$ & $\begin{array}{c}\text { Touchpad - mobile } \\
\text { scope }(\mathrm{n}=12)\end{array}$ \\
\hline Insertion time $(\mathrm{s})$ & $178(142-240)$ & $145(103-185)$ & $188(116-233)$ & $150(98-193)$ & $108(95-142)$ \\
\hline Workload $(\max 25)$ & $17(14-19)$ & $13(10-17)$ & $10(8-14)$ & $11(10-13)$ & $15(12-18)$ \\
\hline Detection rate $(\%)$ & $71(57-71)$ & $86(57-100)$ & $71(57-89)$ & $64(48-89)$ & $71(57-75)$ \\
\hline Values are expressed as median (interquartile range)
\end{tabular}

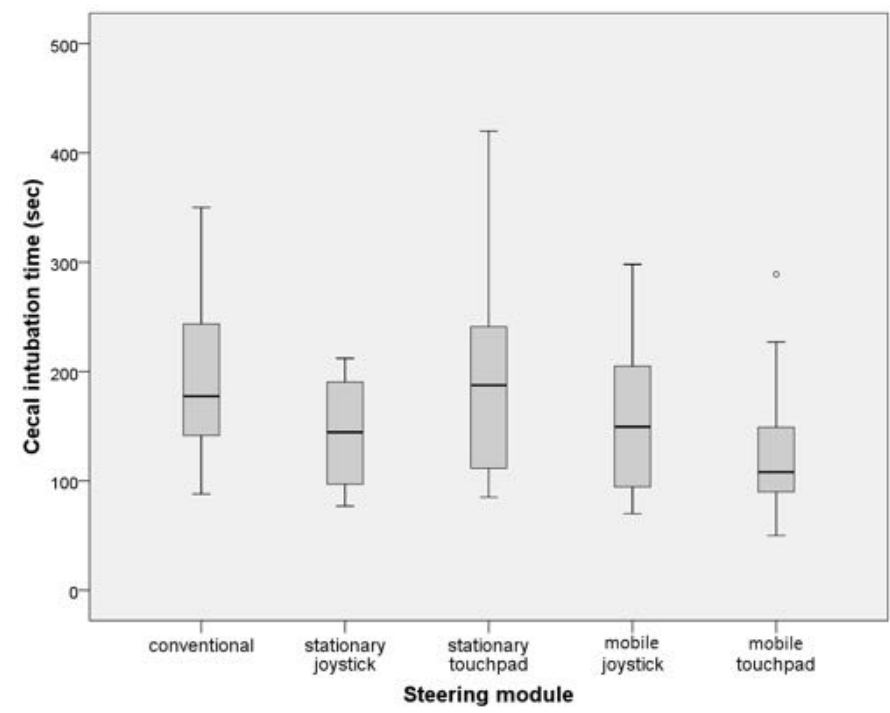

Figure 2.10: Box-Whisker diagram showing the maximal, upper quartile, median, lower quartile and minimal value of cecal intubation time, per steering module. The remote touchpad configuration includes an outlier that is more than three standard deviations apart from the mean intubation time.

Intubation times in group 1 were not significantly different.

The detection rate was not significantly higher or lower using touchpad or joystick control compared to the conventional method.

In group 1, the workload scoring of both mobile joystick and stationary touchpad were significantly better compared to the conventional method, with $\mathrm{p}=0.05$ and 0.025 respectively. In group 2 , only the stationary joystick scores better on workload compared to the conventional method, with $\mathrm{p} 0.025$.

Participants preferred the joystick control (mobile and stationary) over the touchpad and conventional methods in 15 of 24 cases. The conventional steering method would be the first choice for one participant, and last for 16 of 24 participants, Table 2.3 . 
Table 2.3: Preference rates for used control methods.

\begin{tabular}{lccc} 
& First & Second & Third \\
\hline Conventional & 1 & 7 & 16 \\
\hline Joystick (remote \& stationary) & 15 & 6 & 3 \\
\hline Touchpad (remote \& stationary) & 8 & 11 & 5 \\
\hline
\end{tabular}

\subsection{Discussion}

The results indicate that robotic steering by novices improves intubation time and workload experience. Compared to the conventional method, joystick steering with stationary endoscope and touchpad steering with mobile endoscope had significantly faster intubation times. The workload scoring of all robotic setups are significantly better than the conventional method, except for touchpad steering with mobile endoscope. The detection rate was not significantly affected by robotic steering. All novices performed full intubation into the cecum.

Extensive maneuvering of the endoscope shaft was not required during intubation. For that reason nothing conclusive can be said on the necessity of a mobile scope. Future experiments with physicians in a challenging procedure should provide more knowledge. In the interviews all participants complain about the additional weight that needs to be carried in the mobile endoscope setup. One might consider free manipulation only in awkward circumstances such as looping of the shaft. During easy parts of the procedure the scope is docked. Despite the additional weight, novices appreciated the ergonomics and work posture of all robotic setups more than of the conventional setup.

Although participants prefer joystick to touchpad control, data on performance does not endorse that outcome. Possibly, the reduced proprioceptive feedback in touchpad control limits the feeling of being in control. In addition, participants tend to roll the thumb during touchpad control instead of only moving the tip of the thumb over the touch surface. In this case, tip movement will not occur as expected, since the center of the touched surface is not moved as intended. In the mobile setup, rolling the thumb is restricted by the additional weight and the imposed position of the hand with respect to the endoscope, possibly explaining the faster intubation time of the mobile compared to the stationary setup. A system that encourages steering with the tip of the thumb will likely lead to improved touchpad control. Almost all participants thought that the joystick as well as the touchpad controller were too 
sensitive, but they valued the intuitiveness of operation and experienced no delay in tip response. Previous experience with game controllers or touch interfaces did not influence the outcome. Some suggested that up-down in joystick control should be reversed to copy flight control. Sensitivity as well as up-down direction could be made adaptable to comply with user preferences. Force feedback information from the navigation wheels was not available in the robotic setup in our experiment. However, the bending diagram, as described in 2.4.4, was shown during the experiment. We estimated that feedback on the extent to which the tip is bent was essential even in an easy bowel configuration. Novices appreciated this substitute for haptic feedback very much.

\subsection{Conclusion}

A robotic system is built that allows ergonomic single-person control while preserving current endoscope qualities. Acceptance is expected to be high since our robotic setup can easily be implemented in the current clinical workflow. We showed that robotic steering by novices, using touchpad or joystick control, increases efficiency and satisfaction. The effectiveness was not significantly affected by robotic steering. Our results did not show a clear preference for a position-controlled touchpad or a rate-controlled joystick. We will perform additional experiments in which we will critically look at the type of input controller and the accompanying control algorithm. Breaking the mechanical linkage and integrating computer intelligence between operator and end effector provides opportunities for improved usability. However, we also identified critical user aspects of traditional flexible endoscopes that are related to mechanical interfaces, like force feedback. 


\section{Chapter 3}

\section{Robotic steering increases efficiency in endoscope tip control}

Published as:

ED Rozeboom, JG Ruiter, M Franken and IAMJ Broeders

Intuitive user interfaces increase efficiency in endoscope tip control

Surgical Endoscopy, 2014;9:2600-2605

With permission of Springer 


\begin{abstract}
Background

Flexible endoscopes are increasingly used to perform advanced intraluminal and transluminal interventions. These complex interventions demand accurate and efficient control, however, current endoscopes lack intuitiveness and ergonomic control of the endoscope tip. Alternative handheld controllers can improve intuitiveness and ergonomics, though previous studies are inconclusive concerning their effect on the efficiency of endoscope manipulation. The aim of this study is to determine the efficiency of a robotic system with intuitive user interface in controlling the tip of the flexible endoscope.
\end{abstract}

\title{
Methods
}

We compared the efficiency of time and tip trajectory when steering the endoscope tip using the conventional steering wheels and a robotic platform with three different user interfaces: a touchpad in combination with a position control algorithm, a joystick combined with linear rate control, and a joystick combined with non-linear rate control. Fourteen participants, without a medical background, used all four interfaces. They performed both large navigational and fine targeting tasks in a simulated environment which allowed objective cross-subject comparison. Afterward, the participants were asked to select their preferred steering method.

\section{Results}

Participants were significantly faster in steering the endoscope tip when using robotic steering compared to using the conventional steering method. Between the robotic interfaces, using the touchpad was significantly faster compared to the joystick with linear rate control. Use of the joystick with non-linear rate control led to a shorter tip trajectory compared to the touchpad. The majority of participants preferred the joystick with non-linear rate control over the other steering methods.

\section{Conclusions}

This work shows that intuitive user interfaces can improve the efficiency of endoscope tip steering. 


\subsection{Introduction}

Flexible colonoscopes are increasingly used in advanced intraluminal and transluminal therapeutic interventions [6, 55-57]. These complex interventions demand accurate and efficient control of the endoscope and its accessories [55, 58, 59]. Robotics allow the introduction of intuitive and ergonomic user interfaces that can address difficulties in tip steering $[40,60]$ and may reduce the dependence on technical skills. However, recent studies remain inconclusive concerning the effects of a robotic setup with intuitive interfaces on efficiency of endoscope manipulation [38, 61, 62]. Allemann et al. [38] report that both novices and experts required significantly more time to complete a maneuvering task when using a joystick compared to using the conventional system. They ascribed this outcome to the limited maneuverability of the setup and the used control algorithm [40]. Reilink et al. [61] showed that experts perform faster cecal intubation, while novices show no significant difference, when performing simulated colonoscopy using the conventional steering method versus an intuitive interface. They expect improvements with learning and adaptations to the described interface. Eckl et al. [62] found no significant difference in the efficiency of novices bending a flexible rhino endoscope whether using a joystick or the conventional control method. In summary, there are inconclusive results and the used control setup is vital to the outcome. We analyzed the efficiency of the robotic system with intuitive interfaces described by Ruiter et al. [1]. Henceforth, with the 'intuitive interfaces' is referred to the complete system, including both the handheld interface and the robotic system that facilitates the use of alternative interfaces to steer conventional endoscopes. Flexible endoscopy requires both quick tip steering (lumen navigation) and precise targeting (instrument placement for e.g., taking biopsies). Previously mentioned studies showed that both tasks require different control algorithms, which in turn leads to a need for different interfaces [63, 64]. We compared the user performance when using a handheld controller with a touchpad interface and with a joystick interface to the conventional method. The touchpad is combined with a position control algorithm, which has particular advantages in precise movements. The joystick is combined with rate control, which is recommended for wide workspace tasks $[63,64]$. A nonlinear rate control algorithm was implemented that provides both precise movements and quick tip steering with a single joystick, Figure 3.1. The aim of this research is to determine if the robotic setup and used interfaces are able 
to provide efficient control of the tip of a flexible endoscope, in terms of time and tip trajectory.

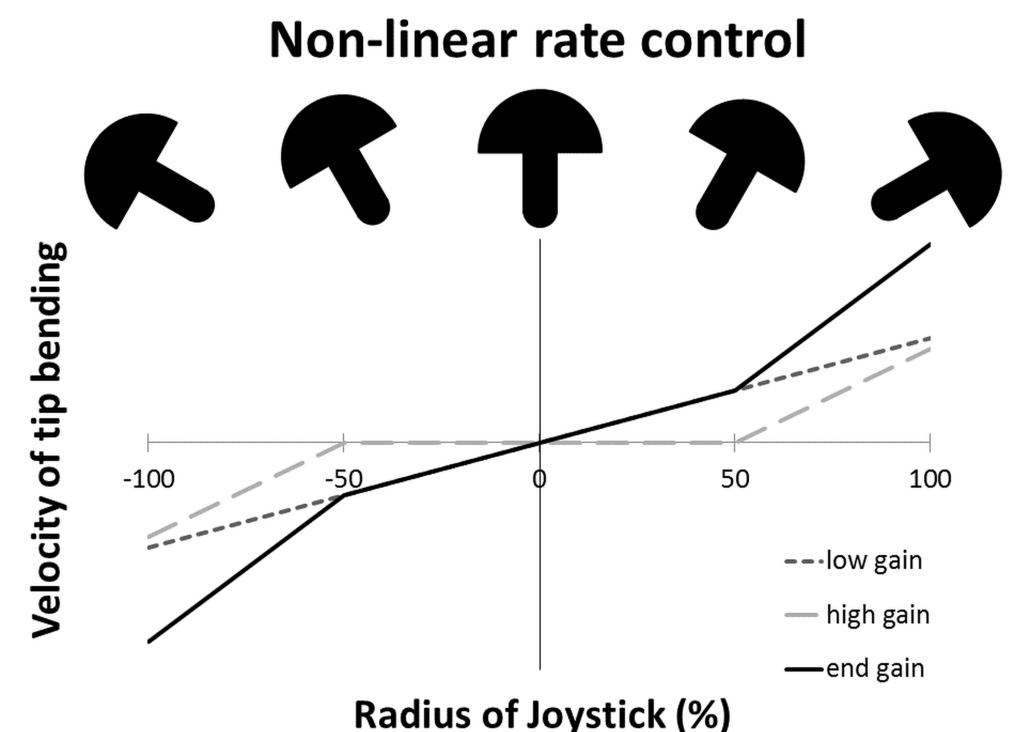

Figure 3.1: A gain relates the joystick's position to the velocity of endoscope tip bending in the corresponding direction. The non-linear algorithm combines a low gain with a higher gain to create two zones, one with low and one with higher velocity changes.

\subsection{Materials and Methods}

\subsubsection{Participants}

Fourteen novices, participants without a medical background and without experience in flexible endoscopy, were included. Novices were chosen to evaluate intuitiveness of the steering methods, since evaluation at the start of a learning curve prevents intrinsic bias to one of the steering methods. There were eight men and six women, with an average age of $28 \pm 5$ years. All participants were righthanded. None of the participants were frequent users of joysticks or touchpads.

\subsubsection{Setup}

The simulated environment consists of a hollow tube with two rings of targets attached to the wall and on a circle inside the tube Figures 3.2 and 3.3. The distal 
$\pm 15 \mathrm{~cm}$ of a standard flexible colonoscope (Exeria II CF-H180AL, Olympus, Tokyo, Japan) was inserted into this tube and fixated before the bending section to exclude shaft manipulation. A standard reusable biopsy grasper instrument (Olympus, Tokyo, Japan) was inserted through the working channel of the endoscope, protruding from the tip of the endoscope. A standard imaging unit (Exeria II CLV- 180, Olympus, Tokyo, Japan) was used to process the endoscopic images. Audio feedback informed the operator when a target was touched.
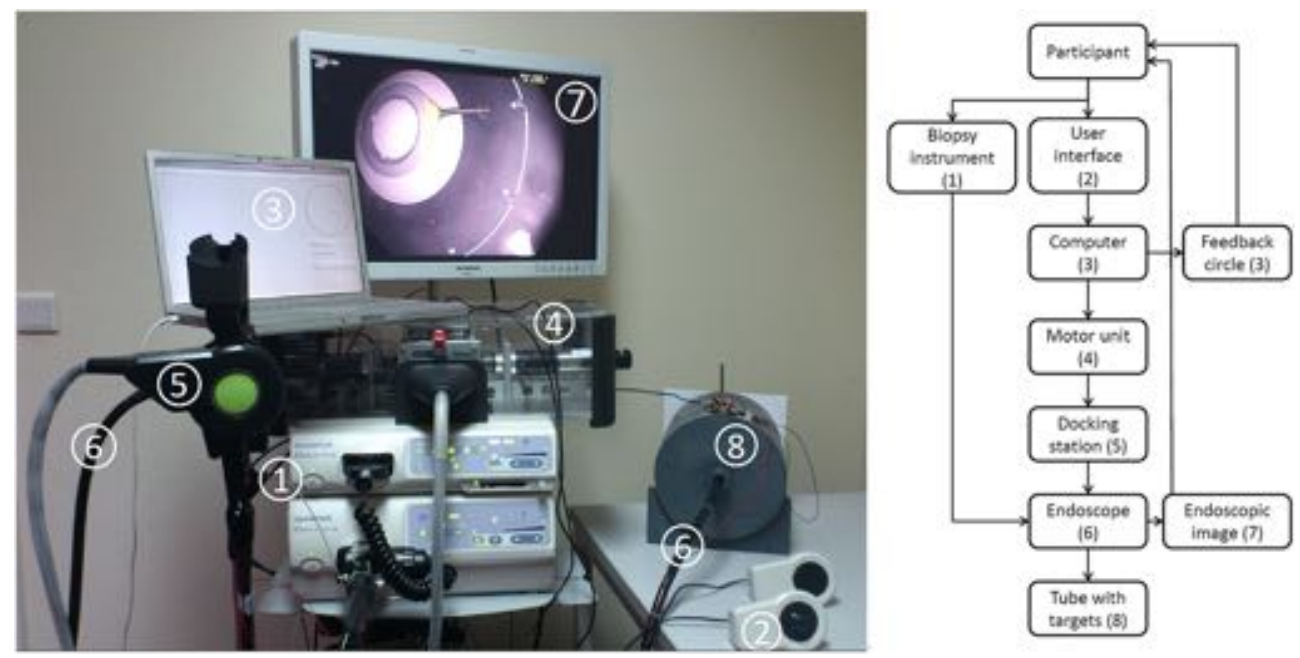

Figure 3.2: Test setup and schematic workflow.

\subsubsection{User Interfaces}

When using the conventional steering method, the user rotates two angulation wheels for up/down or left/right angulation. When using the alternative interfaces, an addon robotic module actuates the angulation wheels. This module is connected to the conventional endoscope and positioned in a docking station as described by Ruiter et al. [1]. In this configuration, a feedback circle is visualized on-screen to inform the participant about the direction and the extent of tip bending, Figure 3.3. The handheld controllers contain either a thumb joystick (model 802, P3 America, San Diego, USA) or a touchpad (Ergonomic touchpad, UK). 


\subsection{MATERIALS AND METHODS}

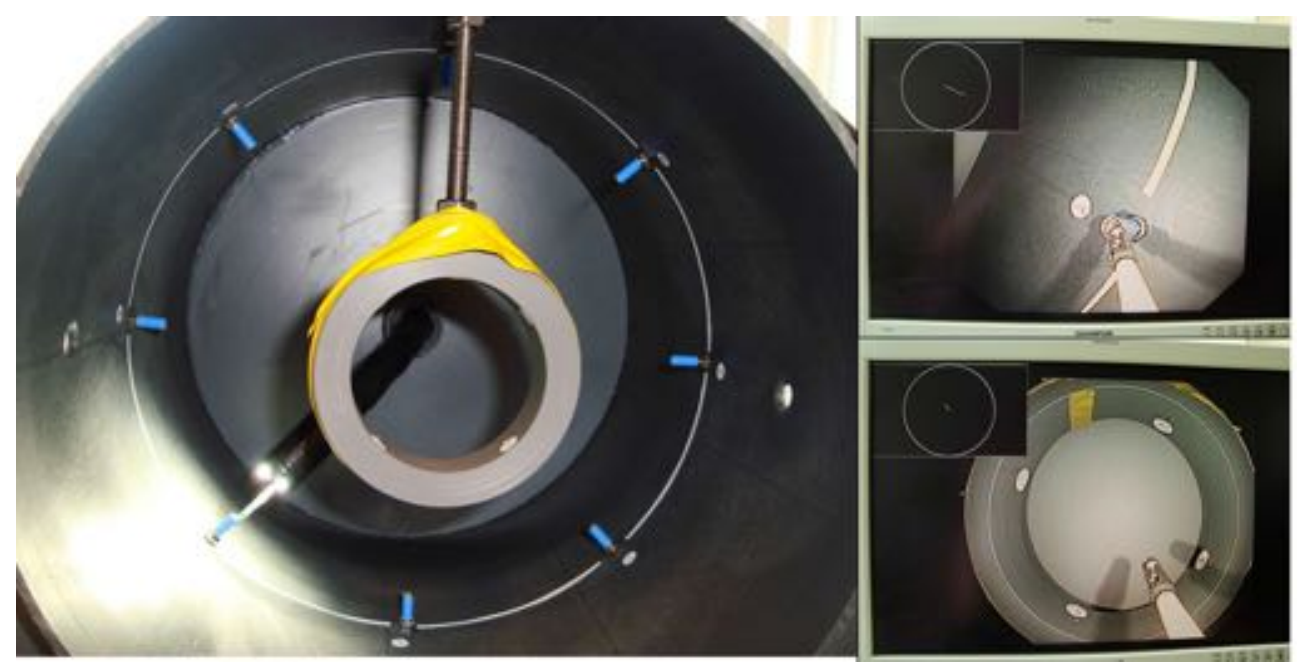

Figure 3.3: (Left) The bendable distal part of the endoscope protrudes through a hollow tube with two rings of numbered targets. Touching the eight targets on the outer ring requires large endoscope tip movements, which represents the navigation task (task 1). The four targets on the inner ring are used for the small tip bending movements in the targeting task (task 2). The upper right image shows the endoscopic view of task 1 , with a numbered target, guiding line to follow to the next target and feedback circle representing the amount and direction of tip bending. The lower right image shows the endoscopic view of task 2 with its feedback circle.

\subsubsection{Control Algorithms}

The touchpad is combined with a position control algorithm, comparable to a laptop touchpad. When the user moves his/her thumb over the touchpad, the endoscope tip will bend in the corresponding direction. A faster thumb movement provides faster tip angulation. As the touchpad surface is smaller than the bending range of the endoscope tip, repeated thumb motions are necessary to reach the full bending range (called clutching). The gain of the position control algorithm was adjusted to enable a single thumb movement on the touchpad to cover the small distance required for the targeting task (task 1). A higher gain would result in less clutching to cover the larger distance of task 2, though this inevitably results in less precision for small movements.

The joystick is combined with rate control. Rate control relates the position of the joystick to a velocity of tip bending in the corresponding direction. The user pushes the joystick in the required angulation direction. Pushing the joystick further from its neutral position will result in faster tip angulation. As the user can hold the joystick in 
a certain position, no clutching is required to reach maximal tip angulation. In linear rate control, a single gain factor relates the angular position of the joystick with the tip's angulation velocity. In non-linear rate control, two gains are combined to enable an area with low velocity and an area with higher velocity, Figure 3.1. The low gain enables higher precision for small distances, while the high gain provides more efficiency in covering larger distances. A single gain (used in linear rate control) is a trade off between precision and speed. All gains were adjusted following a preexperimental testing session.

\subsubsection{Procedure}

Participants were asked to steer the endoscope tip as quickly and fluently as possible to position it in front of eight targets. After positioning the tip, participants had to advance a grasper instrument through the working channel to contact the target. Two rings of numbered targets were located in the tube. To test navigational functionality, the first task was to touch 3-mm targets, equally distributed on a circle with a diameter of $200 \mathrm{~mm}$. A line on the outer surface of the tube indicated the optimal path to the next target. The second task simulated fine targeting functionality. Included were four targets of $1 \mathrm{mmon}$ a circlewith a diameter of $50 \mathrm{~mm}$. Targets were placed such that horizontal, vertical, and diagonal movements were necessary. The size of the targets was adjusted to provide a similar index of difficulty as in the first task (defined by Fitt's Laws the ratio between path length and target size). To generate an equal number of measurements as in the first task, participants were asked to perform this task twice. They were asked to limit contact with the outer surface that represented the bowel wall. Instruction and 5 min practice time were included before every task. Both tasks were performed once with each steering method: conventional, touchpad, linear joystick, and non-linear joystick. The order in which the steering methods were used was counterbalanced to prevent distortions due to learning effects or fatigue. The time between touching targets was electronically recorded, and the total time for each task calculated. Additionally, when using the intuitive interfaces, the motor rotations were registered by means of attached incremental optical encoders. Each encoder pulse relates to an endoscope tip angulation of $* 10^{-5}$ in that direction. Consequently, the number of motor pulses is related to the bending trajectory of the tip. This trajectory cannot be recorded for the conventional configuration. Following 


\subsection{RESULTS}

the experiment, the participants were asked to select their preferred steering method for each task and with regard to their perception of control.

\subsubsection{Statistical Analysis}

Statistical analysis was performed using IBM SPSS statistics version 21. Withinparticipant variances were calculated using Friedman's ANOVA for non-parametric data, followed by Wilkoxon's signed rank test as a post hoc test. The parametric data were analyzed using one-way repeated measures ANOVA with Tukey's LSD correction as the post hoc test [54]. p values under 0.05 were considered statistically significant. Bonferroni corrections were automatically applied. Values are expressed as median with interquartile range (IQR).

\subsection{Results}

The conventional steering method (266, 207 - 367 s) was significantly slower compared to all intuitive interfaces, when navigating over larger distances (task 1). Also, participants were significantly faster when using the touchpad (153, 116 - $184 \mathrm{~s})$ compared to the linear joystick (185,154 - $309 \mathrm{~s})$. There was no significant difference between using the touchpad and the non-linear joystick (148, 132 - 221 s), Table 3.1, Figure 3.4A.

Table 3.1: Total time and covered distance, presented as the median (IQR). The preference rate is the number of participants who preferred the specific controller for each tasks and related to the perception of being in control.

\begin{tabular}{|c|c|c|c|c|}
\hline & Conventional & Touchpad & Joystick & Non-linear Joystick \\
\hline \multicolumn{5}{|c|}{ Total time (s) } \\
\hline Task 1 & $266(207-367)$ & $153(116-184)^{\star, \star \star}$ & $185(154-309)^{\star}$ & $148(132-221)^{\star}$ \\
\hline Task 2 & $244(210-286)$ & $207(165-234)^{\star, \star \star}$ & $240(203-262)$ & $222(160-241)^{\star}$ \\
\hline \multicolumn{5}{|c|}{ Total covered distance (sum of tip angulation) $\left({ }^{\circ}\right.$ ) } \\
\hline Task 1 & NA & $1992(1606-2334)$ & $1882(1551-2678)$ & $1606(1367-1884)^{\bullet}$ \\
\hline Task 2 & NA & $1534(1324-1821)$ & $1540(1332-1806)$ & $1243(997-1373)^{\bullet}$ \\
\hline \multicolumn{5}{|c|}{ Preference rate } \\
\hline Task 1 & 0 & 4 & 3 & 7 \\
\hline Task 2 & 3 & 2 & 1 & 8 \\
\hline Control & 5 & 3 & 3 & 3 \\
\hline
\end{tabular}


When controlling small movements (task 2), participants were significantly faster using the touchpad (207, 165 - $234 \mathrm{~s})$ and the non-linear joystick (222, 160 - $241 \mathrm{~s})$ compared to the conventional method (244, 210 - $286 \mathrm{~s}$ ), Figure 3.4B. Also, using the touchpad was significantly faster compared to the linear joystick (240, $203-262$ s). There was no significant difference between using the touchpad and the non-linear joystick.

Using the non-linear joystick resulted in significant shorter tip trajectories, compared to using the touchpad (task $1: \mathrm{p}=0.022$, task $2: \mathrm{p}=0.008$ ) and linear joystick (task 1: $\mathrm{p}=0.024$, task 2: $\mathrm{p}=0.009$ ), Table 3.1, Figure 3.5.

The majority of participants preferred the non-linear joystick over the other control methods of steering the endoscope tip in large ( 7 out 14) and small (8 out 14) bending ranges. There was no significant difference in the user's preference between steering modules with regard to the perception of control.
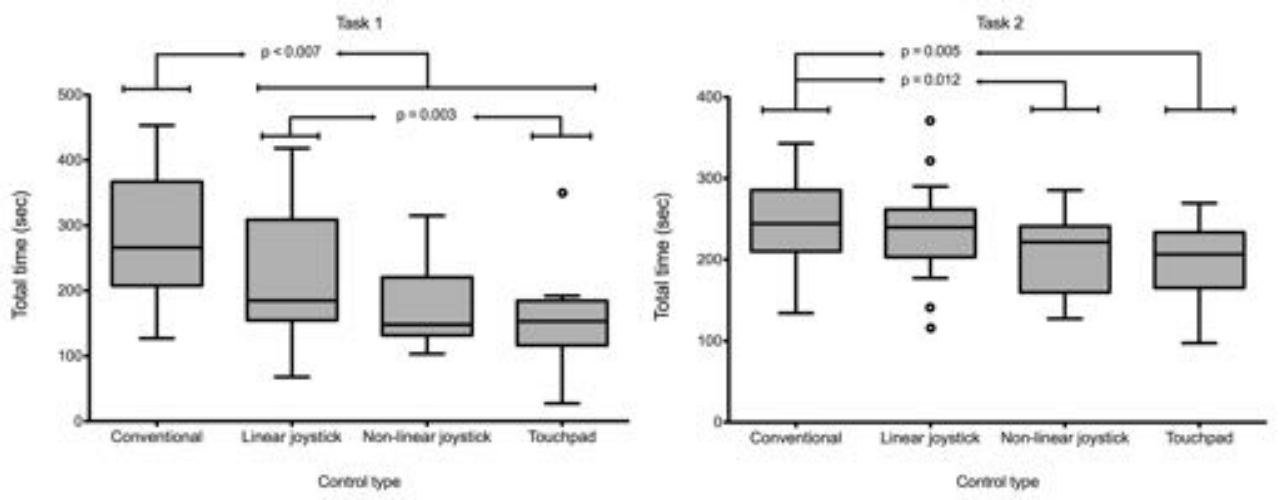

Figure 3.4: Box-and-whisker diagrams representing the median and spread of time taken to perform the first (a) and second (b) task, per controller. In the first (navigational) task, one outlier performs slow on the touchpad. The second task reveals several outliers with the single rate joystick, performing slower and faster. The wide spread in results for this precise targeting task illustrates that there is not a normal distribution.

\subsection{Discussion}

The aim of this study was to determine if the robotic setup with intuitive user interfaces is able to provide more efficient control of the tip of a flexible endoscope. The experiment shows that intuitive interfaces can reduce the time needed to position the endoscope tip compared to the conventional angulation wheels. Between the intuitive 


\subsection{DISCUSSION}

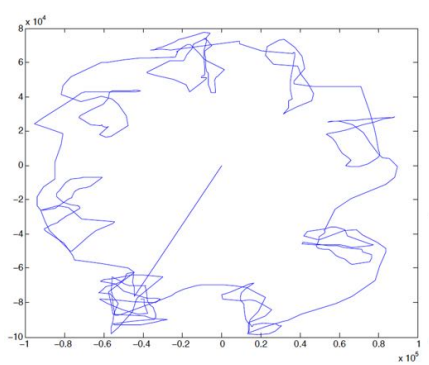

(a) Position control

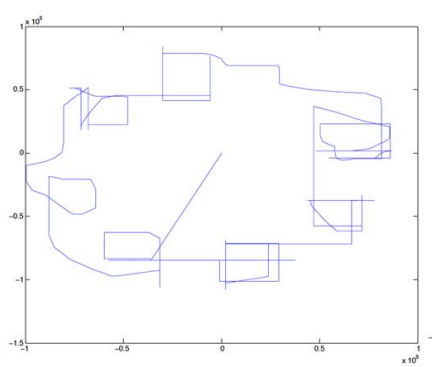

(b) Rate control

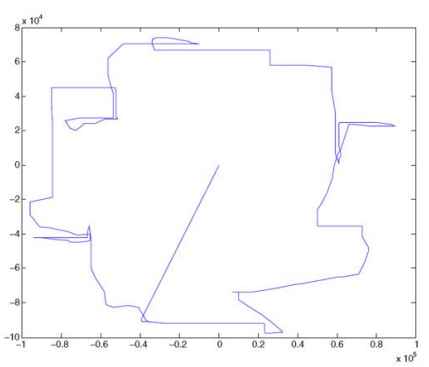

(c) Non-linear rate control

Figure 3.5: Input coordinates for the motors driving the angulation wheels. This is the example of one participant in test 1. Illustrated is the tip trajectory from center to targets $1-8$ and back to 1 .

interfaces, the joystick with non-linear rate control showed a reduced tip positioning time, the shortest tip trajectory and scored highest in users' preference.

The used simulated environment is a strong simplification of clinical practice, where physicians use additional endoscopic maneuvers (e.g., shaft rotation) and the bowel wall response to suction and inflation. We will address these factors as a whole when endoscope manipulation will be evaluated in following experiments. The simple tubular structure currently used enabled objective and cross-subject evaluation of the focus of this study: tip steering only.

Flexible endoscopy requires both quick tip steering (task 1) and precise targeting (task 2). This experiment confirms that a touchpad combined with position control is quicker compared to a joystick combined with (linear) rate control, when performing a small targeting task (task 2).

The fast result for the touchpad in the large navigation task (task 1) was unexpected, since clutching induces additional thumb movements and, therefore, potentially causes increased path length and time [63]. Tip trajectory analysis showed a significant increase in path length, but no increase in time. The paths in this experiment could have been too short to induce clutching-induced time increase.

Apart from clutching, the tip trajectory is also affected by the responsiveness of the endoscope tip. Previous studies have shown that cable-driven flexible endoscopes generate significant hysteresis, which reduces control accuracy [31]. We noticed that participants suffered from over- and understeering when using the intuitive interfaces because they experienced difficulty in estimating the tips response. These unneces- 
sary tip motions could be harmful for the patient, particularly when instruments are protruding from the endoscope tip. When using the conventional control method, direct haptic feedback of the tension on the angulation wheels informs the user of the tip response. Haptic feedback is not yet available on the remote controllers. Instead, users are provided with the feedback circle to inform them about the tip's angulation. Since the participants considered visual feedback a poor substitute for haptic feedback, we will study alternative feedback methods.

We were able to show increased efficiency of endoscope tip positioning when using intuitive user interfaces. Also, we introduced a non-linear rate control algorithm that improved both time and tip trajectory. Based on these results, we will proceed to investigate alternative user feedback options, and continue our evaluations on in vitro anatomical models, and later in vivo experiments performed by experienced endoscopists. 



\section{Chapter 4}

\section{Single-handed controller reduces \\ the workload of flexible endoscopy}

Published as:

ED Rozeboom, JG Ruiter, M Franken, MP Schwartz, S Stramigioli and IAMJ Broeders

Single-handed controller reduces the workload of flexible endoscopy

Journal of Robotic Surgery, 2014;8:319-324

With permission of Springer 


\section{Abstract}

Background The control of the conventional flexible endoscope is nonergonomic and non-intuitive. A novel single-handed interface could reduce the experienced workload, without reducing current efficiency or effectiveness of endoscope manipulation. The aim of this study is to evaluate the workload, efficiency and effectiveness of a single-handed controller in colonoscopy, in comparison to a bimanual controller and the conventional angulation wheels.

Methods Twenty-one inexperienced students performed colonoscopies on a computer simulator using either the single-handed controller with a joystick interface, a bimanual controller with a joystick interface or the conventional angulation wheels. Participants performed three sessions of colonoscopies. After each session, the experienced workload was evaluated using a seven-component absolute scoring scale. Efficiency of the procedure was evaluated by the cecal intubation time and total-used scope length. Effectiveness was evaluated by the percentage of bowel wall visualization.

Results The total workload of the single-handed controller was lower compared to the conventional angulation wheels for all three sessions. The total workload of the bimanual controller was lower compared to the conventional angulation wheels in the second and third session and also lower compared to the single-handed controller in the third session. There was no significant difference between the three control interfaces in time efficiency, used scope length or visualization performance.

Conclusions Single-handed and bimanual controllers with a joystick interface are a feasible approach to reduce the workload of colonoscopy without reducing efficiency or effectiveness of endoscope manipulation. 


\subsection{Introduction}

The colonoscope is advanced through the flexible and tortuous large bowel by combining right-handed shaft manipulation (translation and rotation) with left-handed tip actuation (up/down and left/right angulation) and actuation of the suction and air/water inflation valves [7]. Alternatively, bimanual control is applied on the angulation wheels, while an assistant holds the endoscope shaft. This 60 -year-old control method is not perfect.

Bimanual coordination of one instrument requires complex motor skills, especially when both hands perform different tasks, outphase and in different directions [65]. The mental and physical load on the endoscopists will grow in the coming years. Population-based screening programs increase the demand for colonoscopy, which is currently the 'gold standard' for early detection and removal of adenomatous polyps, the precursors of colorectal cancer [15-17]. This growing demand will probably increase the endoscopic workload of current gastroenterologists, because of volume and growing complexity of endoscopic surgical interventions. It is a known fact that an inverse correlation exists between a physician's workload and the quality of healthcare [66]. Also, a higher rate of physical injuries can be expected, associated with a reduced endoscopic capacity and lower return of educational investments. Robotics have the potential to reduce the experienced workload, because they enable the combination of different degrees of freedom in one intuitive and ergonomic handheld control interface [18]. Robotics have already proven to reduce the mental and physical workload of bimanual manipulation tasks in laparoscopic and endoscopic procedures [1, 19, 20, 67].

This paper describes the design of a single-handed controller with a joystick interface, which is developed to reduce the experienced workload of flexible endoscopy procedures. The workload, efficiency and effectiveness of the single-handed controller and the conventional angulation wheels are compared. A bimanual controller with joystick is included to separate the influence of single-handed vs. bimanual endoscope control from the influence of a joystick as a substitute for the angulation wheels. 


\subsection{Materials and Methods}

\subsubsection{Design considerations}

Design considerations were collected from interviewing seven experienced endoscopists and a workflow analysis of current procedures at the Meander Medical Centre (Amersfoort, The Netherlands) and the Ziekenhuisgroep Twente (Almelo and Hengelo, The Netherlands). Functional requirements include simultaneous control of the degrees of freedom of the endoscope shaft (intubation/ withdrawal and rotation), tip angulation (left/right, up/ down and combined directions) and functions like suction, air/water inflation and photo actuation.

\subsubsection{Single-handed controller}

The single-handed controller consists of an 'over the shaft' grip with a thumbactuated joystick (model 802, P3 America, San Diego, USA), Figure 4.1. This grip allows the user to manipulate the endoscopic shaft and steer the tip with one hand, Figure 4.2. The index finger actuates air inflation and lens rinsing functions, which are, similar to conventional control, combined in one button. A proportional sensor is used to differentiate between these two functions based on the amount of force exerted by the finger. The third finger actuates the suction button, allowing simultaneous inflation and suction without hand repositioning. The heights and positions of the buttons are chosen such that an ergonomic grip is provided and unintended actuation is prevented. The last two fingers release the spring actuated clamping mechanism to translate or rotate the controller over the endoscopic shaft. Three programmable buttons are included for frequently used functions, which can be operated by the thumb or index finger without releasing the controller.

\subsubsection{Bimanual controller}

The bimanual controller with joystick interface was included to separate the influence of single-handed vs. bimanual endoscope control, when using the joystick as a substitute for the conventional angulation wheels. Similar to conventional control, users combine right-handed shaft manipulation with left-handed tip actuation, Figure 4.2. The tip is actuated using the remote controller with thumb joystick (same as 


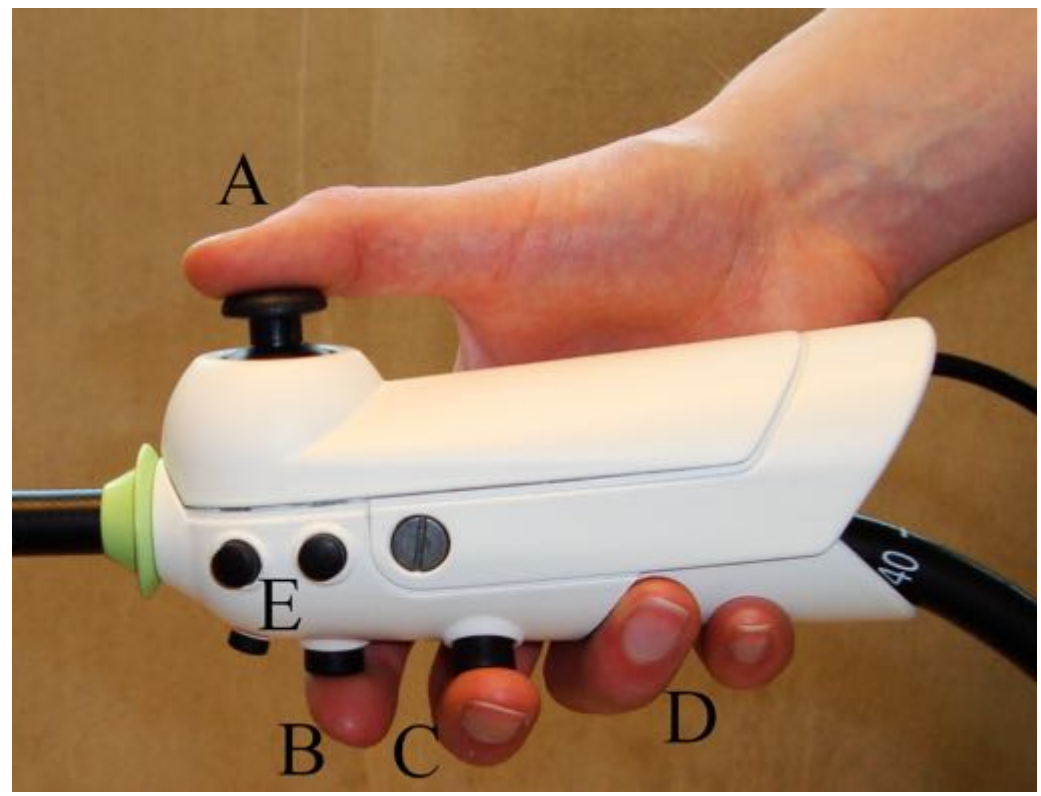

Figure 4.1: The single-handed controller, with: (A) a thumb joystick, (B) air \& water injection button, (C) suction button, (D) spring-actuated release handle and (E) three programmable buttons, e.g. for taking pictures.

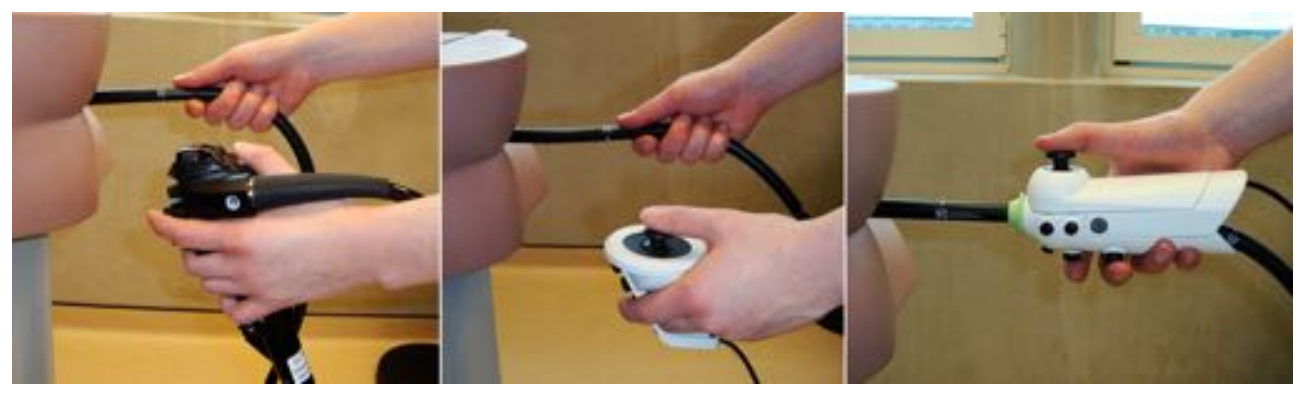

Figure 4.2: Test configurations. Each group of participants used either the conventional (left), bimanual joystick (center) or single-handed joystick (right). 
single-handed controller) from Ruiter et al. [1]. Air inflation, lens rinsing and suction functions are actuated by the index and third finger, similar to the single-handed controller and conventional setup. Conventional control Conventional control was tested using a replica of a standard colonoscope (AccuTouch, CAE Healthcare, Montreal, QC, Canada; previously Immersion Medical, Gaithersburg, MD, USA). Users applied the single-person endoscope steering principle, described in the introduction and Figure 1.3.

\subsubsection{Setup}

All colonoscopies were carried out on the AccuTouch virtual reality endoscopy simulator (CAE Healthcare, Montreal, QC, Canada). The system consists of real-time computer graphics, an interface device with force-feedback on the endoscope shaft and audible response indicating patient discomfort. We used case 1 of the Introduction to Colonoscopy module. Case 1 allows N-loop formation in the sigmoid, though this is not necessarily the case. When using the bimanual or single-handed controllers, control information (tip angulation, suction and air/water inflation) was sent to the simulator through a computer connection. In practice, the computer sends control information to a motor unit, which in turn actuates the endoscopic functions [1]. In this study, the motor unit was omitted to allow a direct connection between computer and simulator, since the simulator requires electronic signals, instead of actual air and water suction/inflation. The control body of the conventional endoscope was placed in a mobile holding standard which allowed translation and shaft rotation, Figure 4.3. A feedback diagram informed the users of the tip's angulation position and the steering direction necessary to straighten the tip [1].

\subsubsection{Participants and procedure}

Twenty-one students of Technical Medicine were included. ${ }^{1}$ These participants had sufficient knowledge to understand the medical risks and consequences of a colonoscopy exam, though without previous experience in endoscopy. The participants, 8 men and 13 women, age $22 \pm 1$ years, were randomly divided into three groups. Each group performed colonoscopies on a computer simulator using one of

\footnotetext{
${ }^{1}$ Technical Medicine is a Master's programme at the University of Twente (The Netherlands) where students integrate advanced technologies with medical sciences to improve patient care.
} 


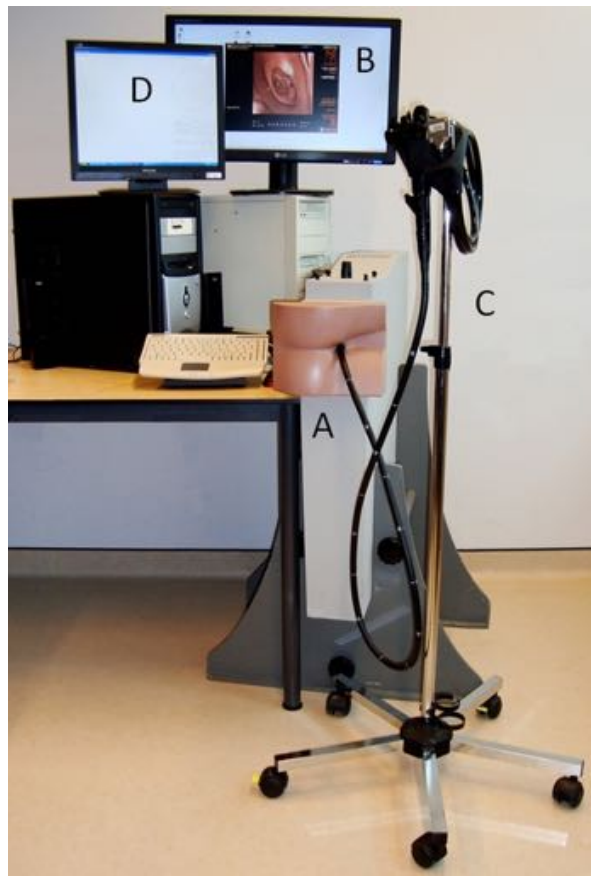

Figure 4.3: Experiment setup, with (A) the virtual endoscopy computer simulator, (B) endoscopic image, (C) holding standard (when using bimanual and single-handed joystick interfaces) and (D) a screen with feedback diagram.

the three control interfaces: the conventional angulation wheels, the bimanual controller with joystick interface or the single-handed controller with joystick interface 4.2. Participants performed three colonoscopies over a period of 3 weeks. They were asked to introduce the endoscope into the cecum as fast as possible, without causing excessive patient pain, and visualise as much of the bowel wall as possible during withdrawal of the endoscope. Six minutes withdrawal time was advised, to conform current colonic polyp screening guidelines [68]. Before each testing session, participants were allowed to practice for 30 min during which they were informed on loop detection and straightening techniques. They were allowed to use the 'external view' option to verify the scope's position and shape in the simulated bowel. This information was not available during the testing sessions.

\subsubsection{Evaluation parameters}

Participants scored their experienced workload after each testing session, using an absolute scoring scale. They were asked to score seven statements on a scale of 1 to 5, with 1 representing a low workload and 5 representing a high workload. The statements are based on the six categories of the NASA Task Load Index, which 


\subsection{RESULTS}

includes the experienced mental, physical and temporal demand, performance, effort and frustration levels [69]. A seventh category is added to evaluate the anticipated endurance level. The participant scores if $\mathrm{s} / \mathrm{he}$ expects to be able to perform the procedure during a whole working day. A sum of the workload scores represents the total experienced workload. The lowest possible total workload is 7 ; the highest possible workload is 35 . The participant's progress in efficiency was evaluated by two parameters; the time to reach complete intubation (cecal intubation time, s) and the total used scope length $(\mathrm{cm})$. Effectiveness of the procedure was evaluated by the percentage of visualised bowel wall, computed by the computer simulator.

\subsubsection{Statistical analysis}

Data was analysed using IBM SPSS Statistics v.21 (2012). Curtosis and skewness z-scores were used to determine if the distributions are normal. Non-parametric, between group, differences were assessed using a Kruskal-Wallis test with MannWhitney as post hoc test. Pearson's correlation coefficient or Kendall's tau were used to evaluate correlation between parameters. A simple linear regression was used to evaluate learning curves between control interfaces. Values are expressed as the median with interquartile range (IQR). $\mathrm{p}$ values under 0.05 were considered significant.

\subsection{Results}

None of the participants caused a perforation. One student was excluded from the experiment because she was not able to reach the cecum with the single-handed controller. Evaluation revealed that this student did not encounter loop formation during the training session, and was unable to straighten the scope when looping occurred during the test.

The total workload of the single-handed control interface was scored significantly lower compared to the conventional angulation wheels for all three sessions ( $\mathrm{p}=0.004,0.019$ and 0.025), Table 4.1 and Figure 4.4. The workload of the bimanual control interface reduced over the three sessions, with Pearson's correlation $r=-0.18$. The workload of the bimanual control interface was not significantly different from the other interfaces in the first session. The bimanual controller scored lower workload compared to the conventional control interface in the second session 
$(p=0.001)$. In the third session, the bimanual controller scored lower compared to both the conventional $(\mathrm{p}=0.002)$ and single-handed interfaces $(\mathrm{p}=0.023)$.

All groups showed significant reduction in both intubation time and used scope length, over the three testing sessions. Overall, the intubation time reduced from $310( \pm 190) \mathrm{s}$ in the first session to $150( \pm 90) \mathrm{s}$ in the last session, for all control interfaces. There was no correlation between the individual total workload scores and the intubation time.

The total used scope length reduced from $370( \pm 120) \mathrm{cm}$ in the first session to $276( \pm 30) \mathrm{cm}$ in the last session. There were no significant differences between the three control interfaces in time efficiency or used scope length. The visualisation performance of all participants was with an average of $97( \pm 1) \%$ not significantly different between the sessions and between the control interfaces.

Table 4.1: Group performance per session and per control interface, expressed as median (IQR) of the total workload, efficiency and effectiveness scores.

\begin{tabular}{|c|c|c|c|}
\hline Control interface & Session 1 & Session 2 & Session 3 \\
\hline \multicolumn{4}{|l|}{ Total workload } \\
\hline Conventional & $22(17-23)$ & $19(17-22)$ & $18(16-21)$ \\
\hline Bimanual & $17(16-21)$ & $12(11-14) \star$ & $9(8-11)^{\star}, \bullet$ \\
\hline Single-handed & $14(12-15)^{\star}$ & $15(13-17)^{\star}$ & $15(11-16)^{\star}$ \\
\hline \multicolumn{4}{|l|}{ Intubation time (s) } \\
\hline Conventional & $271(256-369)$ & $180(157-189)$ & $136(122-214)$ \\
\hline Bimanual & $289(196-307)$ & $198(140-316)$ & $155(99-188)$ \\
\hline Single-handed & $324(215-442)$ & $169(132-313)$ & $114(79-139)$ \\
\hline \multicolumn{4}{|c|}{ Used endoscope length $(\mathrm{cm})$} \\
\hline Conventional & $399(284-496)$ & $299(261-367)$ & $276(265-330)$ \\
\hline Bimanual & $418(310-525)$ & $295(260-371)$ & $280(268-307)$ \\
\hline Single-handed & $343(290-502)$ & $276(251-363)$ & $265(246-296)$ \\
\hline \multicolumn{4}{|c|}{ Visualisation performance (\%) } \\
\hline Conventional & $97(96-98)$ & $97(97-97)$ & $97(97-98)$ \\
\hline Bimanual & $97(97-97)$ & $97(96-98)$ & $97(96-97)$ \\
\hline Single-handed & $97(91-97)$ & $97(97-97)$ & $97(97-98)$ \\
\hline
\end{tabular}

$\star$ Significant difference with conventional angulation wheels

- Significant difference with single-handed control interface 


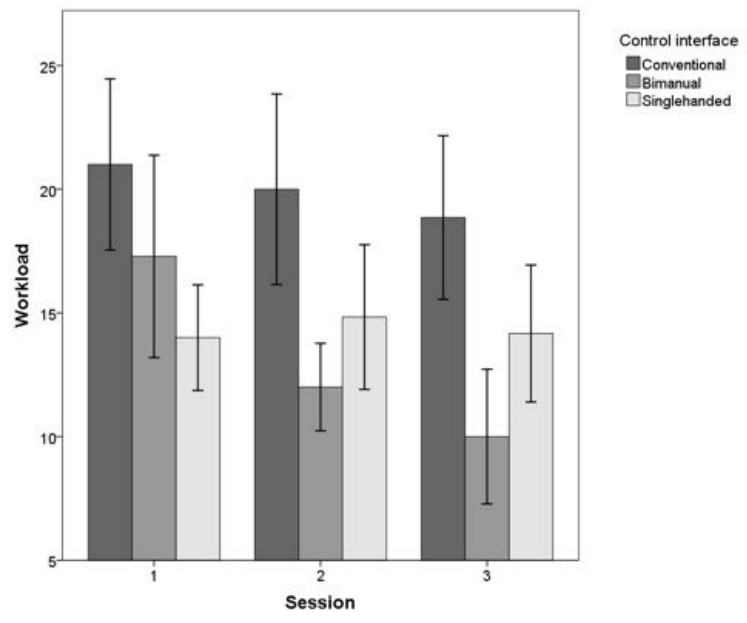

Figure 4.4: Total workload scores per control interface per session with 95\% confidence interval.

\subsection{Discussion}

We introduced a controller that enables single-handed control of both the endoscopic shaft and tip angulation. We showed that this controller with joystick interface is a feasible alternative for the conventional angulation wheels in simulated colonoscopy. The controller reduces the workload of endoscope manipulation while maintaining current efficiency and effectiveness of the procedure.

Using the workload components of the NASA TLX, albeit in a simple scoring scale, allowed us to add the anticipated endurance level and provided a quick and simple impression on the experienced workload for each group. Objective efficiency and effectiveness parameters were added to complete the evaluation of feasibility.

A previous study by Kuperij et al. citeKuperij2011a showed that replacing the angulation wheels by an ergonomic single-handed 'over the shaft' steering principle increases intuitiveness in shaft manipulation in simulated colonoscopy. However, the design suffered from sensor drift and high pressure on the pivoting point, making it unsuitable for clinical practice. Nevertheless, the study introduced two important design requirements: adequate clamping without damaging the scope and easy release of the shaft in order to allow quick repositioning of the controller.

Preliminary studies by Ruiter et al. [1] and Rozeboom et al. [67] showed that bimanual joystick interfaces allow endoscopic tip positioning with reduced workload 
and reduced tip trajectory. A single-handed controller is expected to further reduce the experienced workload, since it creates the illusion that the endoscope is an elongation of the right arm. This configuration could enable easier 'torque steering', a combination of tip angulation, rotation and insertion, which is used to corkscrew the endoscope through the flexible sigmoid [7]. Single-handed actuation of this 'corkscrew' motion was considered less complex, compared to bimanual manipulation [65].

However, this study did not show a persistent reduction in workload scoring for all sessions or in intubation efficiency compared to the bimanual controller with joystick interface. On the contrary, the bimanual workload was lower compared to the single-handed workload in the third session. During the experiments, we noticed that participants in the single-handed group steered the endoscope tip and shaft consecutively, not simultaneously. We assume that they consider the endoscope shaft and endoscope tip as separate systems, making bimanual control a more logical option than single-handed control.

The current repositioning method of the single-handed controller over the shaft might cause the experienced separation of endoscopic shaft and tip steering. Some participants required hand repositioning or left hand assistance to release the clamping mechanism, interrupting the scope manipulation process. An easier and lighter repositioning mechanism should allow continuous single-handed endoscope manipulation and the evaluation of the potential of single-handed endoscope manipulation. This may further reduce the experienced workload of endoscope manipulation.

The single-handed controller introduces a second benefit in endoscopic procedures; it frees the left hand to manipulate instruments like biopsy graspers or snares. Currently, the physician's right hand switches between endoscopic shaft and instrument manipulation, lacking constant control of all degrees of freedom. Using a single-handed controller in the intervention phase relieves the left hand to manipulate the instrument, enabling constant control of all degrees of freedom. A combination of single-handed and bimanual control configurations seems favourable. Wherein, bimanual control benefits manipulation to position the endoscope throughout the bowel and single-handed control could benefit the intervention phase. 


\subsection{Conclusion}

In conclusion, single-handed and bimanual controllers with a joystick interface are a feasible approach to reduce the workload of colonoscopy without reducing efficiency or effectiveness of endoscope manipulation. A combination of bimanual and singlehanded configurations in one controller seems favourable in future.

Our next step is to design a control interface that enables the advantages of both single-handed and bimanual configurations. We will continue our work on optimising the design features, followed by expert evaluations in a clinical setting. 


\section{Chapter 5}

\section{Feasibility of joystick guided colonoscopy}

Published as:

ED Rozeboom, IAMJ Broeders and P Fockens

Feasibility of joystick guided colonoscopy;

assessing the learning curves of experts and novices.

J. Robotic Surgery, 2015;9:173-178 


\section{Abstract}

\section{Background}

The flexible endoscope is increasingly used to perform minimal invasive interventions. A novel add-on platform allows single-person control of both endoscope and instrument at the site of intervention. The setup changes the current routine of handling the endoscope. This study aims to determine if the platform allows effective and efficient manipulation to position the endoscope at potential intervention sites throughout the bowel.

\section{Methods}

Five experts in flexible endoscopy first performed three colonoscopies on a computer simulator using the conventional angulation wheels. Next they trained with the joystick interface to achieve their personal level of intubation time with low pain score. Fourteen PhD students (novices) without hands-on experience performed the same colonoscopy case using either the conventional angulation wheels or joystick interface. Both novice groups trained to gain the average expert level. The cecal intubation time, pain score and visualization performance (\% of bowel wall) were recorded.

\section{Results}

All experts reached their personal intubation time in $6 \pm 6$ sessions. Three experts completed their learning curve with low pain score in $8 \pm 6$ sessions. The novices required $11 \pm 6$ sessions using conventional angulation wheels, and $12 \pm 6$ sessions using the joystick interface. There was no difference in the visualization performance between the novice and between the expert groups.

\section{Conclusions}

This study shows that the add-on platform enables endoscope manipulation required to perform colonoscopy. Experts need only a relatively short training period. Novices are as effective and as efficient in endoscope manipulation when comparing the addon platform with conventional endoscope control. 


\subsection{Introduction}

Previous chapters showed that the add-on platform with joystick interface increases efficiency of endoscope tip positioning compared to the conventional angulation wheels $[1,67]$. Additionally, single-person control of an endoscope and its instrument increases efficiency and satisfaction in a pick-and-place task [34].

The next step is to verify if endoscopists can reach the intervention site without the interruption of docking the add-on platform. Ideally, the endoscopist introduces the endoscope to the site of interest with the endoscope already docked to the add-on platform. At the intervention site, the endoscopist clicks the shaft in a holding system [30], Figure 5.1. This releases the right hand to position and actuate an instrument. The left hand continuously controls the endoscopic tip position with a remote intuitive interface such as a joystick. Small shaft position corrections can be applied using the same remote interface. This study aims to verify if endoscopists can reach the intervention site using the add-on platform. Endoscopists should be able to position the endoscope to potential intervention sites throughout the gastrointestinal tract.

The add-on platform changes the current routine of endoscope manipulation. In the conventional setup, torquing of the rotation stiff endoscopic shaft is the result of a combined effort by the left shoulder, wrist and right hand. Using the platform, the user holds the remote interface in his left hand. Scope rotation now depends entirely on the right hand. Shaft manipulation is critical for adequate endoscopy, with colon loop management being the most difficult challenge [70].

The aim of this study is to verify if our add-on platform with joystick interface enables adequate endoscope manipulation to position the endoscope throughout the bowel. To evaluate the potential of this module, a learning curve is recorded for both experts and novices.

\subsection{Methods}

\subsubsection{Participants}

Two groups of participants were involved; experts in gastrointestinal endoscopy and novices. The expert group consisted of five practicing endoscopists who had completed between 500 and $>5000$ colonoscopies in their careers. There were two male 


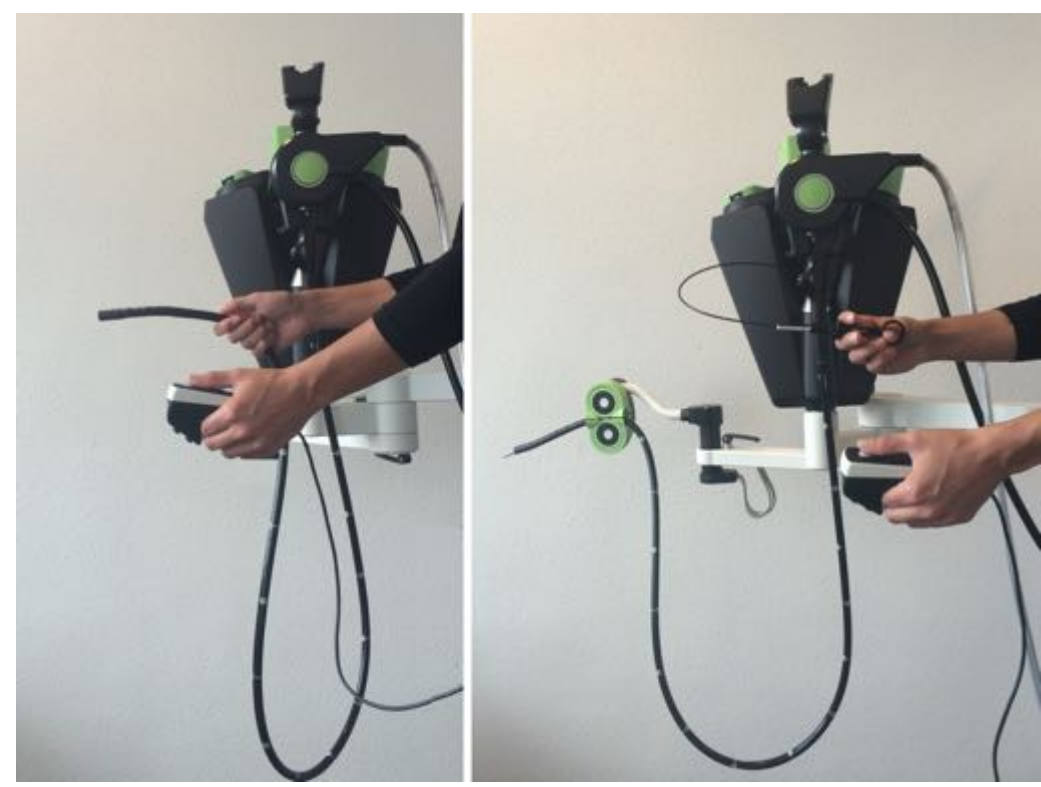

Figure 5.1: Add-on platform with joystick interface. The endoscopist manoeuvres the endoscope to the intervention site with the endoscope already docked to the add-on platform (left). After reaching the intervention site, the shaft is held in position by the easy click-on system, freeing the right hand to manipulate an instrument (right).

and three female experts with a median age of $46 \pm 7$ years. All experts were righthanded.

The novice group consisted of fourteen $\mathrm{PhD}$ students from the department of Gastroenterology and Hepatology of the Academic Medical Center, Amsterdam, who were in their second to fourth year. The novices had no prior experience in steering a flexible endoscope. They were divided in two groups, conventional or add-on platform with joystick interface (hereupon referred to as 'joystick' group). Each group consisted of three men and four women, with a median age of $28 \pm 2$ years. There were two left handed participants in the conventional group.

None of the experts or novices had previous experience with endoscope manipulations using the platform with joystick interface.

\subsubsection{Simulator}

All sessions were carried out on case 6 of the Introduction to Colonoscopy module of the AccuTouch virtual reality endoscopy simulator (CAE Healthcare, Montreal, Que- 
bec, Canada; previously Immersion Medical, Gaithersburg, MD, USA), Figure 5.2. The system consists of real-time computer graphics, an interface device with forcefeedback on the endoscope shaft and audible response indicating patient discomfort. Case 6 is the most difficult case in this version of the simulator, with maximal loop formation and pain scores. This case requires a high level of adequate tip steering and shaft manipulation to complete cecal intubation with low pain score.

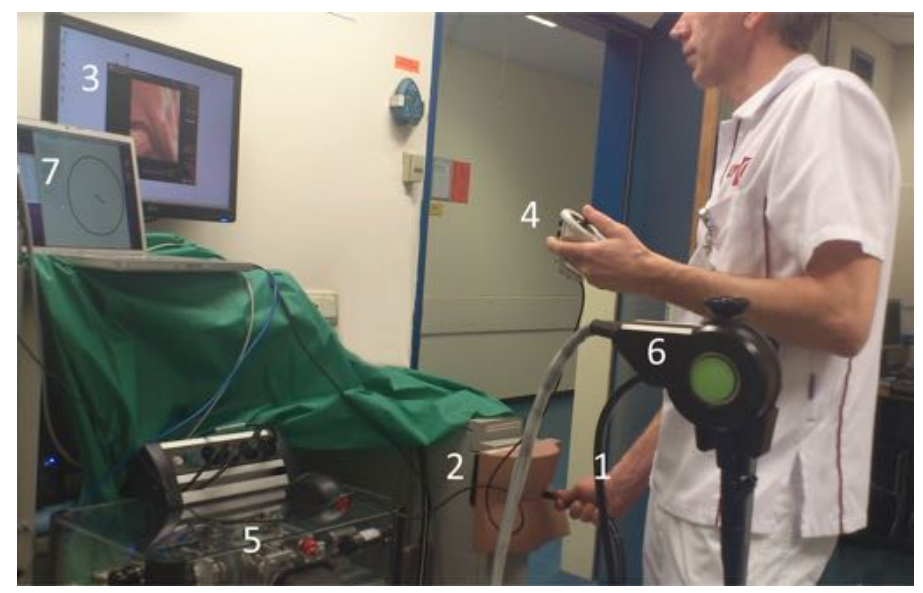

Figure 5.2: The test setup includes (1) a dedicated colonoscope, (2) simulator interface and (3) real-time computer graphics. The add-on platform consists of (4) a remote joystick, (5) stationary motor unit, (6) remote drive unit connected to the endoscope console and positioned in the docking station, and (7) an endoscope tip bending diagram.

\subsubsection{Procedure}

All experts first performed the colonoscopy case three times using the traditional angulation wheels. Next, they practiced the same case using the platform with joystick interface until they reached a personal endpoint in their learning curve. The endpoint for the experts consisted of the average + one standard deviation of their conventional cecal intubation time (IT) and no severe or extreme pain (NP). The novices were divided in two groups: one group used the conventional angulation wheels, the other group used the setup with joystick interface. The end-IT for both novice groups was the average plus one standard deviation of the intubation time of the experts using the conventional angulation wheels. Novices also practiced to reach their end-IT with NP.

The NP endpoint was selected to enforce realistic endoscopic techniques like loop 
detection and straightening techniques. Without the NP endpoint, users are able to forcefully insert the scope into the simulator, leading to unrealistic outcomes.

Before the first session, all participants received written trial-instructions including which parameters were recorded and the simulators cues to detect looping, successful straightening, the level of patient pain and how to recover lumen vision from a red out. They were also allowed to train five minutes on the first (easiest) colonoscopy case to gain familiarity with the simulator. During the sessions, participants were not allowed to use the simulator's options for a virtual attending physician and external view of the endoscope. The sessions lasted 1-2 hours on each occasion. Sessions included 5-10 minutes resting breaks, they could be repeated several times per week and continued over 2-7 weeks.

\subsubsection{Evaluation parameters}

Evaluation parameters measured by the computer simulator were the IT, pain score (\% of procedure time), bowel wall visualisation (\% of bowel wall) and withdrawal time. To enable comparison of visualisation performance, participants were instructed to include a 6 minutes withdrawal time. This is the recommended clinical practice [68]. Afterwards, users were requested to select their preferred steering method.

\subsubsection{Statistical analysis}

Statistical analysis was performed using IBM SPSS Statistics version 21. Differences between novices using conventional or joystick platform were analysed using the Mann-Whitney test. Differences between experts using conventional or joystick platform were analysed using Wilcoxon's Matched Pairs test. For all tests, P values under 0.05 were considered statistically significant. Values are expressed as the mean ( \pm standard deviation).

\subsection{Results}

Experts performed cecal intubation using the conventional angulation wheels in an average of $352 \pm 86$ seconds, Table 5.1 and Figure 5.3. During these fifteen conventional sessions, two experts performed colonoscopy without severe or extreme pain, 
once. All experts reached their personal intubation time in $6 \pm 6$ sessions, using the setup with joystick interface. Three experts reached their personal intubation time with no pain score in $8 \pm 6$ sessions.

One expert caused a simulated perforation during his second joystick session and claimed over-confidence in scope insertion.

Withdrawal time and visualization performance were not significantly different between experts using the conventional or joystick platform, with $\mathrm{p}=0.92$ and 0.68 . There was no significant difference between the number of sessions needed to reach IT or IT+NP for novices using the conventional or joystick platform, with $\mathrm{p}=0.32$ and 0.81 . Withdrawal time and visualization performance were also not significantly different between novices using the conventional and novices using the joystick platform, with $\mathrm{p}=0.17$ and 0.43 .

Three experts, five conventional novices and four joystick novices preferred the joystick steering method to guide the endoscope tip. The others preferred the conventional angulation wheels Table 5.1.

Table 5.1: Efficiency, visualization and preference outcomes.

\begin{tabular}{|c|c|c|c|}
\hline & Expert $(\mathrm{N}=5)$ & $\begin{array}{l}\text { Novice conven- } \\
\text { tional }(\mathrm{N}=7)\end{array}$ & $\begin{array}{l}\text { Novice joystick } \\
(\mathrm{N}=7)\end{array}$ \\
\hline Sessions to achieve end-IT and NP & $8( \pm 6)(\mathrm{N}=3)$ & $11( \pm 6)$ & $12( \pm 6)$ \\
\hline Sessions to achieve end-IT & $6( \pm 6)$ & $5( \pm 2)$ & $4( \pm 1)$ \\
\hline Visualization performance (\%) & $\begin{array}{l}97( \pm 1) \\
\text { Convent. } 94( \pm 5)\end{array}$ & $97( \pm 2)$ & $97( \pm 2)$ \\
\hline Preference conventional & 2 & 2 & 3 \\
\hline Preference joystick & 4 & 5 & 4 \\
\hline
\end{tabular}

\subsection{Discussion}

The aim of this study was to determine if endoscopists can reach the intervention site using an add-on robotic platform. The study shows that both experts in endoscopy and novices are able to complete the most difficult colonoscopy case of a training simulator. Experts are able to learn to work with the platform in a relatively short training period. Furthermore, novices performed colonoscopy tasks equally well compared to using the conventional angulation wheels.

Reaching the intervention site in the torturous and flexible large bowel requires a complex combination of endoscope manipulation techniques. Despite intuitive and 


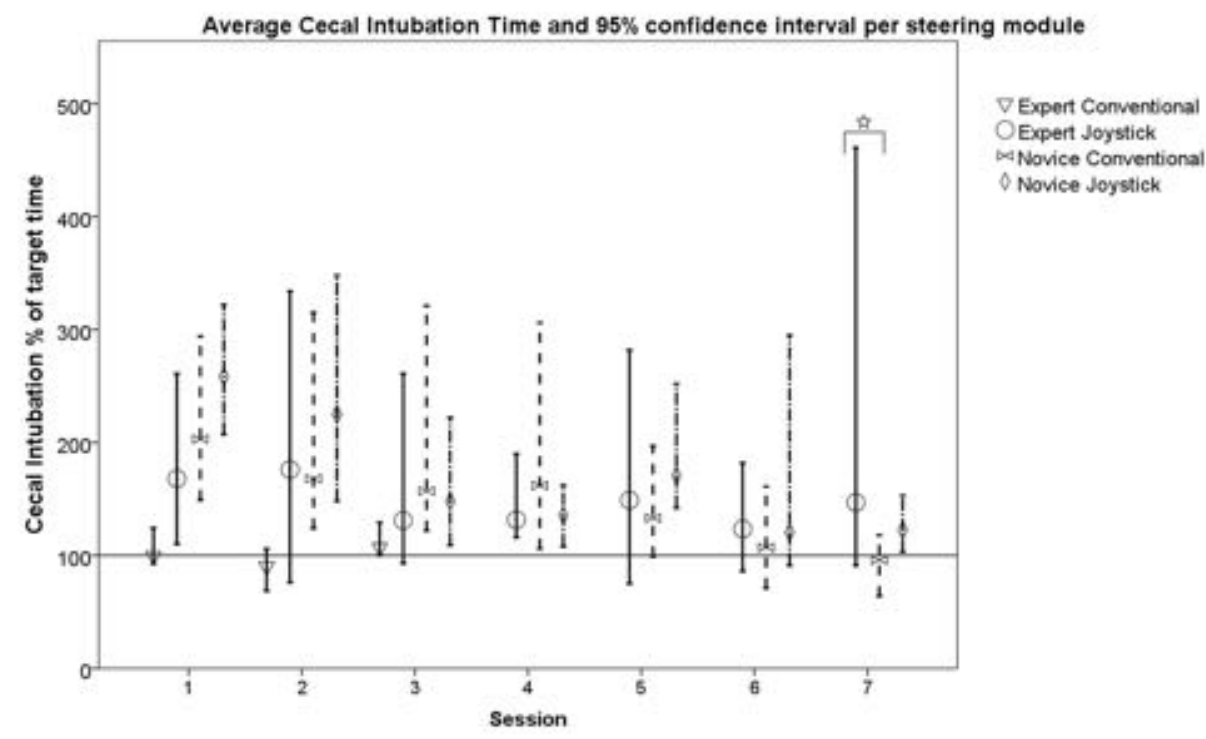

Figure 5.3: Learning curves of the cecal intubation time for all steering modules in the first seven sessions. The table includes the median ( $95 \%$ confidence interval) intubation time per session, for each steering module. The star indicates a significant difference between user groups.

ergonomic shortcomings of the conventional endoscope, experts are competent in scope manipulation without causing excessive patient pain [13, 42]. Previous studies showed that remote actuation platforms could not yet compete with the efficiency of conventional endoscope control $[38,62,71]$. The setup of these platforms prevented adequate scope manipulation $[62,72,73]$. This study shows that our setup and interface enable at least as efficient manipulation of the endoscope and effective visualization of the bowel wall.

Not all experts were able to finish their learning curve with no severe or extreme pain scores. Also few conventional sessions were without severe or extreme pain scores. In hindsight, the NP endpoint may have been too strict, making it too difficult to reach the learning curves endpoint. There are alternatives, such as requiring that more than $97 \%$ of the procedure time is free of patient discomfort, used by Ahlberg et al. [74]. However, this was considered too easy for this task and would fail to enforce realistic loop detection and straightening techniques. A combination of no extreme pain and a 97-98\% of discomfort free procedure time could be a solution for next studies. 
We asked the novices to practice until reaching the experts average intubation time plus one standard deviation. This can be considered a high training standard. Nevertheless, the average expert intubation time was with 438 seconds close to the 7 minutes on the same simulator case that trainees needed before starting clinical colonoscopies in the training study by Ahlberg et al. [74]. Also, since all novices reached the endpoints, they were confirmed not too challenging.

Both conventional and joystick groups showed a large spread (50\% of the average) in the number of sessions that were required to reach the endpoints. We consider this spread the reflection of differences in personal physical and cognitive skills of the inexperienced participants. Since the spread was equally divided between the conventional and joystick groups, it is not attributed to either steering method.

The platform received a low preference rate to use as a tool to navigate an endoscope through the colon. The main reason is the lack of haptic feedback from the tension on the angulation wheels. The addition of a motor drive unit intercepts this haptic signal. Instead we inform users with a visual tip bending diagram. A similar compromise was seen in robotic laparoscopic surgery, which also lacks haptic feedback of instruments. Considering the research carried on about haptic feedback, we expect that a workable solution will be available in the future.

\subsection{Conclusion}

This study indicates that the add-on platform with joystick interface has the potential to guide a flexible endoscope to intervention sites throughout the colon. We will continue to validate this potetial in a patient study.

\subsection{Acknowledgements}

The authors wish to thank doctors Barbara Bastiaansen, Jacques Bergman, Evelien Dekker, Jeanin van Hooft, Cyriel Ponsioen and Kristien Tytgat as well as the $14 \mathrm{PhD}$ students from the Department of Gastroenterology \& Hepatology of the Academic Medical Center, Amsterdam, for participating in this study. Our thanks also go out to the mechatronic company, DEMCON (Enschede, The Netherlands), with special thanks to Dr. Ir. J.G. Ruiter, for the technical support and availability of the joystick setup. 



\section{Chapter 6}

\section{Preliminary safety and efficacy in}

\section{humans}

Published as:

ED Rozeboom, BA Bastiaansen, ES De Vries, E Dekker, P Fockens, and IAMJ Broeders

Robotic flexible colonoscopy; preliminary safety and efficiency in humans

Gastrointestinal Endoscopy, 2016;6:1267-1271 


\section{Abstract}

\section{Background}

The flexible endoscope is used as a platform for minimally invasive interventions. However, control of the conventional endoscope and multiple instruments is difficult. Robotic assistance could provide a solution and better control for a single operator. A novel platform should also enable interventions in areas that are currently difficult to reach. This study evaluates the safety and efficacy of a robotic platform that guides a conventional endoscope through the large bowel.

\section{Methods}

In this feasibility study, adult patients scheduled for routine diagnostic colonoscopy were included. The endoscope was introduced using a robotic add-on to provide tip bending and air/water actuation. The endoscopist directly controlled the scope shaft. Upon cecal intubation, the add-on was detached and the procedure continued using conventional control. Primary evaluation parameters were the number of serious adverse events and the percentage of successful cecal intubations.

\section{Results}

The procedure was performed in 22 consecutive patients who all gave informed consent. There were no serious adverse events. Cecal intubation was successful in 15 patients $(68 \%)$ using the robotic add-on. Six cases were completed after conversion to conventional control: three cases were converted to pass sharp angulation in the flexures and three cases were converted after technical difficulties. One case was not successful with either technique due to severe diverticulosis.

\section{Conclusions}

The robotic add-on steering module allows safe endoscope intubation to reach intervention sites throughout the large bowel. 


\subsection{Introduction}

Previously introduced robotic designs provide single-person control of multiple steerable instruments [21, 23, 37, 71, 75]. However, none of these systems have also proven the essential versatility to arrive at intervention sites that are difficult to reach in humans. In the first chapter we introduced a robotic add-on steering module for complex interventions. Previous chapters describe that studies performed on simulators showed that the tip steering module is effective, increases efficiency and raises satisfaction in a simulated environment with both novices and expert endoscopists $[1,76]$. Albeit simulators are good methods for training and evaluating technical skills, they lack the complexity and fidelity to be useful beyond the novice level [77]. Also, the unpredictable human bowel may require additional steering options like patient repositioning and applying bowel pressure $[70,78]$. These parts of the clinical workflow are not realistically incorporated in simulators.

This is the first human patient study where colonoscopy is performed using a conventional endoscope with add-on robotic control. The aim of this study is to determine the safety and efficacy of cecal intubation using the add-on steering module in a clinical setting.

\subsection{Methods}

\subsubsection{Patients}

Consecutive patients scheduled for a diagnostic colonoscopy exam at the Academic Medical Centre, Amsterdam, were asked to participate in the study. Exclusion criteria were previous abdominal surgery, ASA class 3,4 or 5 and patients with hereditary polyposis syndromes. Patients received verbal and written information on the study 2-3 weeks and 5 days before the procedure. They signed informed consent before the start of the procedure. Approval of the medical ethical committee of the Academic Medical Center was acquired before the start of this study.

\subsubsection{Procedure}

Two endoscopists (BAB, PF), with an experience of $>1000$ and $>5000$ colonoscopies, performed a diagnostic colonoscopy according to the standard protocol. 
They used a robotic add-on steering module to control the endoscope during the intubation phase. Upon cecal intubation, the robotic add-on was disconnected while the endoscope remained in the exact same position in the patient. The procedure (withdrawal and if necessary interventions) was continued using the conventional system. Patients were consciously sedated using midazolam and fentanyl upon the discretion of the endoscopist. After the procedure, the patient was transferred to a recovery room. The heart rate and oxygenation levels were monitored during the procedure and in the recovery room. Ten days after the procedure, patients were contacted for follow-up on their experience and possible adverse events.

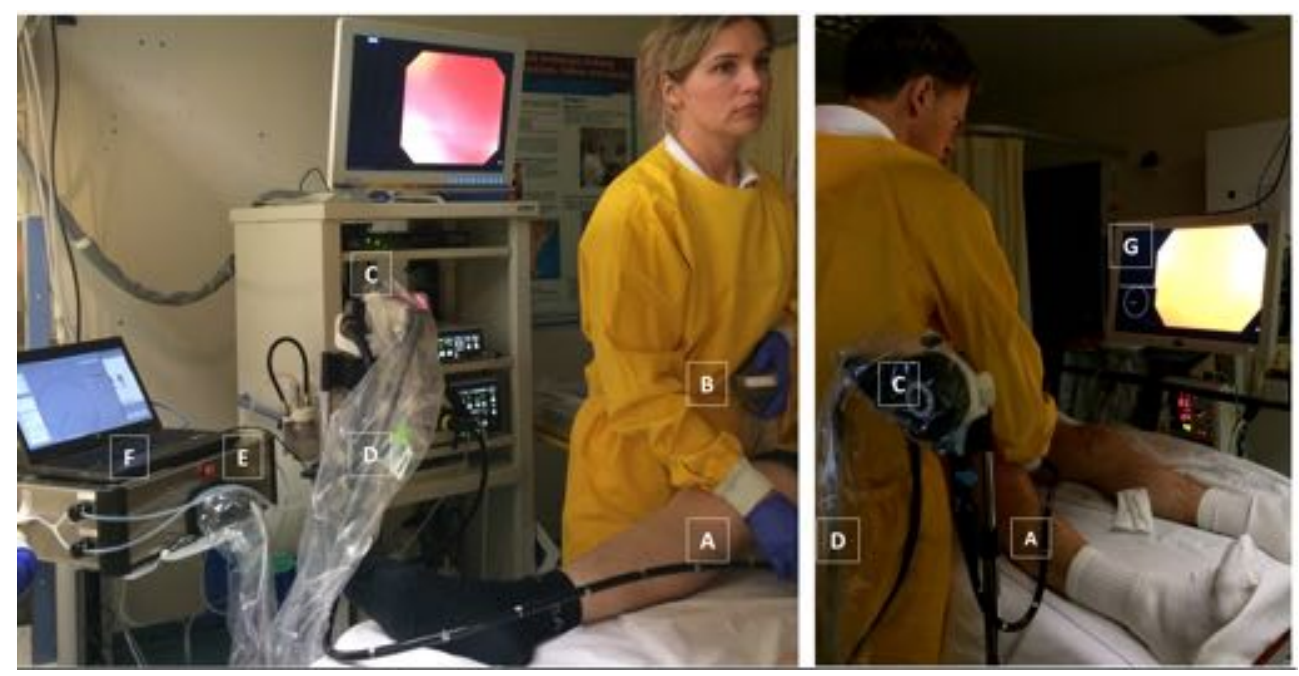

Figure 6.1: Study setup. The endoscopist controls tip bending of a conventional endoscope (A) with a remote joystick (B). The endoscope is connected to a remote drive unit (C). Cables run via flexible transmission (D) to the motor drive unit (E). The computer (F) also provides feedback about the direction and extend of tip bending on screen $(\mathrm{G})$.

\subsubsection{Materials}

The robotic add-on system actuates the navigation wheels on a conventional endoscope [1]. The system consists of a remote controller with which the user controls a motor drive unit and valves for air inflation, water injection and suction, Figure 6.1 [67]. Two motors in the drive unit manipulate bending cables that run through a flexible transmission to a mobile drive unit. The mobile drive unit is connected to the colonoscope console by means of a single plug, providing immediate conversion 
to the conventional system if needed, Figure 6.2. Plastic drapes (Microtek Medical, Inc., Zutphen, The Netherlands) covering the remote controller and remote drive unit were replaced per case. The user is provided with visual feedback on the direction and extent of tip bending. Before this study, both endoscopists received $>100 \mathrm{hrs}$ colonoscopy simulation training to achieve appropriate technical skills with the system.

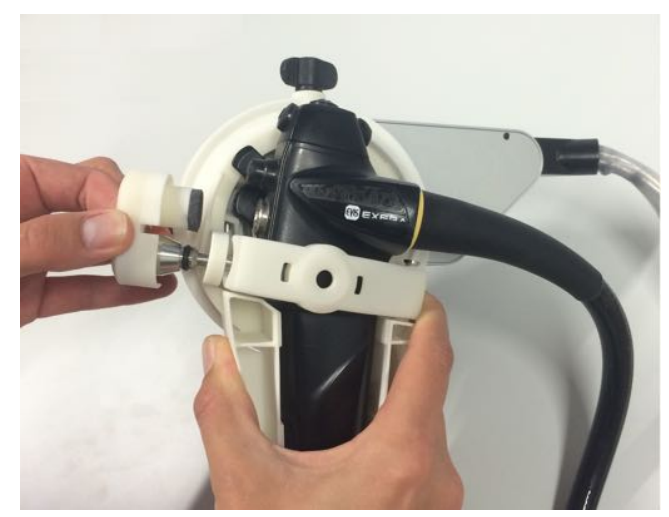

Figure 6.2: Remove the plug to disconnect robotic control and continue with conventional control.

\subsubsection{Parameters}

The main study parameters were safety and efficacy. Safety was expressed as the number of serious adverse events (SAEs) related to the procedure. Efficacy was expressed as the percentage of successful cecal intubations. Secondary study parameters were the usability of the system measured by cecal intubation time. The experts scored their confidence to use the add-on during endoscope intubation on a five-point Likert scale, with $1=$ strongly agree and $5=$ strongly disagree.

\subsubsection{Statistical analysis}

Sample size calculation was based on non-inferiority of the cecal intubation rate. The conventional success rate was assumed 95\% [68]. Considering a short learning curve in scope manipulation, a minimal amount of $80 \%$ complete cecal intubations was required. The study was based on a series of independent success/fail outcomes, with a probability $(\mathrm{P})$ of 0.20 . Following the binomial distribution, an acceptable chance of $5 \%$ that no or one patient receives incomplete scope intubation when the 
real chance is $20 \%$, would require a group size of 22 patients. Data is expressed as median with interquartile range.

\subsection{Results}

We included 22 consecutive patients. 15 were male and all adult. Patients were aged $55( \pm 20)$ years. There were no serious adverse events. Cecal intubation was successful in 15 patients (68\%) using the robotic add-on, Table 6.1. In six patients (27\%), intubation was unsuccessful using the robotic add-on but successful after conversion to the conventional control method. One intubation (5\%) was unsuccessful using robotic control as well as after conversion to conventional control due to severe diverticulosis. Of the six cecal intubations after conversion, three cases were considered to have failed with the robotic assistance due to sharp angulation of the hepatic and splenic flexure. The other three failed due to technical issues. The errors consisted of absence of air inflation or motor rotations. Patients and physicians were at no point in time during the procedure at risk. Omitting the cases with technical difficulties, the cecal intubation rate was 79\% (15/19) using robotic control.

Table 6.1: Patient data, study results and sedation dosages. Cases are ordered in groups of successful intubation and increasing intubation time.

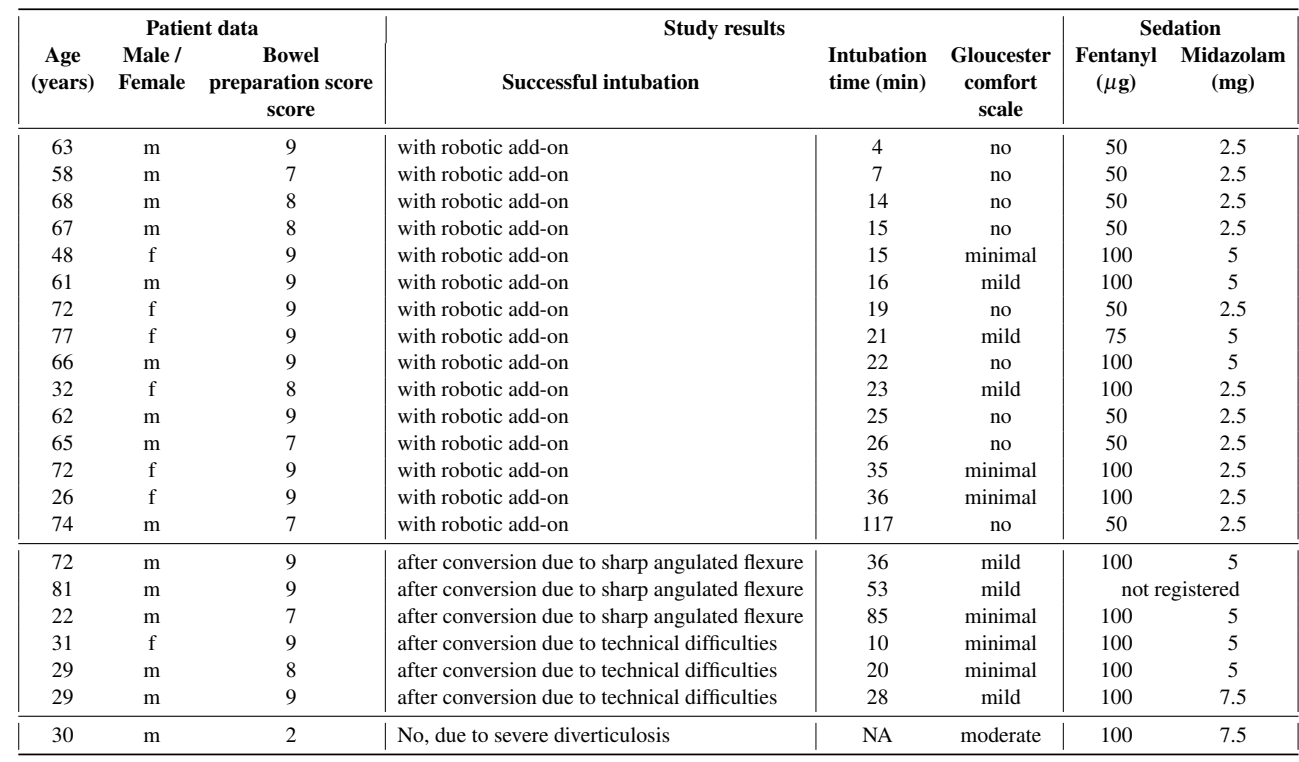


Cecal intubation time for successful procedures was median 21 minutes (16-36). Sedation dosages for successful procedures was median 50 (50-100) $\mu \mathrm{g}$ Fentanyl and 5 (5-5) mg Midazolam. Conversion to conventional control happened after a median time of 26 minutes (20-50). All conversions from robotic add-on to conventional control were carried out in a median time of 1 minute (1-3) while the endoscope remained in the exact same position in the patient. Endoscopists indicated to be confident when using the add-on steering module in 17 cases, they disagreed in 2 cases and were neutral in 3 cases. The quality of the bowel preparation was good with a median Boston bowel preparation score of 9 (8-9). The assisting endoscopy nurse scored Gloucester comfort score with a median score of 2 (1-3), representing minimal (no-mild) pain scores.

\subsection{Discussion}

We performed the first human patient colonoscopy study using a conventional endoscope with add-on robotic control. Our study showed that this setup allowed safe endoscope introduction to potential intervention sites throughout the large bowel.

Three cases that were successful after conversion to conventional control showed that this robotic design is challenged when sharp colonic angulations have to be passed. Passing sharp angulations requires a combination of maximal tip bending and shaft torqueing. As a safety measure, robotic wheel rotation was limited to prevent damage to the endoscope cables. The wheel rotation might have been too limited for the endoscopes used in this study. A future solution could be to use force sensing when rotating the wheel, since this will allow limitation of the motor force instead of the wheel angle.

Cecal intubation using the robotic add-on was with 21 minutes slow compared to conventional colonoscopy. However, the current setup was not designed for routine diagnostic endoscopy and a short learning curve might still be present. We emphasize the feasibility of the system for complex interventions that require control of multiple and/or steerable instruments such as endoscopic submucosal dissections. Albeit, the intuitive tip navigation might be appealing to many endoscopists who now deal with the non-intuitive and non-ergonomic control handle. An important challenge to overcome in the robotic setup is to allow easier shaft rotation. Shaft torqueing in the robotic method differs from conventional endoscope control. Using conventional 
control, the shaft is torqued by a combined effort of both the right and left arm. Using robotic control the left hand holds the remote control and the right hand alone rotates the thin and slippery shaft. This increases the workload on the right arm. We are currently looking into assistance modules that actively or passively rotate the drive unit to reduce the force needed to torque the shaft.

\subsection{Conclusion}

With this study, we showed that the robotic setup allows a safe and feasible first step towards endoscopic interventions throughout the bowel. The next step is to determine the safety and efficacy of instrument control. 


\section{Chapter 7}

\section{Feasibility of automated lumen centralization for colonoscopy}

Published as:

HJM Pullens, N Van der Stap, ED Rozeboom, MP Schwartz, F Van der Heijden, MGH Van Oijen, PD Siersema and IAMJ Broeders

Colonoscopy with robotic steering and automated lumen centralization: a feasibility study in a colon model

Endoscopy, 2015;48:286-290

And

C2015 Georg Thieme Verlag KG

N Van der Stap, ED Rozeboom, HJM Pullens, F Van der Heijden and IAMJ Broeders Feasibility of Automated Target Centralization in Colonoscopy

Int. J. Comp. Ass. Radiology and Surgery, 2016;11:457-165 


\section{Abstract}

\section{Background}

Flexible endoscopy is difficult to learn and time consuming. Robotic control improves the experienced workload and efficiency. Image-based automatic navigation may further improve endoscope control. The goal of this study is to investigate the clinical and technical feasibility of an assisting automated navigation algorithm for colonoscopy.

\section{Methods}

Automated lumen centralization (ALC) was implemented in a robotic add-on steering module. Eight expert endoscopists and ten novices performed a diagnostic colonoscopy on a validated colon model with simulated polyps. They used both conventional and robotic control with ALC in a randomized cross-over design. Clinical feasibility was evaluated using cecum intubation time and polyp detection rate. Technical feasibility was evaluated by recording the use of ALC during the procedure and collecting user feedback.

\section{Results}

There was no significant difference in cecum intubation time between conventional and robotic control with ALC. Experts found more polyps using conventional control with $81 \%$ vs. $69 \%$ when using robotic control with ALC. Novices turned on ALC a median $4.2 \%$ of the time during intubation and $0.3 \%$ during withdrawal. For experts this was $4.0 \%$ of the time during intubation and $11.6 \%$ during withdrawal.

\section{Conclusions}

It is clinically and technically feasible to perform colonoscopy using robotic control in combination with automated lumen centralization. The non-inferiority of this system is shown for novices, although ALC use was lower than expected. The relatively extensive use of ALC during the withdrawal phase of the procedure suggests a possibly interesting added value of the system during this phase. 


\subsection{Introduction}

A robotic system with intuitive controllers reduces the experienced workload and improves control intuitiveness. Image-based navigation may further help to improve intuitiveness of robotic systems [79]. Image guidance could be useful in finding a target direction and steering toward it automatically.

In colonoscopy, the colon is visible as a tubular, folded structure. During scope introduction, the target of the colonoscope almost always is the deepest visible area, often corresponding to the center of the lumen. This area usually presents as the darkest area in the endoscopic image, which is a useful feature for image-based navigation. Both central lumen detection and automated endoscope steering have been investigated before [80-84]. Most of the research in this area focuses on segmenting the central lumen area as accurately as possible. Although accurate central lumen detection in colonoscopic images is technologically feasible, to our knowledge, none of the mentioned systems are clinically accepted or even tested for clinical applicability. All previous techniques are based on the assumption that by centralizing the lumen, the colonoscope will travel the right path through the colon. Complicating factors herein are image artefacts, such as fluids or bubbles on the lens, which make images hard to interpret. The lens may also be pressed against the colon wall, causing a 'redout' or 'wall view'. Additionally, the camera can be moved substantially between frames, causing motion blur artefacts [80]. These complicating factors and artefacts hindered a successful implementation of this technique up to now. Moreover, centralizing the lumen is not always desired by the endoscopist. Sometimes, maneuvers using the colonic wall are performed on purpose to advance the endoscope further [70, 78].

Van der Stap et al. [85] developed and evaluated a new algorithm for colonoscope steering based on dark region centralization. This algorithm is implemented in an assisting fashion and predicts whether images will contain useful information. The prediction diminishes the influence of artefacts. This algorithm was adapted to be implemented in our add-on robotic setup for flexible endoscopy $[1,86]$. The vision-based functionality is meant to assist during endoscope introduction and can be actively turned on and off by the endoscopist.

The aim of the current study is to evaluate the robotic add-on control with assisting automated lumen centralization (ALC) algorithm in terms of clinical and techni- 
cal feasibility.

Clinical feasibility means that the system enables colonoscopy that is at least as efficient and effective as the conventional method (non-inferiority). Technical feasibility is defined as the system performance during colonoscopy and includes user feedback on system functionality.

\subsection{Methods and materials}

\subsubsection{Automatic lumen centralization - ALC}

The design and preliminary testing of the navigation algorithm was previously described in depth by Van der Stap et al.(2014) [85]. In short, the automatic control system is designed based on the following main requirements; real-time functionality, expert's option to overrule the control instantaneously at any point; easy to learn and easy to implement in clinical practice. The first two are recapitulated below, the latter two are addressed in this study.

The assisting algorithm's main task is to detect the target of the endoscope, the lumen center, through image analysis. The algorithm finds the darkest region in endoscopic images. This is usually the area furthest away from the endoscope tip, corresponding with the lumen of the bowel. It uses information from previous images to estimate the lumen location and corrects this with the current image information. A flowhart, Figure 7.1, illustrates the steps taken. The inversion of the frame results in a search for a maximum instead of a minimum pixel value (darkest region becomes lightest region). To suppress noise influence, Gaussian low-pass filtering is applied. This restricts the search area to a vicinity of the previously estimated lumen position. We iterate once to increase the bias caused by the Gaussian convolution, meaning larger shifts of the target between frames still result in accurate target estimation. Performance of the algorithm was evaluated in a previous study using human colonoscopy images [85]. 


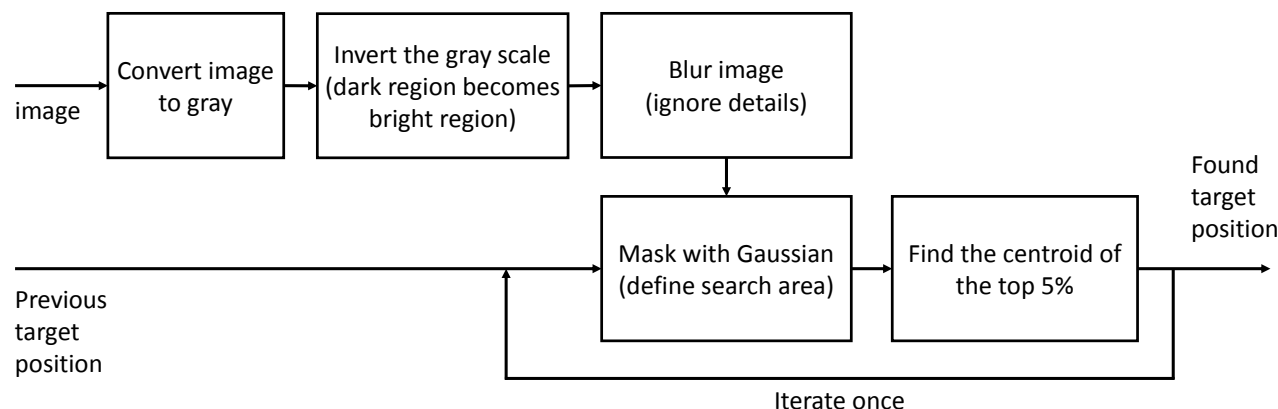

Figure 7.1: Flowchart of algorithm steps. The current image and the previous target are used as input to find the current target location.

\subsubsection{Robotic control with ALC}

The ALC algorithm detects the lumen in a bowel. When the ALC target corresponds to the actual target, the participant can actively decide to let a robotic platform steer the scope to center this point in the endoscopic image. We used the add-on robotic setup that was described in Chapter 2. The combined system of add-on robotic control with the assisting lumen centralization function is hereafter referred to as robotic control with ALC. The system consists of a joystick controller, motor module, steering wheel module and endoscopic display (Figure 7.2). With this setup, the user manually inserts the endoscopic shaft to navigate to the lumen.

The endoscopic display provides continuous feedback of the endoscopic image, the amount and direction of endoscope tip bending, and complementary the ALC target. The ALC target is visualized on the endoscopic image by means of a white circle (Figure 7.3, left pane (A)). When the user agrees that the position of the circle corresponds to the desired steering direction, he or she can decide to activate ALC. This is done by pressing and holding a designated button on the joystick controller (Figure 7.4). Releasing the button immediately stops the platform from steering the tip. This enables the criterion to instantaneously overrule the automatic control at any point in time. For both "manual joystick" and ALC control types the control loop is passed in real-time (Figure 7.5) [61]. 


\subsection{METHODS AND MATERIALS}

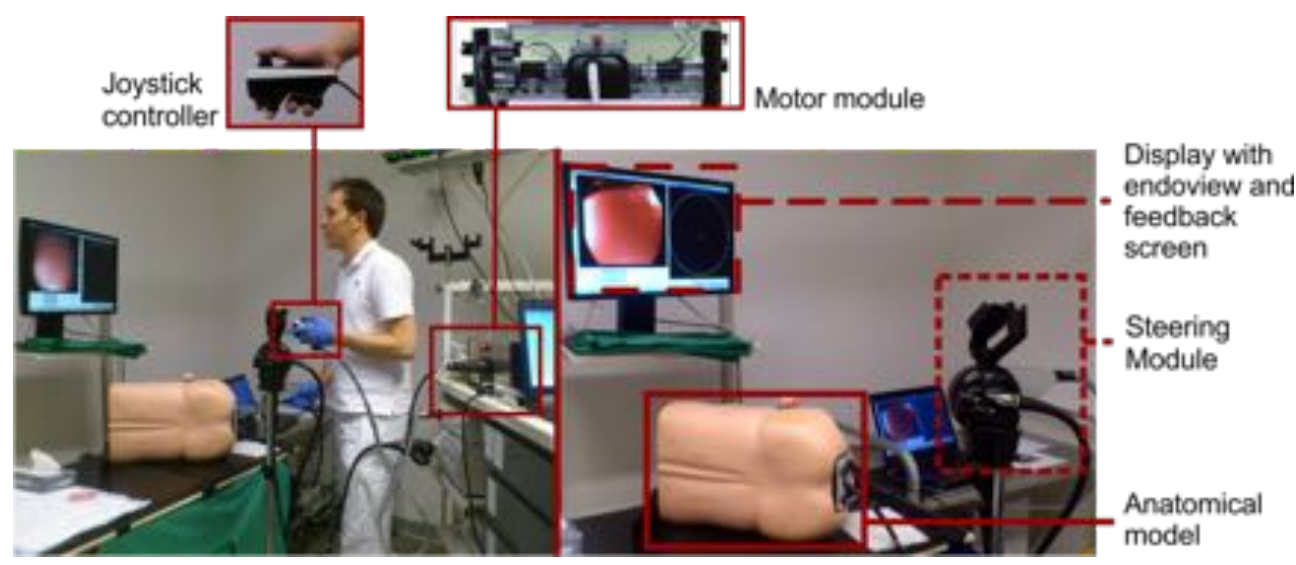

Figure 7.2: The setup for robotic control with ALC. The user looks at the display and controls the endoscope tip with the joystick.

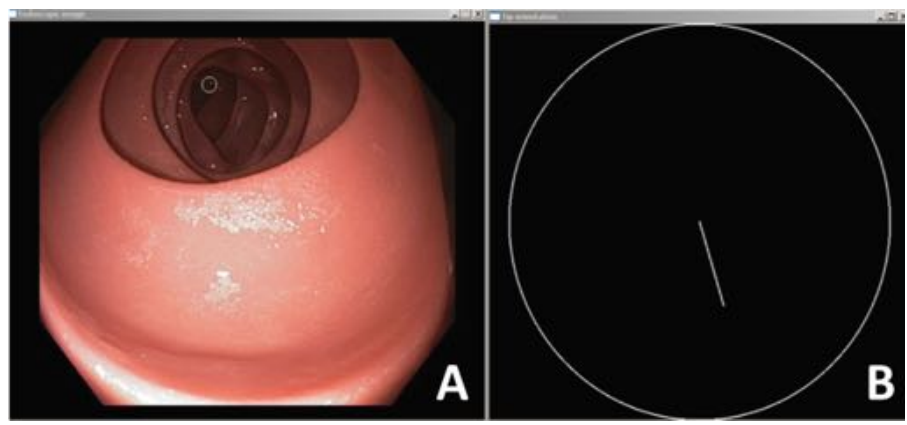

Figure 7.3: Screenshot of a representative situation during the procedure. With left (A) showing the endoscopic image with a small white circle indicating the target position found by ALC. The right pane (B) shows the tip bending diagram, currently illustrating a tip that is bent halfway downward.

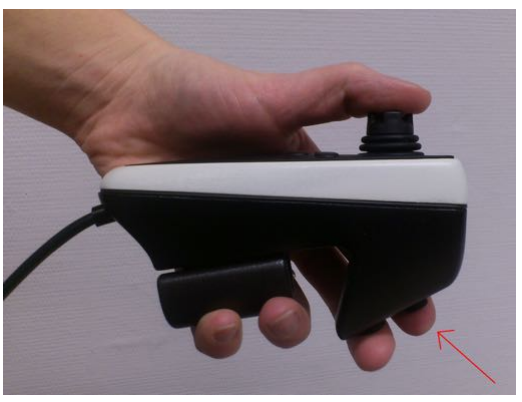

Figure 7.4: The button to enable automated navigation can be pressed by the forefinger.

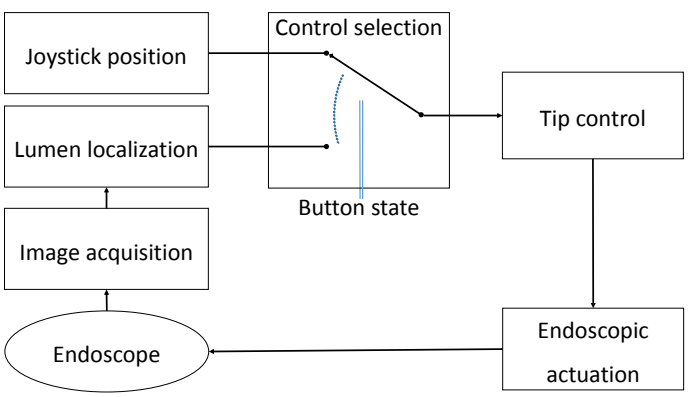

Figure 7.5: Control loop of robotic control with ALC that was used in this study. 


\subsection{Methods}

\subsubsection{Participants}

Eight experts in endoscopy (each performed $>1000$ endoscopic procedures) and ten inexperienced participants, novices, performed colonoscopies on a simulated colon model. The novices were students of technical medicine at the University of Twente, Enschede, the Netherlands. All had basic knowledge of gastrointestinal anatomy and pathophysiology and all knew the technical principles of gastrointestinal endoscopy. None of the novices had any experience in performing endoscopy.

\subsubsection{Procedure}

The participants were asked to perform a colonoscopy twice: once using conventional endoscope control and once using robotic control with ALC. The order in which they performed the procedures was randomized: half of the participants started with the robotic method and half of the participants with the conventional method. Before testing, each participant received both verbal and written instructions on the goals of the study, the colon model, and the working with robotic control with ALC. Novices were also instructed how to work with conventional control. The circle depicting the lumen position found by the ALC algorithm was always visible, even during the conventional colonoscopic procedures.

Before the conventional session, experts were allowed 5 minutes to familiarize with the colon model using conventional control. They practiced 20 minutes before the session using robotic control with ALC. Novices were granted 10 minutes to get used to the colon model and 20 minutes to practice each modality. Participants were instructed to have the endoscope reach the cecum as fast as possible and withdraw in 6 minutes, during which they inspected the bowel wall for lesions. During testing, we allowed no additional instructions. Participants who were not able to reach the cecum with one of the steering modalities were excluded. After completion of the tests, participants were asked for their subjective opinion by means of a questionnaire.

\subsubsection{Experimental setup}

All procedures were performed with an Olympus Exera II CLV-180 light source, CV180 video system and CF H180-AL colonoscope (Olympus, Tokyo, Japan). This type 
of colonoscope produces 576,768 pixel images with 25 frames per second. It has a field of view of $170^{\circ}$ and a field depth of $3100 \mathrm{~mm}$. The ALC algorithm was implemented in Python 2.7 (v. 2014) using OpenCV (v. 2014) on a standard Windows laptop (Dell Probook 6560b). Participants performed simulated colonoscopy on the Kyoto Kagaku Colonoscope Training Model (Kyoto Kagaku Co. Ltd, Kyoto, Japan), which is a physical colon model consisting of a life-size plastic torso with a synthetic colon inside. The colon was configured into standard cases, according to the layout guides provided by the manufacturer. Experts used case 2 of the colon model, this case was previously validated for assessing colonoscope intubation skills [87]. During pretesting of the platform setup feasibility, none of the novices was able to reach the cecum with either modality while using this case. Therefore, novices performed the easier case 1 . This did not hinder study evaluation because the performance was not compared between groups, but between modalities.

We manually applied 21 foam fabric simulated polyps, varying in size, throughout the colon in a distribution similar to that reported by Gralnek et al. [32]. The novices used a shorter part of the synthetic colon for case 1, so the simulated polyps were redistributed to obtain the same distribution per colonic segment as in case 2 (Figure 7.6). The participants were blinded with regard to the number of simulated polyps and the fact that they performed both procedures on the same case of the colon model.
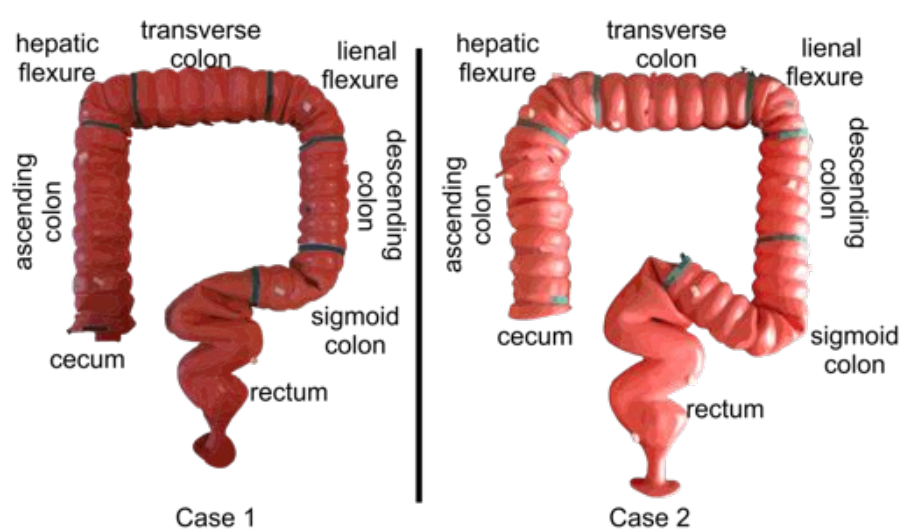

Figure 7.6: Case configurations 1 (left, novices) and 2 (right, experts). Anatomical names for colon segments are also illustrated per case. Segments are bordered by the green lines to ensure logging consistency between experiments. The colon configuration inside the torso was invisible to participants. 


\subsubsection{Evaluation parameters}

Clinical feasibility was evaluated using the cecum intubation time and the number of detected simulated polyps during endoscope withdrawal.

Technical feasibility focuses on the use of the system and can be compared between the two participant groups. Main technical evaluation parameters were: the percentage of time using ALC (ALC use, \% of total), the time ALC was on (TO, number of times) and the 'on'-time per period (DUR, in frames). The simulated colon was divided into seven segments (Figure 7.6), and transitions of the endoscope from one segment to the other were timed. This was done to enable parameter evaluation per segment. It was expected that the ALC would predominantly be used in the longer, straight segments of the colon. The lumen can be optimally viewed in this area, indicating high agreement between the algorithm and the user. We hypothesized that if ALC would be turned 'on', the introduction would be faster than without automatic lumen centralization.

Concluding the sessions, all participants were asked to subjectively evaluate their experience and potential use of the robotic control with ALC.

\subsubsection{Statistical analysis}

Analyses were done using IBM SPSS Statistics 20 (IBM, Armonk, NY, USA) and MATLAB R2011b (The Mathworks Inc., Natick, MA, USA). Overall statistical evaluation was done, if relevant, using a Mann-Whitney U-test. Fisher's exact test was used to compare the median 'on' times of the two participant groups using robotic control with ALC and for the categorical variables. All tests were two-tailed. We considered a $p$ value of less than 0,05 to be significant. Data was expressed using median values with their interquartile range. Because this was a pilot study, no power calculation was performed beforehand.

\subsection{Results}

A total of 8 expert endoscopists and 12 novices participated in the study. Of the experts, 7 were men. The experts were on average $48 \pm 8$ years. The novices included 3 men and were aged $21 \pm 1$ years. We excluded the data for 2 novices, both female, from further analysis. One of these novices failed to reach the cecum dur- 
ing colonoscopy with conventional steering (randomized to start with robotic control with ALC). The other novice failed to complete the first procedure without additional instructions (randomized to start with conventional steering).

We separately describe clinical and technical feasibility as well as the results from the subjective questionnaire.

\subsubsection{Clinical Feasibility}

Novices showed no significant difference in cecum intubation times between using conventional control, 707s (499-933), or robotic control with ALC, 536s (406-994), $\mathrm{p}=0.65$. Experts were not significantly faster using the conventional method for scope introduction with 129 (73-448) vs. 781 (309-1014)s using robotic control with ALC, $\mathrm{p}=0.12$. Significant results were found when comparing steering modules per colon segment, Table 7.1. Novices were significantly faster in inserting through the descending colon with the robotic setup with ALC. Experts were significantly faster in many segments using the conventional method, but not in the descending colon and the splenic flexure.

Table 7.1: Median intubation times. Only significant differences per colon segment are reported, fastest control module is formatted bold.

\begin{tabular}{|c|c|c|c|}
\hline & $\begin{array}{l}\text { Robotic control } \\
\text { with ALC (s) }\end{array}$ & $\begin{array}{l}\text { Conventional } \\
\text { (s) }\end{array}$ & $\begin{array}{l}\text { Significance } \\
\text { level }(p)\end{array}$ \\
\hline Cecum intubation novices & $536(406-994)$ & 707 (499-933) & 0.65 \\
\hline Cecum intubation experts & $129(73-448)$ & $781(309-1014)$ & 0.12 \\
\hline \multicolumn{4}{|l|}{ Segments novices } \\
\hline Descending colon & 16.1 & 19.7 & 0.04 \\
\hline \multicolumn{4}{|l|}{ Segments experts } \\
\hline Rectum & 87.1 & 33.4 & 0.02 \\
\hline Sigmoid colon & 103.7 & 34.5 & 0.02 \\
\hline Transverse colon & 225.5 & 21.7 & 0.03 \\
\hline Hepatic flexure & 16.7 & 3.1 & 0.01 \\
\hline Ascending colon & 14.8 & 4.4 & 0.03 \\
\hline
\end{tabular}

Novices found with $88 \%$ (80-95) not significantly more polyps with the robotic method compared to using the conventional system of $79 \%$ (75-92). Experts found significantly more polyps using the conventional method with a detection rate of $81 \%$ (76-86) against 69\% (61-75) when using the robotic method with ALC, $p=0.02$. The withdrawal times of the experts were within the range of 3.42-6.15 min. One expert 
was an outlier who withdrew in $>8.5$ min using the conventional setup. For novices, the withdrawal range was 3.83-7.64 min.

\subsubsection{Technical Feasibility}

Novices using robotic control actively turned ALC a median of $4.2 \%$ of the time during intubation and a median $0.3 \%$ of the time during withdrawal. Experts turned on ALC $4.0 \%$ of the time during intubation and $11.6 \%$ during withdrawal. The number of times ALC was turned on was a median 77 times per procedure for the experts and 59 times for the novices. The mean duration of ALC use (DUR) was significantly longer in the expert group than in the novices group $(\mathrm{p}<0.001)$. Median DUR was 12 frames for experts and 7 frames for novices.

\subsubsection{Subjective questionnaire results}

All novices and three experts stated that endoscope intubation was easier with robotic control with ALC. However, at least four experts indicated that they expect additional value of the ALC functionality during withdrawal. Rotation of the endoscope tip with the joystick, used for colon wall lesion inspection, became even easier when the tip could be centralized automatically. 10 novices and 7 experts agreed that the robotic system would make performing a colonoscopy easier for novices.

An additional finding of the lumen centralization algorithm (not in the questionnaire) was that during the experiments, some test persons indicated that they 'followed the white circle' while inserting the endoscope also during conventional procedures.

\subsection{Discussion}

In this study, we evaluated the clinical and technical feasibility of an assisting automated lumen centralization algorithm implemented in a robotic add-on platform for flexible endoscopes.

Clinically, we showed that both experts and novices were at least as efficient with the robotic system as with the conventional one, with a trend toward faster cecum introduction. We expected that experts, who are fully trained to use the conventional 
control, would be faster using the conventional method. From the current similar results, we expect that performance with the new system could improve with training.

Overall, the proportion of simulated polyps detected by the participants in our study during colonoscopy with conventional steering was larger than the $52.9 \%$ of the in vitro colonoscopy study by Gralnek et al. [88]. We based the location of the simulated polyps in our colon model on the model used by Gralnek et al., but instead of metallic beads, we used simulated polyps made of foam fabric. These may have been easier to identify. The high polyp detection rate could also be caused by increased withdrawal time. Due to the unequal withdrawal times by the experts, polyp detection is not considerd a reliable outcome measure to compare performance in this group.

A strength of this study is the randomized, crossover design, which prevented the influence of a learning effect with the colon model. A potential drawback of this study is that the time to practice on the colon model was short, especially for novices. Participants were asked to combine many different cognitive and motor tasks that were new to them. Nonetheless, considering that this was a feasibility study and as such not designed and powered to detect significant differences between the different modalities and participant groups, the results are promising.

It is uncertain how much ALC contributed to the robotic results, because of the low use of the automated control. This low use of ALC could theoretically be due to the low level of agreement of the users with the target location of the central lumen. Therefore, we compared the automatically found target location to the location that medical experts would steer the endoscope, Figure 7.7.

From this comparison we found that when ALC was turned on, the lines correspond well, i.e. the lumen was found by the algorithm. However, there were also regions where the lines correspond well and ALC was not turned on. Therefore, we anticipate that lack of training with the system causes the low use of ALC, which should therefore be improved in a next study. 


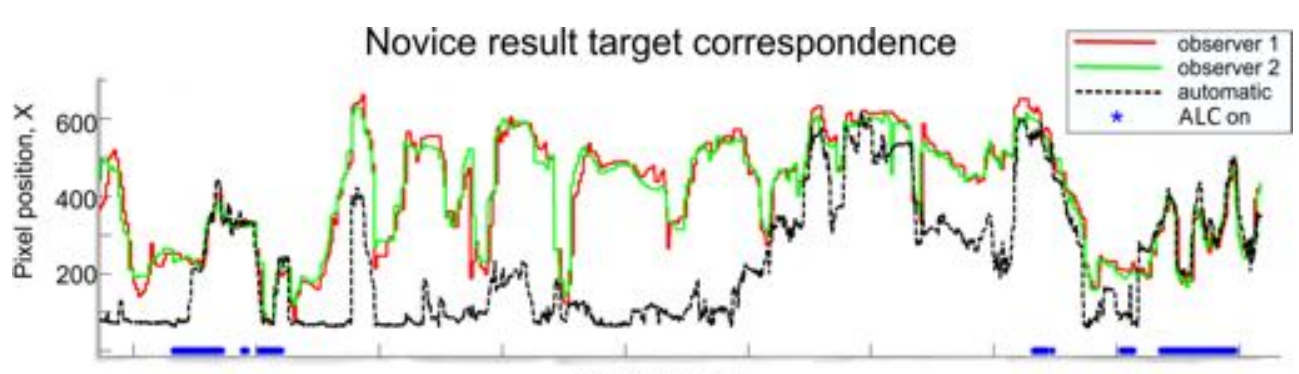

Frame number

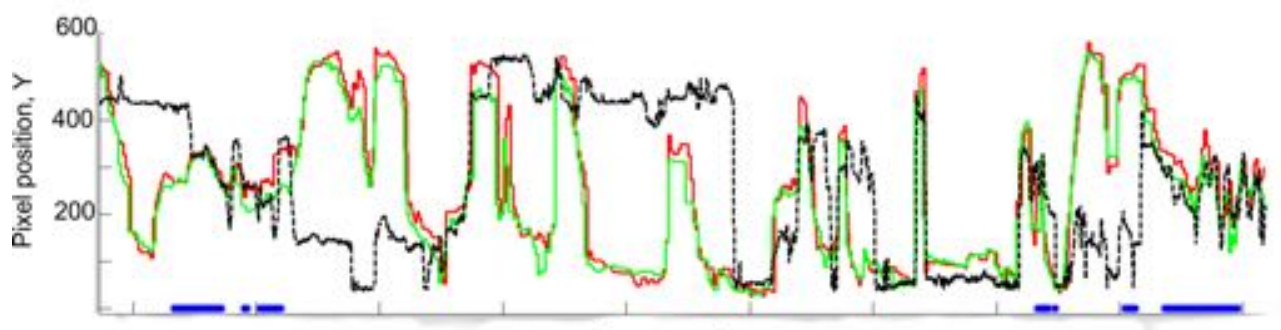

Frame number

Figure 7.7: Example showing $X$ (top) and $Y$ (bottem) pixel coordinates of the found target in the image. The dashed lines indicate the automatically found target, the other lines show the manually indicated target. The straight lines at the bottom of each graph indicate periods that ALC was turned on.

The algorithm did not always find the same position an endoscopist would steer towards, this is due to a number of factors, including the fact that endoscopists not always steer toward the central lumen to move forward. This is the reason the ALC functionality is designed in an assisting fashion where the user can actively decide to activate the control or not.

The system was developed to support endoscope intubation and was expected to be easier and faster in this part of the procedure. Interestingly however, experts used ALC almost $12 \%$ of the time during the withdrawal phase of the procedure while this was not the purpose of the developed application. When asked for their opinion, all expert users and some of the novices indicated that they experienced additional value of the ALC functionality during withdrawal. It was considered more intuitive to centralize the lumen with the robotic system during the wall inspection for possible lesions than with the conventional system. Furthermore, all users indicated to see added value of the system for novice users.

Study results also revealed interesting comments on the visual cue that indicated the automatically found lumen direction. Several novice and expert users not only deemed the little white circle helpful, but stated they were following the cue even 
when they were not using the ALC function. This implies that the added functionality of the ALC algorithm may be partly established by visual assistance and partly by autonomous correction of the tip.

\subsection{Conclusion}

In conclusion, the ALC algorithm combined with the robotic add-on control works well in an experimental setup that closely resembles the clinical environment. Noninferiority of this system is shown for novices, although ALC use was lower than expected. The relatively extensive use of ALC during the withdrawal phase of the procedure suggests a possibly interesting added value of the system during this phase. 


\section{Chapter 8}

\section{Evaluation of tip bending response in clinically used endoscopes}

Published as:

ED Rozeboom, R Reilink, MP Schwartz, P Fockens and IAMJ Broeders

Evaluation of tip bending response in clinically used endoscopes

Endoscopy International Open, 2016;4:466-471 


\begin{abstract}
Background

Endoscopic interventions require accurate and precise control of the endoscope tip. The endoscope tip response depends on a cable pulling system, which is known to deliver a significantly nonlinear response that eventually reduces control. It is unknown whether the current technique of endoscope tip control is adequate for a future of high precision procedures, steerable accessories, and add-on robotics. The aim of this study was to determine the status of the tip response of endoscopes used in clinical practice
\end{abstract}

\title{
Methods
}

We evaluated 20 flexible colonoscopes and five gastroscopes, used in the endoscopy departments of a Dutch university hospital and two Dutch teaching hospitals, in a bench top setup. First, maximal tip bending was determined manually. Next, the endoscope navigation wheels were rotated individually in a motor setup. Tip angulation was recorded with a USB camera. Cable slackness was derived from the resulting hysteresis plot.

\section{Results}

Only two of the 20 colonoscopes (10\%) and none of the five gastroscopes reached the maximal tip angulation specified by the manufacturer. Four colonoscopes (20\%) and none of the gastroscopes demonstrated the recommended cable tension. Eight colonoscopes $(40 \%)$ had undergone a maintenance check 1 month before the measurements were made. The tip responses of these eight colonoscopies did not differ significantly from the tip responses of the other colonoscopes.

\section{Conclusions}

This study suggests that the majority of clinically used endoscopes are not optimally tuned to reach maximal bending angles and demonstrate adequate tip responses. We suggest a brief check before procedures to predict difficulties with bending angles and tip responses. 


\subsection{Introduction}

Flexible endoscopy depends to a high degree on steering the endoscope tip in the desired direction. This is important for scope introduction, mucosal inspection, and interventional procedures. Unfortunately, control of the endoscope is difficult. Even fully trained endoscopists are not able to complete colonic intubation in up to $25 \%$ of procedures (depending on the clinical setting and indication) [89-91]. Also, adenoma miss rates with current colonoscopic techniques are high, with up to $27 \%$ of adenomas missed in a back-to-back study [92]. We suspect that these inadequate outcomes, which are clinically important, are caused by difficulties with tip control.

Endoscopic tip steering is based on a cable pulling system (Figure 8.1) [93]. Cables run from two navigation wheels on the control handle through the shaft to pull the tip in an up, down, left or right facing position. This system of traction cables enables high flexibility of the endoscopic shaft. Flexibility is needed to move through the tortuous and confined environment of the bowel. However, cable actuated systems are prone to a significant non-linear response, such as backlash, cable slacking and eventually reduced control [94]. Whereas too little cable tension causes delays and unresponsive tip bending, too tight cable tension increases friction and reduces predictability of response.

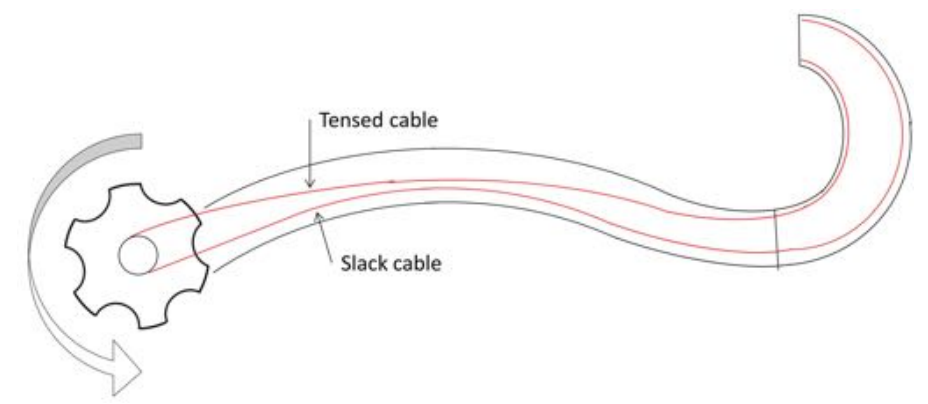

Figure 8.1: A set of antagonistic cables running from navigation wheel (left) to the bent tip (right).

Endoscopists currently combine tactile feedback of the tension on the navigation wheel with the visual reference of the endoscopic image to determine the endoscope tip response. This manual feedback loop is a direct, accurate and stable compensation mechanism. The question rises if the current physician dependent feedback method is adequate for the future. The need for tip control has increased with the de- 
velopment of high precision procedures, such as POEM, ESD and (hybrid) NOTES $[4,6,95]$. Additional challenges derive from the need to control steerable accessories and robotic systems that function as add-ons to flexible endoscopes [34, 73]. These systems may also depend on traction cables, while they are not equipped with manual user feedback [31].

Solutions are available to cope with the nonlinear effects of cable pulling systems; these include cable pre-tension mechanisms that add external sensors registering true vs. predicted tip position and software compensation algorithms that predict tip response [93]. We surveyed the current status of the endoscope tip response to learn how to deal with these issues in robot-assisted endoscope steering.

\subsection{Materials and Methods}

\subsubsection{Included endoscopes}

Included in the study were twenty colonoscopes and five gastroscopes (Table 8.1) from three Dutch hospitals. As standard procedure, the scopes are checked once or twice per year, with additional maintenance provided upon a physician's request. Used service agencies are Olympus Nederland (Zoeterwoude, the Netherlands), SurgiTec (Didam, the Netherlands) and Rescope (Nijmegen, the Netherlands). These maintenance checks include at least tuning of the bending angles and cable tension. Maximal tip angulation is evaluated by manually rotating the wheel in each direction and reading the bending angle from an angle specification sheet. Cable tension is determined to be optimal when the tip (visibly) responds to wheel rotation while the shaft is in a looped position. Colonoscopes are positioned with the shaft in a loop of 360 degrees (O-loop). Gastroscopes are positioned with the shaft in a loop of 180 degrees (U-loop).

Eight colonoscopes from one of the hospitals had undergone their yearly maintenance checks 1 month before the hysteresis measurements. Unfortunately, records of the last maintenance checks of the other scopes were not available. Records of the number of procedures in which each endoscope had been used since the last maintenance were not available for any endoscope. 
Table 8.1: Endoscopes used for evaluation and validation.

\begin{tabular}{l|l|l} 
& Type & $\begin{array}{l}\text { Nr of measured } \\
\text { endoscopes }\end{array}$ \\
\hline \multirow{2}{*}{ Colonoscope 190 series } & CFHQ 190L & 8 \\
& PCFH 190L & 1 \\
\hline \multirow{3}{*}{ Colonoscope 180 series } & CFH 180A & 2 \\
& CFQ 180AL & 6 \\
& CFH 180DL & 2 \\
\hline \multirow{2}{*}{ Colonoscope 160 series } & Q 160DL & 1 \\
& Q 160ZL & Validation scope \\
\hline \multirow{2}{*}{ Gastroscopes } & GIF H190 & 3 \\
& GIF Q160 & 2 \\
& GIF H180 & Validation scope \\
\hline
\end{tabular}

\subsubsection{Setup}

First, maximal tip angulation was evaluated for each bending direction, using an angle specification sheet provided by Olympus Nederland. The tip was maximally rotated by hand. Then, the endoscope was positioned in a bench-setup that records the tip position while rotating the navigation wheel. The endoscopic shaft was placed in loop position as is done during maintenance. Tip response when rotating small and large wheels were individually recorded, resulting in a total of two measurements per endoscope.

The endoscope's navigation wheels were actuated by a remote drive unit, connected to two DC servo motors (EC max 40-70W, Maxon, Sachseln, Switzerland) via two sets of pre-tensed antagonistic Nokon Bowden cables (Carl Stahl Nokon, Sen, Germany) [1]. It can be argued that this setup with flexible Bowden cables increased the non-linear response of the endoscope. However, preliminary bench tests revealed that this setup did not significantly affect the measurements compared to a complex setup without flexible transmission. On the contrary, this setup was easy to use in different hospital room settings and required no modifications to the endoscopes.

The endoscope navigation wheels were rotated in alternating up-and-down or left-and-right bending directions. Colonoscope wheels were rotated 10 times back and forth. Each time, the rotation angle was increased, up to a maximum of 115 degrees. Gastroscope wheels were rotated to 90 degrees in six rounds. The endoscope tip position was recorded with a camera (Chameleon CMLN-13S2M, Point Grey Research, Richmond, Canada), at a rate If 60 frames per second. Image recognition software written using IEP (Interactive Editor for Python, version 3.2, 2012) detected 
the tip position. Tip position was registered as the x-coordinate of the detected tip in a 1280 960-pixel image frame. The resulting data were post-processed with Matlab, version R2013b (MathWorks; Natick, Massachusetts, USA). The endoscopic tip was placed above the table to be free of friction. A light studio setup was used to prevent shadows (Figure 8.2).
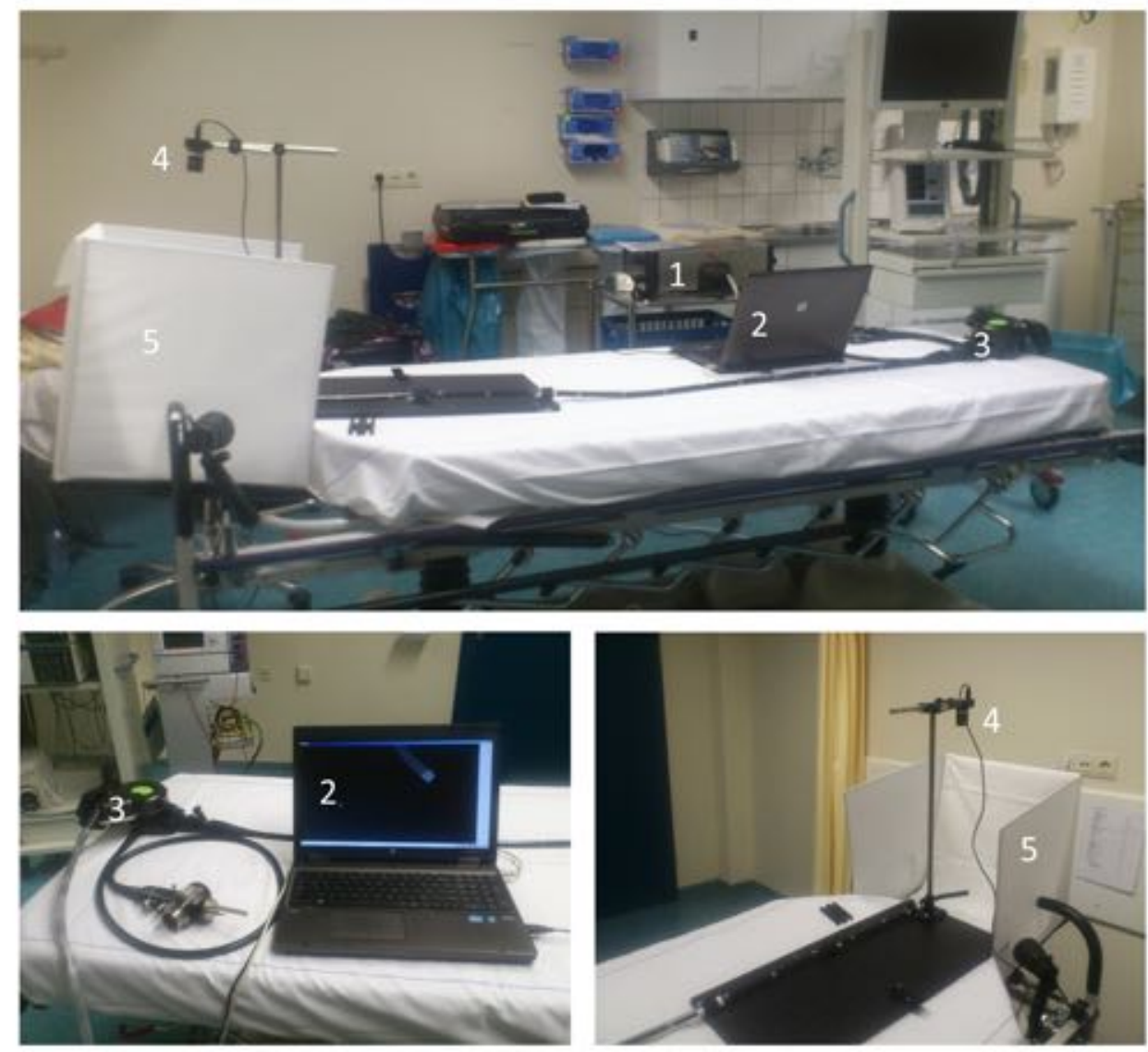

Figure 8.2: In-hospital example of setup for hysteresis measurement: 1, motor module; 2, computer; 3, remote drive unit connected to the navigation wheels of a conventional endoscope; 4 , camera capturing images of the endoscope tip; 5, light studio to prevent shadow formation from the hovering tip.

\subsubsection{Evaluation parameters}

Tip response was determined using maximal bending angles and cable slackness. The tip bending response is described in a hysteresis plot (Figure 8.3). 


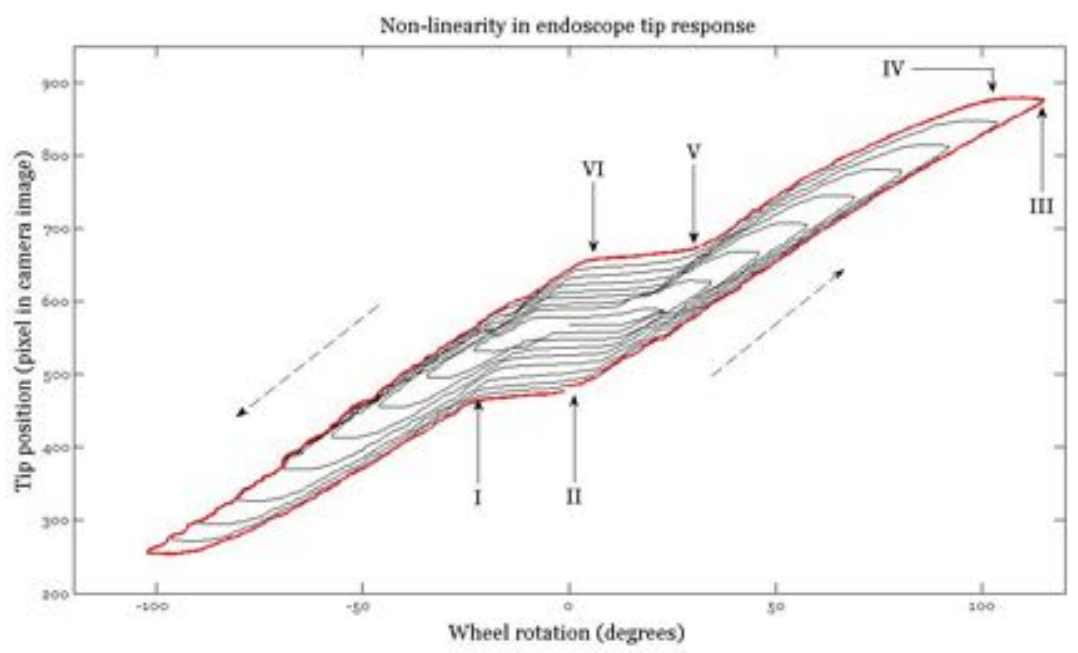

Figure 8.3: Non linearity in endoscope tip response. The tip is angulated in alternating up-and-down directions, with increasing bending angles. I. Cable pulling starts in neutral position. II. Tip starts bending. III. Tensed cable is released. IV. Tip starts to relax and return to straight position. V. Pulling the antagonistic cable. VI. Tip follows the antagonistic cable.

When the endoscopic shaft is in a straight position, the cables lie relatively loose in their guiding tubes (Figure 8.3, point I, neutral position). Wheel rotation first tenses the cable before the tip starts to bend in the corresponding direction (Figure 8.3, point II, start of tip bending). The amount of wheel rotation needed to start tip bending represents the cable slackness.

Rotating the wheel in the opposite direction causes cable relaxation (Figure 8.3, point III). The amount of wheel rotation needed to start tip straightening represents the virtual play (Figure 8.3, points III and IV). After the tip is straight, further wheel rotation pulls the antagonistic cable to bend the tip in the opposite direction (Figure 8.3 , point $\mathrm{V}$, pulling the antagonistic cable).

Looping of the endoscope shaft results in stretching and shortening of the path of the antagonistic cables, this increases tension on the cables. The settings recommended by the manufacturer ${ }^{1}$ for endoscope cable tension are such that a colonoscope with its shaft in a 360-degrees loop and gastroscope with its shaft in a 180degree loop have no cable slackness. Therefore, a straight tip responds immediately to navigation wheel rotation. There is no plateau between points I and II or between

\footnotetext{
${ }^{1}$ From expert maintenance technician, Olympus Nederland, Zoeterwoude, The Netherlands
} 
points V and VI in the hysteresis plot.

In this study, cable slackness was calculated as the maximal width of the hysteresis plot (Figure 8.4, section B) minus the average widths of the virtual play in up/right and down/left pulling cables (Figure 8.4 sections A and C). Therefore, cables are considered to be well tuned when slackness is 0 or lower.

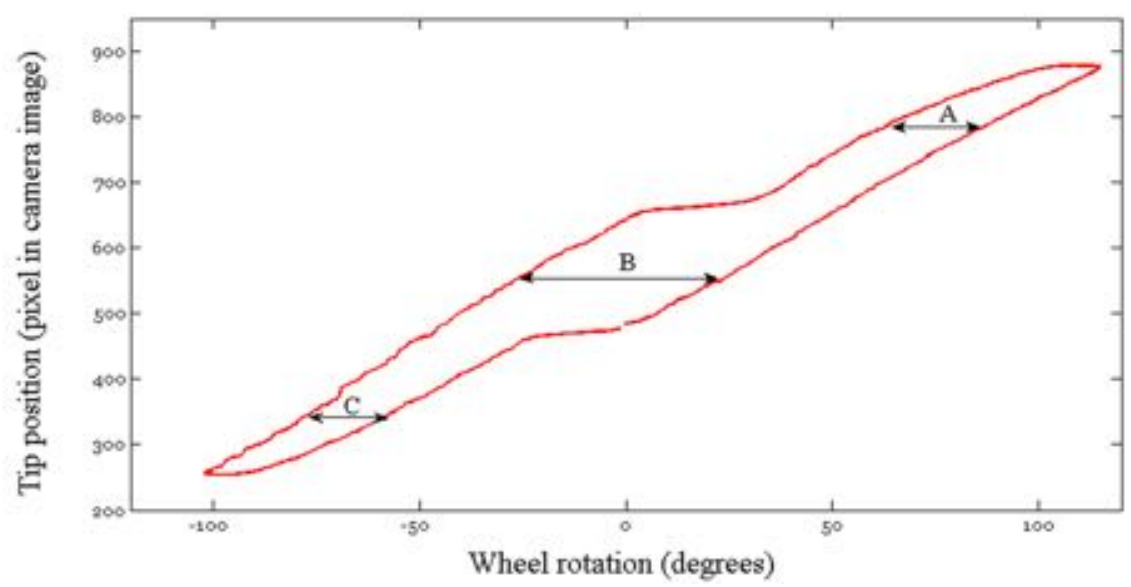

Figure 8.4: Parameters describing nonlinearity: A, virtual play up/right cables; B, cable slackness; C, virtual play down/left cables.

\subsubsection{Setup validation}

One colonoscope (CF-Q160ZL) and one gastroscope (GIF H180) were repeatedly measured with different cable tensions to confirm the hypothesis that hysteresis width represents cable tension. An expert repair and maintenance mechanic of Olympus Nederland gradually adjusted the cable tension from loose to optimal (as prescribed by the manufacturer). From the hysteresis plots, we were able to confirm that in loop configuration, a plateau was not present for well-tensed cables but gradually appeared as the cables slackened (Figure 8.5). 


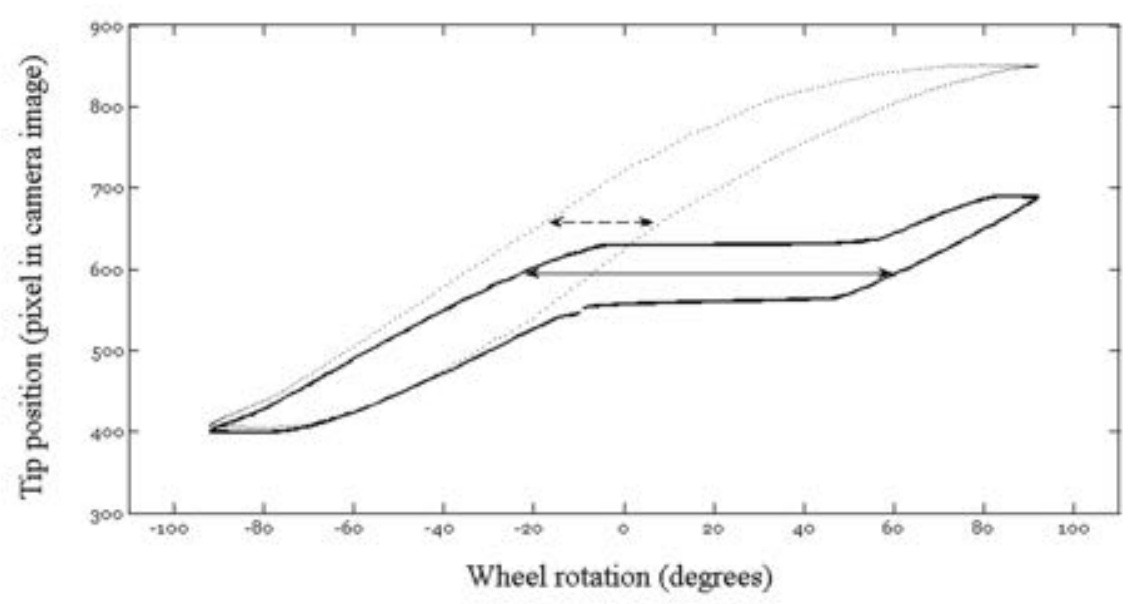

Figure 8.5: Hysteresis plot of a gastroscope with well-tensed (dotted lines) and loose (solid lines) cables. The maximal width is increased with loose cables.

\subsubsection{Accuracy}

Repeated measurements of one colonoscope revealed accuracy of the evaluation system. A well-tensed CF-H180AL colonoscope was repositioned and reconnected to simulate five full cycles of large and small wheel measurements in a looped configuration. The greatest variance for endoscope repositioning was 1.7 degrees (Table 8.2.

A second set of five measurements included changes in camera positions because an identical camera position cannot be guaranteed when the setup is moved to another hospital. The endoscope was placed in a straight position to simulate the possibility of poor cable tension in the evaluated endoscopes. The variance in hysteresis width to consider with changes in camera position in a setting of poor cable tension is 3 degrees.

Table 8.2: Validation measurements of cable slackness.

\begin{tabular}{ll|cc} 
& Configuration & $\begin{array}{c}\text { Average } \\
\text { (degrees) }\end{array}$ & $\begin{array}{c}\text { Variance } \\
\text { (degrees) }\end{array}$ \\
\hline Endoscope repositioning $(\mathrm{n}=5)$ & Looped, large wheel & -12 & 1.7 \\
& Looped, small wheel & -19 & 0.8 \\
\hline Camera respositioning $(\mathrm{n}=5)$ & Straight, large wheel & 36.5 & 3.0 \\
\hline
\end{tabular}




\subsubsection{Statistical analysis}

Statistical analysis was done, where applicable, using Wilcoxon's signed ranks test and a significance level of $P=0.05$. Data are presented as median with interquartile range (IQR).

\subsection{Results}

Only two of the 20 colonoscopes reached the maximal angulation for all bending directions as prescribed by the manufacturer (including a maximal deviation of 10 degrees). None of the five gastroscopes reached the maximal angulation. Overall, the maximal colonoscope angles deviated at a median of 20 degrees (IQR 10-20) and at a maximum of 50 degrees from the manufacturer's prescribed settings (Table 8.3). Gastroscope angles deviated at a median of 13 degrees (IQR 8-13) and at a maimum of 25 degrees from the manufacturer's prescribed settings (Table 8.3).

Table 8.3: Maximal tip bending angles: prescribed manufacturer settings vs. clinical equipment.

\begin{tabular}{l|ll|ll} 
& \multicolumn{2}{|c|}{ Colonoscope $(\mathrm{N}=20)$, degrees } & \multicolumn{2}{c}{ Gastroscope $(\mathrm{N}=5)$, degrees } \\
& Prescribed & Measured & Prescribed & Measured \\
\hline Up & 180 & $165(155-165)$ & 210 & $195(190-195)$ \\
Down & 180 & $155(150-155)$ & 90 & $80(70-80)$ \\
Left & 160 & $145(139-145)$ & 100 & $85(85-85)$ \\
Right & 160 & $143(130-143)$ & 100 & $90(90-90)$ \\
\hline
\end{tabular}

Cable slackness of the validation colonoscope with optimal cable tension was -11 degrees for the large wheel and -14 degrees for the small wheel. Cable slackness of the gastroscope was -4 degrees for both wheels.

Only three colonoscopes and no gastroscopes showed cable slackness below 0 degrees in both cable sets when in loop configuration (Table 8.4). Four colonoscopes showed appropriate cable tension in one of both cable sets. In the remaining colonoscope cable sets, cable slackness ranged from a minimum of 5 to a maximum of 46 degrees. For gastroscopes, these values ranged from 8 to 30 degrees.

No correlation was found between the maximal tip angulation and the wheel rotation needed to start tip bending for all directions in both the colonoscopes and the gastroscopes.

Eight colonoscopes from one hospital had undergone their yearly maintenance check 1 month before the hysteresis measurements. Their tip responses did not differ 
significantly from the tip responses of the other colonoscopes, for both cable sets.

\subsection{Discussion}

In this study we assessed endoscope tip response the navigation wheels of clinically used flexible colonoscopes and gastroscopes were rotated. We anticipate that current cable-driven endoscopes may not be able to deliver the response that is required for innovative therapies and add-on control methods.

This study confirms that tip bending is frequently limited in clinically used endoscopes. As a general rule, endoscopists refer equipment for maintenance when technical issues arise. However, this survey strikingly shows that an angulation deficiency of 50 degrees was not enough send the endoscope back for repairs. The authors assume that tip bending of 160 instead of 180 degrees might limit inspection behind bowel folds or retroflexion when it is needed. We expect that with experience, endoscopists develop methods of torquing and manipulation that enable them to reach clear clinical end points as cecum intubation and polyp removal. Nevertheless, our main concern is that inadequate tip response delays the procedure and reduces wall inspection. Unfortunately, it is difficult to estimate the clinical effect of limited tip bending. There is no objective method for registering the number of endoscopic procedures that are prematurely ended or lengthened because of an inadequate endoscope tip response.

In this study, the slackness of most endoscope cables was greater than what the manufacturer recommended. Although slack cables increase scope flexibility, greater wheel rotation is required before the endoscope tip starts to bend. An endoscopist can tell when the tip starts to bend by the increased tension on the wheel. However, control can be hindered when such a large wheel motion is required that the fingers driving the wheel must be repositioned. Also, large differences among endoscopes reduce the predictability of responses, especially when an operator is learning to control the instrument.

There are two possible explanations for the poor tip response of the endoscopes that had undergone maintenance 1 month before this evaluation. Either the maintenance was unsuccessful in checking and tuning the cables and tip, or 1 month of use was enough to reduce cable status. A long-term analysis would be able to demonstrate the decline of cable status during clinical use and the effect of maintenance on 
functional status.

With regard to adding motor-driven accessories and remote control, this short inventory shows that there is already a large degree of nonlinearity of the tip response. Adding cable-driven systems will increase nonlinearity, and tip position errors will grow. Compensation methods should be highly adaptive to different endoscopes and their configuration. Another strategy could be the use of non-cable driven endoscopes. Promising alternatives currently under investigation are magnet- [96] and sleeve-controlled camera navigation [27, 97]. However, these are experimental designs not yet ready to be tested as cost-effective, safe and user-friendly diagnostic procedures.

For current daily practice, we suggest a brief check before procedures to predict problems in large angulations and inaccurate tip response. The maximal tip angulation serves as one method to quickly assess the endoscope cable status. A second method is to visually determine the response when rotating the navigation wheels of an endoscope in loop configuration. This takes slightly more time but may be worthwhile before the initiation of challenging procedures in which a quick tip response is necessary.

\subsection{Conclusion}

This study shows that a substantial percentage of the endoscopes used in daily clinical practice are not optimally tuned to reach maximal bending angles and demonstrate adequate tip responses. We suggest a short pre-procedural check to predict problems with large angulations and inaccurate tip responses. A long-term analysis would be able to demonstrate the decline of cable status during clinical use and the effect of maintenance on functional status.

\subsection{Acknowledgements}

The authors wish to thank Mr. K. Verdouw, expert maintenance technician for flexible endoscopes at Olympus Nederland, for his advice and assistance regarding validation measurements. 
Table 8.4: Cable slackness values of the validation and hospital endoscopes in loop configuration. Values represent the maximal hysteresis width minus the average widths of the virtual play in up/right and down/left pulling cables. Cables are considered well tensed when slackness is 0 or lower.

\begin{tabular}{|c|c|c|}
\hline Scope & Large wheel & Small wheel \\
\hline \multicolumn{3}{|l|}{ Validation scopes } \\
\hline Colonoscope CF-Q160ZL & -11 & -14 \\
\hline Gastroscope GIF-H180 & -4 & -4 \\
\hline \multicolumn{3}{|c|}{ Colonoscopes with all cables well tensed } \\
\hline CF-Q180AL & -14 & -17 \\
\hline CF-H180AL * & -4 & -18 \\
\hline CF-Q160DL & -3 & -4 \\
\hline \multicolumn{3}{|c|}{ Colonoscopes with one good cable set } \\
\hline CF-HQ190L $* \bowtie$ & -7 & 4 \\
\hline CF-Q180AL $\bowtie$ & 9 & -3 \\
\hline CF-H180DL * & 12 & -16 \\
\hline XCF-Q180AYL & 13 & -9 \\
\hline \multicolumn{3}{|c|}{ Colonoscopes with all cables too slack } \\
\hline CF-HQ190L & 5 & 19 \\
\hline CF-HQ190L * & 5 & 6 \\
\hline CF-H180DL * & 10 & 19 \\
\hline CF-Q180AL & 12 & 18 \\
\hline CF-Q180AL & 14 & 18 \\
\hline CF-H180AL * & 18 & 25 \\
\hline H190L & 20 & 15 \\
\hline Q190L & 20 & 22 \\
\hline Q190L & 26 & 22 \\
\hline CF-Q180AL & 29 & 27 \\
\hline CF-HQ190L * & 33 & 46 \\
\hline HQ190L & 34 & 42 \\
\hline CF-HQ190L * & 44 & 41 \\
\hline \multicolumn{3}{|c|}{ Gastroscopes with all cables too slack } \\
\hline GIF-H180 & 9 & 8 \\
\hline GIF-H190 & 13 & 15 \\
\hline GIF-ITQ160 & 15 & 29 \\
\hline GIF-ITQ160 & 22 & 15 \\
\hline GIF-H190 & 30 & 22 \\
\hline \multicolumn{3}{|c|}{$\begin{array}{l}\text { * Endoscope received yearly maintenance check } 1 \text { month } \\
\text { before hysteresis measurements. }\end{array}$} \\
\hline$\bowtie$ Endoscope reached max & angles in all & irections. \\
\hline
\end{tabular}





\section{Chapter 9}

\section{Conclusion \& Discussion}


The flexible endoscope is a valuable tool in gastroenterology. However, the conventional control design has reached its limits. Robotics are able to improve endoscope control and enable complex interventions without losing the current benefits like cleanability, manoeuvrability and good image quality.

This dissertation introduced and evaluated the design of a tip steering platform for a conventional flexible endoscope. The presented platform enables currently employed endoscope manipulation techniques and adds an ergonomic user interface with tailored control algorithm.

When introducing novel technology, one would prefer overwhelming proof that the novel method is better than the conventional system. Robotic developments especially raise the expectation on improved ergonomics and easy to learn interfaces. The expectations of the platform and encountered technical challenges are discussed in the following paragraphs.

\subsection{Reduce tip steering difficulty}

The aim of this thesis was to improve usability of conventional flexible endoscopes by reducing difficulty of endoscope tip control. It was expected that easier tip steering would lead to improved clinical performance.

The first step was to determine the optimal combination of user interface and control algorithm. The presented platform offers the possibility to adapt both interface and algorithm to personal preferences. Nonetheless, the intention was to find one user interface that serves as an optimal base for everyone. This ensures a fast setup of the equipment and facilitates easy change of operators during procedures, e.g. for training or second-opinions. The presented studies identified the bimanual joystick interface with non-linear rate control as the most promising combination. This interface reduced the experienced workload of endoscopy naive participants and was preferred by most participants.

It was expected that easier tip steering would lead to improved clinical performance, such as reduced navigation time. This succeeded partially. Novices indeed improved their efficiency in tip positioning when using the add-on platform compared to conventional control. They did not show a time advantage in simulated colonoscopy procedures. Trained experts were able to learn to use the platform up to their personal level of expertise with conventional endoscope control in simulated 
colonoscopy. Major performance improvements were not expected by experts using the platform, considering their extensive experience with the conventional system.

Easier tip steering was also expected to improve visualisation of the intestinal tract. Indeed, in a laboratory setting, the joystick interface allowed a quick and smooth tip steering trajectory. Unfortunately, this did not translate to finding more polyps or visualising more of the mucosal wall in simulated colonoscopy procedures.

While novices and experts experienced a reduction in workload, they scored similar efficiency and effectiveness in simulated endoscopy procedures. This was unexpected, although there are two explanations. First, endoscope tip positioning depends both on tip steering and shaft manipulation. Shaft manipulation is changed when using the platform. Where conventional steering allows shaft rotation by torquing the control handle, this is not possible with the remote user interface of the platform. Guiding the flexible shaft now depends on the right hand, which might have affected its manoeuvrability. Secondly, the participants were instructed to perform as high as possible on efficiency and effectiveness. It can be argued that this motivation, together with the relatively short and interesting experiments reduced the effect of workload on procedure time and effectiveness. Regular and longer procedures are more likely to be affected by a higher workload.

Overall, the studies showed non-inferiority of the add-on platform for endoscope navigation. Although this is not enough to earn a position in routine diagnostic procedures, it shows the platform's capacity to reach the site of an intervention without compromising navigation efficiency. The next step is to perform the actual intervention, introducing the challenge of simultaneous instrument control.

\subsection{Single-person instrument control}

The flexible endoscope allows the introduction of small instruments to the tip. The challenge was to enable single-person control of both endoscope and instrument using the add-on platform. Two user interfaces were designed that allow control of both endoscopic shaft and tip in one hand, while freeing the other hand for instrument control (Figure 9.1).

The designs were based on manual control of the endoscopic shaft to ensure force feedback during endoscope introduction. The drawback of this design was that single-handed gripping of the shaft and joystick proved limited. Participants of our 

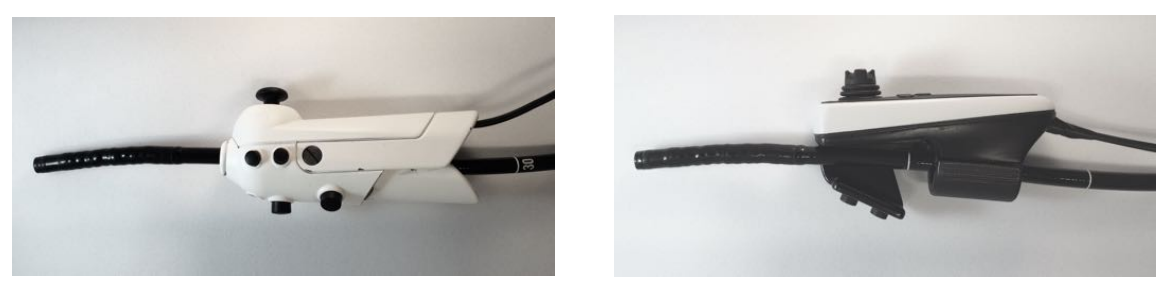

Figure 9.1: Two user interfaces that allow gripping of the endoscope shaft and tip steering with the right hand while freeing the left hand for instrument control. See Chapter 4.

studies were inclined to add the second hands for shaft manipulation and stabilisation, thereby opposing the anticipated value of single-hand control.

A promising alternative is in robotic control of the shaft, such as presented by the shaft module from Ruiter et al. (2013) [1], Figure 1.6, centre setup. The module is intended for stabilisation and small corrections of the shaft position if needed. It can be quickly attached at the site of intervention and easily removed. The difficulty of this system lies in safe and intuitive control of all degrees of freedom of endoscope and instrument. Image-guided automated control is considered a promising strategy to really free the endoscopists hand and mind for instrument control. Image-based target locking has the potential to stabilise the endoscopic tip at the site of intervention, even though real-time and robust steering algorithms are not available yet [79].

Regardless of the control method, manipulation of the endoscope from outside the patient does not guarantee the intended movement at the intervention site. This is due to the mechanical principle of the flexible endoscope, which introduces its own challenges.

\subsection{Challenges of conventional endoscopes}

The endoscope's flexibility is needed to move through the torturous and confined environment of the bowel. However, pushing a flexible shaft through a flexible tube does not give a predictable response. Bowel movements and looping of the endoscopic shaft result in under- and overshoot of endoscope tip response. Chapter 8 illustrated that there is also unpredictability of endoscopic tip bending when rotating the endoscopic wheels.

In conventional procedures, unpredictability is solved by the 'human in the loop' principle. The endoscopist perceives the endoscope's progress by interpreting the 
endoscopic image and force feedback and reacts accordingly. In robotic control, opportunities for closing the control loop are via adding feedback from position and orientation sensors on the endoscope or instrument. Concepts using magnetic tracking also show promising results in accurate and precise positional feedback [98]. Sensors could be added in a sleeve-like design, to ensure the endoscope's current benefits of cleanability and compatibility with available accessories is maintained.

Even with high-frequency feedback, it is questionable if the conventional cabledriven endoscope will be able to perform on the requested level of accuracy and precision. Accuracy and precision levels need to be high to guarantee safe and effective procedures. A strategy around limitations of the conventional equipment it to design a novel 'endoscopic' platform.

\subsection{Alternative endoscope designs}

Alternative endoscope designs could improve instrument and camera steering without the current limitations in cable-driven actuation. These designs should allow the minimal invasive (non-abdominal) route to intervention sites, and could include the much sought advantages of instrument triangulation, independent camera and instrument motions, stable and accurate platform positioning at the intervention site.

For many years, this request has been heard. University research groups, independent innovators and established market parties have developed and studied endoscopic redesigns. Until now, no platform has been tested as cost effective and userfriendly. The current limitations of a redesign include costly development, purchase and training, technical difficulties to combine flexibility with precise and accurate instrument positioning and preserving the clinical standards of cleanability. On top of that, the novel method should prove substantial benefits in efficiency, effectiveness and ease of use to be accepted as standard care.

\subsection{Route for the future}

Provided the technical limitations are resolved, the presented add-on modular system is currently the most promising route for introducing robotics in the clinical practice of flexible endoscopy. The easy click-on principle of the add-on platform allows accessible introduction in the daily workflow. Modular systems have the potential to 
identify procedures, or steps in a procedure, that benefit from a (semi-) automative approach. The next step is to develop dedicated software and instruments for these (steps in) procedures to ensure clinical advantage without inordinate investments.

Target interventions could be POEM and ESD (Figure 1.2, p. 3). Both interventions have laparoscopic alternatives that are currently the gold standard. A shift form laparoscopic to endoscopic approach could introduce the advantages expected from scarless interventions, such as shorter hospital stay, reduced complications and improved cosmetics. The first short studies of POEM and ESD show the clinical advantages of the endoscopic route $[99,100]$. The robotic setup has the potential to further reduce difficulty of endoscope and instrument control. Easier tip control is expected to have more effect on reducing procedure time and training trajectories of these complex procedures, compared to the diagnostic procedures evaluated in this thesis.

The presented robotic add-on steering method has the potential to further improve tip steering. Opportunities for improvement are in adding position feedback to close the control loop and in adding smart image-guided tip control algorithms that assist the endoscopist. 


\section{Bibliography}

[1] Jeroen G. Ruiter, Esther D. Rozeboom, Mascha C Van der Voort, G. M. Bonnema, and Ivo A. M. J. Broeders. Design and Evaluation of Robotic Steering of a Flexible Endoscope. In IEEE International Conference on Biomedical Robotics and Biomechatronics, pages 761-767, Rome, Italy, 2012.

[2] Fumio Omata, Sachiko Ohde, Gautam a Deshpande, Daiki Kobayashi, Katsunori Masuda, and Tsuguya Fukui. Image-enhanced, chromo, and cap-assisted colonoscopy for improving adenoma/neoplasia detection rate: a systematic review and meta-analysis. Scandinavian journal of gastroenterology, 49(2):222-37, 2014.

[3] Venkataraman Subramanian, Krish Ragunath, Venkataraman Subramanian, and Krish Ragunath. Advanced Endoscopic Imaging: A Review of Commercially Available Technologies. Clinical Gastroenterology and Hepatology, 12:368-376, 2014.

[4] Yutaka Saito, Yosuke Otake, Taku Sakamoto, Takeshi Nakajima, Masayoshi Yamada, Shin Haruyama, Eriko So, Seiichiro Abe, and Takahisa Matsuda. Indications for and technical aspects of colorectal endoscopic submucosal dissection. Gut and liver, 7(3):263-9, may 2013.

[5] Haruhiro Inoue, H. Minami, Y. Kobayashi, Y. Sato, M. Kaga, M. Suzuki, H. Satodata, N. Odaka, H. Itoh, and S. Kudo. Peroral endoscopic myotomy (POEM) for esophageal achalasia. Endoscopy, 42:265-271, 2010.

[6] ASGE/SAGES. ASGE/SAGES Working Group on Natural Orifice Translumenal Endoscopic Surgery White Paper October 2005. Gastrointestinal endoscopy, 63(2):199-203, feb 2006.

[7] Christopher B. Williams. Insertion Technique. In Jerome D Waye, Douglas K Rex, and Christopher B Williams, editors, Colonoscopy: Principles and Practice, chapter 40, pages 537-559. Blackwell Publishing Ltd., London, UK, 2nd edition, 2009.

[8] A Liberman, I Shrier, and P Gordon. Injuries sustained by colorectal surgeons performing colonoscopy. Surgical endoscopy, 19(12):1606-9, dec 2005.

[9] I-1 Lee and C-s Wu. Less patient discomfort by one-man colonoscopy examination. International journal of clinical practice, 60(6):635-8, jun 2006. 
[10] W H Kim, Y J Cho, J Y Park, P K Min, J K Kang, and I S Park. Factors affecting insertion time and patient discomfort during colonoscopy. Gastrointestinal endoscopy, 52(5):600-5, nov 2000.

[11] Esther D. Rozeboom, Jeroen G. Ruiter, Michel Franken, Matthijs P. Schwartz, Stefano Stramigioli, and Ivo a. M. J. Broeders. Single-handed controller reduces the workload of flexible endoscopy. Journal of Robotic Surgery, jun 2014.

[12] Suck Lee, Il Chung, Sun Kim, Jin Kim, Bong Ko, Young Hwangbo, Won Kim, Dong Park, Sang Eok Lee, Cheol Park, Il Baek, Seun Park, Jeong Ji, Byung Jang, Yoon Jeen, Jeong Shin, Jeong Byeon, Chang Eun, and Dong Han. An adequate level of training for technical competence in screening and diagnostic colonoscopy: a prospective multicenter evaluation of the learning curve. Gastrointestinal endoscopy, 67(4):683-9, apr 2008.

[13] Robert E. Sedlack. Training to competency in colonoscopy: assessing and defining competency standards. Gastrointestinal endoscopy, 74(2):355-366, aug 2011.

[14] Amandeep K Shergill, Krishna Asundi, Alan B. Barr, Janak Shah, James Ryan, Kenneth McQuaid, and David Rempel. Pinch force and forearm-muscle load during routine colonoscopy: a pilot study. Gastrointestinal endoscopy, 69(1):142-6, jan 2009.

[15] Laura C. Seeff, Thomas B. Richards, Jean a. Shapiro, Marion R. Nadel, Diane L. Manninen, Leslie S. Given, Fred B. Dong, Linda D. Winges, and Matthew T. McKenna. How many endoscopies are performed for colorectal cancer screening? Results from CDC's survey of endoscopic capacity. Gastroenterology, 127(6):1670-1677, dec 2004.

[16] Sietze T van Turenhout, Jochim S Terhaar sive Droste, Gerrit a Meijer, Ad a Masclée, and Chris J J Mulder. Anticipating implementation of colorectal cancer screening in The Netherlands: a nation wide survey on endoscopic supply and demand. BMC cancer, 12(1):46, jan 2012.

[17] Lynn Butterly, Christopher Olenec, Martha Goodrich, Patricia Carney, and Allen Dietrich. Colonoscopy demand and capacity in New Hampshire. American journal of preventive medicine, 32(1):25-31, jan 2007.

[18] David Klibansky and Richard I. Rothstein. Robotics in endoscopy. Current opinion in gastroenterology, 28(5):477-82, sep 2012.

[19] Dimitrios Stefanidis, Fikre Wang, James R Korndorffer, J Bruce Dunne, and Daniel J Scott. Robotic assistance improves intracorporeal suturing performance and safety in the operating room while decreasing operator workload. Surgical endoscopy, 24(2):377-82, feb 2010.

[20] N Hubert, M Gilles, K Desbrosses, J P Meyer, Jacques Felblinger, and Jacques Hubert. Ergonomic assessment of the surgeon' s physical workload during standard and robotic assisted laparoscopic procedures. International journal of Medical Robotics and Computer Assisted Surgery, 9(January):142-147, 2013. 
[21] Louis Soo Jay Phee, Soon Chiang Low, Van An Huynh, Andy P Kencana, Zhenglong Sun, and K Yang. Master and slave transluminal endoscopic robot (MASTER) for natural orifice transluminal endoscopic surgery (NOTES). In 31th Annual International Conference of the IEEE Engineering in Medicine and Biology Society., volume 2009, pages 1192-5, jan 2009.

[22] Philip Waiyan Chiu, Louis Soo Jay Phee, Pradeep Bhandari, Kazuki Sumiyama, Tomohiko Ohya, Jennie Y.Y. Wong, Hisao Tajiri, Kiyokazu Nakajima, Lawrence Khek Yu Ho, and Endoscopy International Open. Enhancing proficiency in performing endoscopic submucosal dissection ( ESD ) by using a prototype robotic endoscope. Endoscopy International Open, 3:E439_ E442, 2015.

[23] Antonio De Donno, Florent Nageotte, Philippe Zanne, Laurent Goffin, and Michel de Mathelin. Using simulation to design control strategies for robotic no-scar surgery. Studies in health technology and informatics, 184:117-21, jan 2013.

[24] Louis Soo Jay Phee, Nageshwar Reddy, Philip Waiyan Chiu, Pradeep Rebala, Guduru V. Rao, Zheng Wang, Zhenglong Sun, Jennie Y.Y. Wong, and Lawrence Khek Yu Ho. Robot-Assisted Endoscopic Submucosal Dissection Is Effective in Treating Patients With Early-Stage Gastric Neoplasia. Clinical Gastroenterology and Hepatology, 10(10):1117-1121, 2012.

[25] ICube. ISIS - Robotization of flexible systems for minimally invasive surgery, 2014.

[26] Nisha Patel, Ara Darzi, and Julian Teare. The endoscopy evolution: the superscope era'. Frontline Gastroenterology, 6(2):101-107, 2015.

[27] Thomas Rösch, Andreas Adler, Heiko Pohl, Elke Wettschureck, Martin Koch, Bertram Wiedenmann, and Nicolas Hoepffner. A motor-driven single-use colonoscope controlled with a handheld device: a feasibility study in volunteers. Gastrointestinal endoscopy, 67(7):1139-46, jun 2008.

[28] Felice Cosentino, Emanuele Tumino, Giovanni Rubis Passoni, Elisabetta Morandi, and Alfonso Capria. Functional evaluation of the endotics system, a new disposable self-propelled robotic colonoscope: in vitro tests and clinical trial. The International journal of artificial organs, 32(8):517-27, aug 2009.

[29] Boris Vucelic, Douglas K Rex, Roland Pulanic, Jorge Pfefer, Irena Hrstic, Bernard Levin, Zamir Halpern, and Nadir Arber. The aer-o-scope: proof of concept of a pneumatic, skill-independent, self-propelling, self-navigating colonoscope. Gastroenterology, 130(3):672-7, mar 2006.

[30] Jeroen G. Ruiter. Robotic Flexible Endoscope. Promotion thesis, University of Twente, Enschede, 2013

[31] Baldwin Po Man Yeung and Terence Gourlay. A technical review of flexible endoscopic multitasking platforms. International journal of surgery (London, England), 10(7):345-354, may 2012. 
[32] Keith L Obstein and Pietro Valdastri. Advanced endoscopic technologies for colorectal cancer screening. World journal of gastroenterology: WJG, 19(4):431-9, jan 2013.

[33] Stefan Groth, Douglas K Rex, Thomas Rösch, and Nicolas Hoepffner. High cecal intubation rates with a new computer-assisted colonoscope: a feasibility study. The American journal of gastroenterology, 106(6):1075-80, jun 2011.

[34] Jeroen G. Ruiter, G. M. Bonnema, M. C. Voort, and Ivo A. M. J. Broeders. Robotic control of a traditional flexible endoscope for therapy. Journal of Robotic Surgery, 7(3):227-234, apr 2013.

[35] Rob Reilink. Image-Based Robotic Steering of Advanced Flexible Endoscopes and Instruments. Dissertation, University of Twente, 2013.

[36] Nanda Van Der Stap. Image-based endoscope navigation and clinical applications. PhD thesis, University of Twente, 2016.

[37] Bérengère Bardou, Florent Nageotte, Philippe Zanne, and Michel de Mathelin. Design of a telemanipulated system for transluminal surgery. In 31th Annual International Conference of the IEEE Engineering in Medicine and Biology Society., volume 2009, pages 5577-82, jan 2009.

[38] Pierre Allemann, Laurent Ott, Mitsuhiro Asakuma, Norbert Masson, Silvana Perretta, Bernard Dallemagne, Dimitri Coumaros, Michel De Mathelin, Luc Soler, and Jacques Marescaux. Joystick interfaces are not suitable for robotized endoscope applied to NOTES. Surgical innovation, 16(2):111-6, jun 2009.

[39] S.H. Zhang, D.X. Wang, Y.R. R Zhang, Y.G. R Y.H. Y.G. R Y.H. Wang, and X. P. Ma. The Human machine Interface Implementation for the Robot assisted Endoscopic Surgery System. In IEEE Int. Workshop on Robotics and Human Interactive Communication, pages 442-447, Berlin, 2002. IEEE.

[40] Rob Reilink, Stefano Stramigioli, Astrid M L Kappers, and Sarthak Misra. Evaluation of flexible endoscope steering using haptic guidance. The international journal of medical robotics + computer assisted surgery : MRCAS, 7(2):178-86, jun 2011.

[41] Daniel Cohen, Jahnavi Naik, Leonardo Tamariz, and Ryan Madanick. The perception of gastroenterology fellows towards the relationship between hand size and endoscopic training. $\mathrm{Di}$ gestive Diseases and Sciences, 53:1902-1909, 2008.

[42] Amandeep K Shergill, Kenneth McQuaid, and David Rempel. Ergonomics and GI endoscopy. Gastrointestinal endoscopy, 70(1):145-53, jul 2009.

[43] Stephanie L. Hansel, Michael D. Crowell, Darrell S. Pardi, Ernest P. Bouras, John K. DiBaise, Stephanie L. Hansel, Michael D. Crowell, Darrell S. Pardi, Ernest P. Bouras, and John K. DiBaise. Prevalence and Impact of Musculoskeletal Injury Among Endoscopists: A Controlled Pilot Study. Journal of Clinical Gastroenterology, 43(5):399-404, 2009. 
[44] Asimina Gaglia, Ioannis S Papanikolaou, and Wilfried Veltzke-Schlieker. New endoscopy devices to improve population adherence to colorectal cancer prevention programs. World journal of gastrointestinal endoscopy, 2(7):244-251, 2010.

[45] Gregory D Hager, Allison M Okamura, Peter Kazanzides, Louis K Whitcomb, Gabor Fichtinger, and Russell H Taylor. Surgical and Interventional Robotics: Part III: Surgical Assistance Systems. IEEE Robot Automatisation Magazine, 15(4):84-93, 2008.

[46] Ian C. Roberts-Thomson and Edward Teo. Colonoscopy: Art or science? Journal of Gastroenterology and Hepatology (Australia), 24(2):180-184, 2009.

[47] Michael Bretthauer, Geir S. Hoff, Espen Thiis-Evensen, Gert Huppertz-Hauss, and Eva Skovlund. Air and carbon dioxide volumes insufflated during colonoscopy. Gastrointestinal Endoscopy, 58(2):203-206, 2003.

[48] Curtis Hardyck and Lewis F Petrinovich. Left-Handedness. PSychological bulletin, 84(3):385404, 1977.

[49] O. Korner, Klaus Rieger, and M Reinhard. Haptic Display for All Degrees of Freedom of a Simulator for Flexible Endoscopy. Lecture Notes in Computer Science, 3078:161-167, 2004.

[50] Shumin Zhai and Paul Milgram. Human Performance Evaluation of Manipulation Schemes in Virtual Environments. In IEEE Virtual Reality Annual International Symposium (VRAIS), Seattle, 1993.

[51] ISO. ISO 9241 - 11: Ergonomic requirements for office work with visual display terminals ( VDTs ) : Guidance on usability. International Organization, 1998:1-28, 1998.

[52] Kasper Hornbæk. Current practice in measuring usability: Challenges to usability studies and research. International Journal of Human-Computer Studies, 64(2):79-102, feb 2006.

[53] Sandra G Hart, Moffett Field California, and Lowell E Staveland. Development of NASA -TLX (Task Load Index): Results of Emperical and Theoretical Research. Advances in Psychology, 52:139-183, 1988.

[54] Andy Field. Disovering Statistics Using SPSS (and sex and drugs and rock ' $n$ ' roll). SAGE Publications, Los Angeles, third edit edition, 2009.

[55] Shinji Tanaka, Shiro Oka, Iwao Kaneko, Mayuko Hirata, Ritsuo Mouri, Hiroyuki Kanao, Shigeto Yoshida, and Kazuaki Chayama. Endoscopic submucosal dissection for colorectal neoplasia: possibility of standardization. Gastrointestinal endoscopy, 66(1):100-7, jul 2007.

[56] Kevin Reavis and W Melvin. Advanced endoscopic technologies. Surgical endoscopy, 22(6):1533-46, jul 2008. 
[57] Anthony Yuen Bun Teoh. Current developments in natural orifices transluminal endoscopic surgery: An evidence-based review. World Journal of Gastroenterology, 16(38):4792, 2010.

[58] Hironori Yamamoto. Endoscopic Submucosal Dissection for Colorectal Tumors. In $\mathrm{K}$ Mönkemüller, CM Wilcox, and M Muñoz-Navas, editors, Interventional and Therapeutic Gastrointestinal Endoscopy, volume 27, pages 287-295. Karger, Basel, 2010.

[59] Frieder Berr, Thierry Ponchon, Daniel Neureiter, Tobias Kiesslich, Jelle Haringsma, Georg F Kaehler, Friedrich Schmoll, Helmut Messmann, Naohisa Yahagi, and Tsuneo Oyama. Experimental endoscopic submucosal dissection training in a porcine model: learning experience of skilled Western endoscopists. Digestive endoscopy : official journal of the Japan Gastroenterological Endoscopy Society, 23(4):281-9, oct 2011.

[60] Georg Spaun, Bin Zheng, and Lee L Swanström. A multitasking platform for natural orifice translumenal endoscopic surgery (NOTES): a benchtop comparison of a new device for flexible endoscopic surgery and a standard dual-channel endoscope. Surgical endoscopy, 23(12):2720-7, $\operatorname{dec} 2009$.

[61] Rob Reilink, Stefano Stramigioli, and Sarthak Misra. Image-Based Flexible Endoscope Steering. In IEEE/RSJ International Conference on Intelligent Robots and Systems, pages 2339-2344, Taipei, Taiwan, 2010.

[62] R Eckl, Jan D J Gumprecht, Gero Strauss, M Hofer, A Dietz, and Tim C Lueth. Comparison of manual steering and steering via joystick of a flexible rhino endoscope. In 32nd Annual International Conference of the IEEE Engineering in Medicine and Biology Society., volume 2010, pages 1234-7, Buenos Aires, Argentina, jan 2010.

[63] Wond S. W.S. Kim, Frank Tendick, Stephen R. Ellis, and Lawrence w Stark. A comparison of position and rate control for telemanipulations with consideration of manipulator system dynamics. IEEE Journal on Robotics and Automation, 3(5):426-436, oct 1987.

[64] Shumin Zhai. Human Performance in Six Degree of Freedom Input Control. PhD thesis, University of Toronto, 1995.

[65] Stephan Swinnen and Nicole Wenderoth. Two hands, one brain: cognitive neuroscience of bimanual skill. Trends in Cognitive Sciences, 8(1):18-25, jan 2004.

[66] Jean E Wallace, Jane B Lemaire, and William A Ghali. Review Physician wellness : a missing quality indicator. Lancet, 374:1714-21, 2009.

[67] Esther D. Rozeboom, Jeroen G. Ruiter, Michel Franken, and Ivo A. M. J. Broeders. Intuitive user interfaces increase efficiency in endoscope tip control. Surgical endoscopy, 9(28):2600-2605, mar 2014. 
[68] Douglas K Rex, John L Petrini, Todd H Baron, Amitabh Chak, Jonathan Cohen, Stephen E Deal, Brenda Hoffman, Brian C Jacobson, Klaus Mergener, Bret T Petersen, Michael a Safdi, Douglas O Faigel, and Irving M Pike. ASGE Quality indicators for colonoscopy. Gastrointestinal endoscopy, 63(4 Suppl):S16-28, apr 2006.

[69] Sandra G Hart. NASA task load index (NASA-TLX); 20 years later. In Proceedings of the Human Factors and Ergonomics Society 50th Annual Meeting, pages 904-908, Santa Monica, 2006.

[70] S. G. Shah, Brian P Saunders, J. C. Brooker, and Christopher B. Williams. Magnetic imaging of colonoscopy: an audit of looping, accuracy and ancillary maneuvers. Gastrointestinal endoscopy, 52(1):1-8, jul 2000.

[71] Keiichiro Kume, Takeshi Kuroki, Takahiro Sugihara, and Masafumi Shinngai. Development of a novel endoscopic manipulation system: The Endoscopic operation robot. World journal of gastrointestinal endoscopy, 3(7):145-50, jul 2011.

[72] Chen Fang, Weiwei Sang, Jan D J Gumprecht, Gero Strauss, and Tim C Lueth. Image-Guided Steering of a Motorized Hand-Held Flexible Rhino Endoscope in ENT Diagnoses. In 2012 IEEE International Conference on Robotics and Automation, pages 1086-1091, Guangzhou, China, 2012.

[73] Rob Reilink, Astrid M L Kappers, Stefano Stramigioli, and Sarthak Misra. Evaluation of robotically controlled advanced endoscopic instruments. The international journal of medical robotics and computer assisted surgery, 9(April):240-246, 2013.

[74] G Ahlberg, R Hultcrantz, E Jaramillo, A Lindblom, and D Arvidsson. Virtual Reality Colonoscopy Simulation: A Compulsory Practice for the Future Colonoscopist? Endoscopy, 37(12):1198-1204, 2005.

[75] Salman Can, Hermann Mayer, Adam Fiolka, Armin Schneider, Dirk Wilhelm, Hubertus Feussner, and Alois Knoll. The Highly Versatile Single Port System for laparoscopic surgery: Introduction and first clinical application. In 4th European conference of the international federation for medical and biological engineering, pages 1650-1654, 2009.

[76] Esther D. Rozeboom, Ivo A. M. J. Broeders, and Paul Fockens. Feasibility of joystick guided colonoscopy; assessing the learning curves of experts and novices. Journal of Robotic Surgery, 9(1):173-178, 2015.

[77] James Ansell, John Mason, Neil Warren, Peter Donnelly, Neil Hawkes, Sunil Dolwani, and Jared Torkington. Systematic review of validity testing in colonoscopy simulation. Surgical endoscopy, 26(11):3040-52, nov 2012.

[78] Stephanie L. Hansel, J a Prechel, B Horn, Michael D. Crowell, and John K. DiBaise. Observational study of the frequency of use and perceived usefulness of ancillary manoeuvres to facilitate 
colonoscopy completion. Digestive and liver disease : official journal of the Italian Society of Gastroenterology and the Italian Association for the Study of the Liver, 41(11):812-6, nov 2009.

[79] Nanda van der Stap, Ferdinand van der Heijden, and Ivo A. M. J. Broeders. Towards automated visual flexible endoscope navigation. Surgical endoscopy, 27(10):3539-47, oct 2013.

[80] Shankar M Krishnan, C.S. Tan, and K.L. Chan. Closed-boundary extraction of large intestinal lumen. Proceedings of 16th Annual International Conference of the IEEE Engineering in Medicine and Biology Society, pages 610-611, 1994.

[81] Shunren Xia, Shankar M Krishnan, Marta P Tjoa, and Peter M Y Goh. A Novel Methodology for Extracting Colon's Lumen from Colonoscopic Images. J Systemics, Cybernetics and Informatics, 1(2):7-12, 2003.

[82] K V Asari. A fast and accurate segmentation technique for the extraction of gastrointestinal lumen from endoscopic images. Medical engineering \& physics, 22(2):89-96, 2000.

[83] Gul N. Khan and Duncan F. Gillies. Vision based navigation system for an endoscope. Image and Vision Computing, 14(10):763-772, 1996.

[84] Xue Zhiyun. Computerized Detection of Abnormalities in Endoscopic Oesophageal Images. $\mathrm{PhD}$ thesis, Nanyang Technological University, 2000.

[85] Nanda Van der Stap, C H Slump, Ivo A. M. J. Broeders, and Ferdinand van der Heijden. Imagebased navigation for a robotized flexible endoscope. In CARE, volume 8899, pages 77-87, 2014.

[86] Jeroen G. Ruiter, Mascha C Van der Voort, and G. M. Bonnema. User-centred system design approach applied on a robotic flexible endoscope. In C.J.J. Paredis, C. Bishop, and D. Bodner, editors, Conference on Systems Engineering Research (CSER'13), volume 00, Atlanta, GA, USA, 2013.

[87] Robert Barclay, Joseph Vicari, Andrea Doughty, John Johanson, and Roger Greenlaw. Colonoscopic withdrawal times and adenoma detection during screening colonoscopy. The New England journal of medicine, 355(24):2533-41, dec 2006.

[88] Ian M Gralnek, David L Carr-Locke, Ori Segol, Zamir Halpern, Peter D Siersema, Alan Sloyer, Jay Fenster, Blair S Lewis, Erwin Santo, Alain Suissa, and Meytal Segev. Comparison of standard forward-viewing mode versus ultrawide-viewing mode of a novel colonoscopy platform: a prospective, multicenter study in the detection of simulated polyps in an in vitro colon model (with video). Gastrointestinal endoscopy, 77(3):472-9, mar 2013.

[89] Hemant a Shah, Lawrence F Paszat, Refik Saskin, Therese a Stukel, and Linda Rabeneck. Factors associated with incomplete colonoscopy: a population-based study. Gastroenterology, 132(7):2297-303, jun 2007. 
[90] David a Lieberman, P De Garmo, David Fleischer, G Eisen, and M Helfand. Patterns of endoscopy use in the United States. Gastroenterology, 118(3):619-24, mar 2000.

[91] Y. Hazewinkel and Evelien Dekker. Colonoscopy: basic principles and novel techniques. Nat.Rev. Gastroenterol. Hepatol., 8:554/564, 2011.

[92] Douglas K Rex, C S Cutler, G T Lemmel, E Y Rahmani, D W Clark, D J Helper, G a Lehman, and D G Mark. Colonoscopic miss rates of adenomas determined by back-to-back colonoscopies. Gastroenterology, 112(1):24-8, jan 1997.

[93] Florent Nageotte, Bérengère Bardou, Philippe Zanne, Laurent Ott, and Michel De Mathelin. Control Issues and Possible Solutions in Robotized Flexible Endoscopy. In Marc Garbey, Barbara Lee Bass, Scott Berceli, Christophe Collet, and Pietro Cerveri, editors, Computational Surgery and Dual Training: Compuing, Robotics and Imaging, chapter Chapter 12, pages 193-. Springer New York, New York, NY, 2014.

[94] Varun Agrawal and William J. Peine. Modeling of a closed loop cable-conduit transmission system. In 2008 IEEE International Conference on Robotics and Automation, pages 3407-3412. Ieee, may 2008.

[95] Lee L Swanström and Silvana Perretta. Interventional endoscopy and single incision surgery. Annals of the New York Academy of Sciences, 1232:411-7, sep 2011.

[96] Arianna Menciassi, Pietro Valdastri, C Quaglia, E Buselli, and Paolo Dario. Wireless steering mechanism with magnetic actuation for an endoscopic capsule. 31th Annual Conference of the IEEE Engineering in Medicine and Biology Society, 2009:1204-7, jan 2009.

[97] Irwan Kassim, Louis Soo Jay Phee, Wan S Ng, Feng Gong, Paolo Dario, and Charles a Mosse. Locomotion techniques for robotic colonoscopy. IEEE engineering in medicine and biology magazine : the quarterly magazine of the Engineering in Medicine \& Biology Society, 25(3):4956, 2006.

[98] Hideki Atsumi, Mitsunori Matsumae, Akihiro Hirayama, Kenichiro Sato, Hideaki Shigematsu, Go Inoue, Jun Nishiyama, Michitsura Yoshiyama, and Jiro Tominaga. Newly Developed Electromagnetic Tracked Flexible Neuroendoscope Technical Note . Neurologia Medico-Chirurgica, 51:611-616, 2011.

[99] A. J. Bredenoord, Thomas Rösch, and Paul Fockens. Peroral endoscopic myotomy for achalasia. Neurogastroenterology \& Motility, 26(1):3-12, 2014.

[100] Yutaka Saito, Masayoshi Yamada, Eriko So, Seiichiro Abe, Taku Sakamoto, Takeshi Nakajima, Yosuke Otake, Akiko Ono, and Takahisa Matsuda. Colorectal endoscopic submucosal dissection: Technical advantages compared to endoscopic mucosal resection and minimally invasive surgery. Digestive Endoscopy, 26:52-61, 2013. 



\section{About the author}

Esther Rozeboom was born in Groningen on October 9th, 1986. She grew up in Emmen, Nootdorp and later Hoogeveen, where she attended high-school. There she learned that she had a passion for the workings of the human body, as well as interest in maths and physics. This combination was supported in the new curriculum of Technical Medicine at the University of Twente. She joined the Bachelor program in 2005 and graduated Cum Laude with a Master's degree in Robotics and Imaging in 2012. Her graduation research on robotics in flexible endoscopy was continued in a $\mathrm{PhD}$ position under supervision of Prof. dr. Ivo Broeders, which resulted in this thesis.

During her studies, Esther enjoyed the opportunities to go abroad. She organised the 2009 study-tour to Japan and spend a 12 week internship in Canada. The successful cooperation between the University of Twente, Meander Medical Center, Academic Medical Center and DEMCON Advanced Mechatronics led to several scientific publications presented in this thesis. The results enabled Esther to present her work on conferences in France, Germany, Austria and the USA. This has brought her a broad technical - medical network that supports her in her work as a technical physician. What started with participating in the BEST summerschool at the IRCAD institute in Strasbourg (Fr.) led to a warm contact between the University of Twente and IRCAD. Resulting in an official cooperation on education and research programs, of which Esther is currently the project leader. 



\section{Dankwoord}

Alhoewel er maar 1 naam op de omslag van dit proefschrift staat zijn er veel mensen die hebben bijgedragen aan de totstandkoming hiervan. Hierbij aan iedereen hartelijk dank! Met deze uitspraak maak ik me er in enkele gevallen te gemakkelijk af. Daarom wil ik hier enkele personen bij naam noemen.

Allereerst Prof. dr. Broeders, Ivo, promotor, heel veel dank voor de vele kansen en enorme vrijheid die je me hebt gegeven. Je was de eerste robotica-arts in Nederland en ik bewonder je duidelijke visie voor de medische wereld en je geduld om mij hierin mee te nemen. Nadat je me hielp aan een stageplaats in Canada bood je me een afstudeerplaats binnen de MISR groep wat later zou voortvloeien in deze promotie binnen RAM. Ik moest even nadenken of ik nog zo lang in Enschede wilde blijven, maar dankzij je vertrouwen, uitdaging en motivatie zijn die jaren omgevlogen. 'Haal alles uit je promotie' is je advies dat ik ter harte heb genomen wat heeft geresulteerd in veel ervaringen die lang niet altijd serieus zijn. Als laatste ben ik je dankbaar omdat je me hebt geleerd om een boodschap duidelijk op papier over te dragen alsook in presentaties voor een breed publiek. Iets waar ik veel gebruik van maak bij het schrijven van dit proefschrift en de uiteindelijke verdediging.

Prof. dr. Fockens, Paul, het is een eer om jou als goeroe in de endoscopie als $2 \mathrm{e}$ promotor te hebben. Je zorgde vanaf het allereerste moment voor een warm welkom bij het AMC. Zonder jouw enthousiasme, geduld en hulp bij onze zoektocht naar klinische vernieuwing hadden we niet zover kunnen komen. Uiteraard geldt dit voor de patiëntenstudie en simulator studies maar ook voor de uitvoerige feedback sessie die we regelmatig hebben gehad. Ik heb het persoonlijk enorm prettig gevonden om met je te mogen samenwerken. Zelfs als dat betekende dat ik om 5.15 de trein richting het westen moest pakken. Je was niet de enige in het AMC die heeft geholpen met het tot stand komen van dit proefschrift. Agaath, Bas, Cyriel, Elsemieke, Evelien, Jac- 
ques, Jeanine en Kristien hebben met energie, tijd en geduld een belangrijke bijdrage geleverd. Barbara, jou wil ik in het bijzonder bedanken voor je oneindige geduld met onze opstelling die keer op keer voor een uitdaging wist te zorgen.

Nanda, met jou heb ik veel kunnen delen en sparren tijdens onze ervaringen samen. Hoewel ons werk veel raakvlak had, konden we toch ieder onze eigen gang gaan. Daarbij hoort natuurlijk wel een goed koffiemoment om van gedachten te wisselen over werk, maar vaker over één van de vele gedeelde interesses. Als reisgenoot hebben we goed met elkaar kunnen optrekken. Zo zijn er genoeg momentjes in vele steden te noemen, maar de fancy (bad-)kamer in Wenen mag toch zeker niet ontbreken. Dat ik vervolgens ook nog paranimf bij je promotie mocht zijn voelde als een mooie afsluiting van een intense en bovenal leuke periode samen.

Jeroen, veel dank dat je mij tijdens je eigen promotie hebt begeleid en meegenomen in de kunst van het ontwerpen en valideren. Jij hebt het robotische platform bedacht en ontworpen. Samen hebben we heel veel novices geïnstrueerd, artsen uitgevraagd en de feedback verwerkt in nieuwe ontwerpen. Dankzij jouw oog voor detail, geduld en oplossingsvermogen staat er nu een mooi systeem dat we zelfs succesvol in de kliniek konden gebruiken.

Daarbij wil ik ook de rest van het team van DEMCON bedanken; Michel, voor het sparren tijdens de fietstochten naar Oldenzaal, Rob, voor alle last-minute telefoontjes als de opstelling op moment suprême kuren vertoonde en Benno, voor je heldere structuur als projectleider.

Thijs, je bent vanaf het begin betrokken geweest bij dit project. Heel veel dank voor je klinische feedback en design ideen. Dankzij jouw inzet hebben we mooie studies kunnen uitvoeren en waren onze studenten ook bij de rest van het endoscopie team in het Meander van harte welkom. Speciaal dank aan Paul voor de ontspannen samenwerking aan de twee papers.

John, zonder jouw inzet binnen en namens Olympus hadden we niet zo ver kunnen komen. Veel dank voor de materialen, kennis en contacten die je belangeloos hebt ingebracht. Ook Cees en Maarten, dank voor jullie meedenken en mee werken aan de studies.

Collega's bij de UT wil ik van harte danken voor de fijne werkplek. Stefano voor je aanstekelijke enthousiasme, Jolanda en Sandra voor jullie hulp bij alle organisatorische taken en mijn kamergenoten voor het delen van de klusprojecten en 
weekendplannen. Wim, Marcel, Gerben en Hennie, van harte dank voor jullie ondersteuning. Zonder jullie hulp was er geen werkende testopstelling. Tanja dank voor je persoonlijke contact en het trouw volgen van onze klus-blog.

Promoveren doe je niet in je eentje, ik zou nog veel mensen willen bedanken. Maar ook aan een dankwoord komt een eind. Eddy, familie en vrienden, jullie bedank ik graag persoonlijk terwijl we samen vieren dat deze uitdaging succesvol is afgerond! 